\title{
Thermal Ablation of Biological Tissues in Disease Treatment: A Review of Computational Models and Future Directions
}

\author{
Sundeep $\operatorname{Singh}^{1 *}$ and Roderick Melnik ${ }^{1,2}$ \\ ${ }^{1}$ MS2Discovery Interdisciplinary Research Institute, Wilfrid Laurier University, \\ 75 University Avenue West, Waterloo, Ontario, N2L 3C5, Canada \\ ${ }^{2}$ BCAM - Basque Center for Applied Mathematics, \\ Alameda de Mazarredo 14, E-48009 Bilbao, Spain
}

ORCID iD's:

Sundeep Singh: https://orcid.org/0000-0002-8342-1622

Roderick Melnik: https://orcid.org/0000-0002-1560-6684

*Corresponding Author

Dr. Sundeep Singh,

MS2Discovery Interdisciplinary Research Institute,

Wilfrid Laurier University, 75 University Avenue West,

Waterloo, Ontario, Canada, N2L 3C5

E-mail: ssingh@wlu.ca

The reference to the final published version of this paper is: Sundeep Singh \& Roderick Melnik, "Thermal ablation of biological tissues in disease treatment: A review of computational models and future directions", Electromagnetic Biology and Medicine, Vol. 39(2), pp. 49-88, 2020. 


\begin{abstract}
Percutaneous thermal ablation has proved to be an effective modality for treating both benign and malignant tumors in various tissues. Among these modalities, radiofrequency ablation (RFA) is the most promising and widely adopted approach that has been extensively studied in the past decades. Microwave ablation (MWA) is a newly emerging modality that is gaining rapid momentum due to its capability of inducing rapid heating and attaining larger ablation volumes, and its lesser susceptibility to the heat sink effects as compared to RFA. Although the goal of both these therapies is to attain cell death in the target tissue by virtue of heating above $50{ }^{\circ} \mathrm{C}$, their underlying mechanism of action and principles greatly differs. Computational modelling is a powerful tool for studying the effect of electromagnetic interactions within the biological tissues and predicting the treatment outcomes during thermal ablative therapies. Such a priori estimation can assist the clinical practitioners during treatment planning with the goal of attaining successful tumor destruction and preservation of the surrounding healthy tissue and critical structures. This review provides current state-ofthe-art developments and associated challenges in the computational modelling of thermal ablative techniques, viz., RFA and MWA, as well as touch upon several promising avenues in the modelling of laser ablation, nanoparticles assisted magnetic hyperthermia and noninvasive RFA. The application of RFA in pain relief has been extensively reviewed from modelling point of view. Additionally, future directions have also been provided to improve these models for their successful translation and integration into the hospital work flow.
\end{abstract}

Keywords: Thermal Ablation; Minimally Invasive Treatment; Microwave Ablation; Radiofrequency Ablation; Laser Ablation; Nanoparticles-assisted Ablation; Nerve Ablation; Bioheat Transfer; Tissue Deformation; Blood Vessels; AI and Machine-Learning Algorithms; Multiscale Modelling. 


\section{Introduction}

Thermal ablation is one of the rapidly emerging and promising alternative treatment modalities for curative and palliative treatment of vast varieties of benign and malignant tumors. The energy source for inducing the heat during thermal ablation procedures includes radiofrequency current, microwave, laser and high intensity focused ultrasound (Ahmed et al., 2011, Brace, 2011, Chu and Dupuy, 2014, Kim, 2018, Vogel and Venugopalan, 2003). The main goal during these hyperthermic ablative procedures is to attain direct cellular injury by the application of heat that occurs after $1-2 \mathrm{~min}$ at $50{ }^{\circ} \mathrm{C}$ and within few seconds above 60 ${ }^{\circ} \mathrm{C}$ (Almekkawy et al., 2019). Cryoablation is another form of a thermal ablative procedure whereby cell death occurs by freezing it (Chu and Dupuy, 2014). Figure 1 presents the different types of image-guided thermal ablative modalities used in clinical practices. Among all these image-guided thermal ablative modalities, radiofrequency ablation (RFA) is the clinically dominant modality, while microwave ablation (MWA) is a newly emerging modality gaining rapid interest that offers several advantages over RFA, particularly for treating large-size tumors. Importantly, the heating mechanism is substantially different among both the therapies, since MWA (915 MHz or $2.45 \mathrm{GHz})$ and RFA (450-550 kHz) are performed at different frequencies. During MWA, the heating is induced due to kinetic energy induced by the rapid oscillation (between 2 and 5 billion times per second) of polar molecules (water, proteins, etc.) of the biological tissues that ultimately leads to coagulative necrosis (Singh et al., 2019). Whereas, during RFA, resistive (or ionic) heating is induced by a high-frequency alternating electrical current $(450-550 \mathrm{kHz})$ which is incapable of inducing molecular rotation (Singh et al., 2019). Moreover, the treatment outcomes of MWA are less susceptible to the heat-sink effects caused by the large blood vessels in close proximity of the target tissue and are not limited by the formation of charring and water vaporization that allows high energy deposition for longer durations yielding greater tissue temperatures and steeper thermal gradients. Further, contrary to RFA, there is no requirement of ground pads during MWA that eliminates the associated complications of skin burns during the course of therapy. The above-mentioned advantages of MWA over RFA have resulted in its emergence as a most cost-effective ablation modality capable of attaining large zone of volumetric heating in short treatment times (Lopresto et al., 2017b, Ward et al., 2013). Figure 2(a) presents the schematic of a thermal ablation system and Fig. 2(b) presents the inherent different mechanism of energy deposition during the MWA and RFA procedures (Chu and Dupuy, 2014, Kim, 2018). Other hyperthermic ablative modalities, namely, laser ablation and high intensity focused ultrasound are conceptually similar to MWA and RFA but have been studied to a lesser extent (Ahmed et al., 2011, Chu and Dupuy, 2014). Laser ablation induces 
electromagnetic heating, similar to RFA and MWA, while high intensity focused ultrasound ablation utilizes acoustic energy to induce coagulative necrosis in the selected focal zone and is the only non-invasive hyperthermic modality (Chu and Dupuy, 2014). The schematic of the effects of hyperthermic ablation on the biological tissue is represented in Fig. 2(c).

Computational modelling plays a vital role in the design and development of new protocols, along with the optimization and improvement of existing protocols of clinical systems. They not only provide a quick, convenient and inexpensive evaluation of the treatment outcomes of the thermal ablative procedure but also serve as a means of understanding the interaction between the various physical phenomena that occur during such therapies. The application of computational modelling is extensively explored in the patientspecific treatment planning of thermal ablative therapies for the prediction of post-procedure damage volume and improving its efficacy (Andreozzi et al., 2019, Berjano, 2006, Chiang et al., 2013, Prakash, 2010, Zhang et al., 2016). Moreover, computational modelling of the thermal ablative procedures also play a vital role in investigating and understanding the effects of various extrinsic and intrinsic factors on the treatment outcome, viz., applied power, treatment time, tissue biophysical properties, etc. (Cavagnaro et al., 2015b, Lopresto et al., 2017b).

This review provides current state-of-the-art developments, associated challenges and future directions in the computational modelling of thermal ablative techniques, viz., RFA and MWA, as well as touch upon several promising avenues in the modelling of laser ablation, nanoparticles assisted magnetic hyperthermia and non-invasive RFA. The application of RFA in pain relief has been extensively reviewed from the modelling point of view. The review article is organized as follows. Section 2 provides the mathematical framework adopted for modelling different types of thermal ablative procedures and discusses different bioheat transfer and tissue damage models available in the literature. Section 3 focuses on the current trends in the improvements and modifications of most commonly applied thermal ablative procedures, viz., RFA and MWA. This includes accurate modelling of bio-physical parameters, incorporation of non-Fourier lags in bioheat transfer analysis, coupling of mechanical deformation model to the thermo-electric model for quantifying the induced expansion and contraction in the biological tissues subjected to elevated temperatures, incorporation of solid-fluid interaction models in the heat transfer analysis for quantifying the effects of both small capillaries and large blood vessels on the treatment outcomes. Additionally, the importance of image-based multiscale modelling has also been highlighted in this section. Section 4 highlights the application of laser ablation in different types of disease treatments by reviewing some of the recent articles in this research 
area. Section 5 provides the modelling details of nanoparticle assisted magnetic hyperthermia and non-invasive RFA along with their associated challenges and difficulties. Section 6 focuses on the application of RFA in treating chronic pain and provides a brief background along with reviewing all the computational studies reported in this area to date. Section 7 highlights the importance of multiscale modelling for treating neurological disorders along with providing the importance of machine learning algorithms in the area of thermal ablation. Finally, Section 8 highlights some of the key challenges and provides a future road map for the development of more accurate computational models of RFA and MWA with the aim of providing more precise predictions of the treatment outcomes, so that these numerical predictions can be successfully translated into the clinical applications.

\section{Mathematical modelling of thermal ablation}

The application of mathematical modelling has been widely explored in the past decades with the aim of improving the efficacy of thermal ablative modalities and to reach a stage where such models can be readily integrated with the clinical workflow for providing a priori estimates of the treatment outcomes during the treatment planning stage of such therapies (Andreozzi et al., 2019, Berjano, 2006, Chiang et al., 2013, Prakash, 2010, Zhang et al., 2016). Numerical modelling and simulations have already become a powerful tool for predicting the tissue response subjected to thermotherapies. Importantly, such predictions are based on utilizing the two major mathematical models, viz., bioheat transfer and tissue damage models. The present section provides the basic framework of such associated models of different thermotherapies used in clinical practices.

\subsection{Modelling of heat transfer in biological tissue}

The continuous development and application of numerical models of heat transfer in living tissues for predicting the temperature distribution during thermotherapies have been a topic of vital interest (Huang and Horng, 2015). Currently, there are three approaches for conducting such complicated and complex quantitative analysis in blood-perfused biological tissues, viz., continuum model, discrete vascular model and the combination of the first two (Raaymakers et al., 2009, LeBrun and Zhu, 2018). In continuum models, the blood vessels are not modelled individually, rather its effects are lumped into a single factor that is accounted in the heat transfer analysis by either incorporating an additional term or altering thermophysical parameters in the bioheat transfer equation. Contrary to the simplified continuum model approach, the discrete vascular model actually accounts for blood flow in each 
individual blood vessels and thus requires high computational resources for predicting pointto-point blood and tissue temperature during thermotherapies. However, in the combined approach, small blood vessels are modelled using the continuum approach, while only those large blood vessels that are considered to be a major cause of temperature non-homogeneity are discretely modelled. Several modifications have been reported in these conventional models and subsequently, more complex models have been developed and reported in the quest for a more accurate prediction of the temperature distributions within the biological tissues during thermal ablative procedures (Khanafer and Vafai, 2009, Zhu, 2009). (Bhowmik et al., 2013) provided a comprehensive review regarding both the conventional and newly developed bioheat transfer models available in the literature for the vascularized tissue. More recently, (Andreozzi et al., 2019) reported a review article providing a clear overview regarding the modifications of conventional bioheat transfer models focused on hyperthermia treatments of cancer.

Among the different bioheat transfer models, the Fourier-conduction-based Pennes bioheat transfer equation (Pennes, 1948) is the most widely used bioheat transfer model for analyzing the heat transfer within the biological tissue subjected to thermal ablative procedures due to its simplicity and feasibility (Andreozzi et al., 2019, Bhowmik et al., 2013), and is given by:

$$
\rho c \frac{\partial T}{\partial t}=\nabla \cdot(k \nabla T)-\rho_{b} c_{b} \omega_{b}\left(T-T_{b}\right)+Q_{m}+Q_{p},
$$

where $\rho$ is the density $\left(\mathrm{kg} / \mathrm{m}^{3}\right), c$ is the specific heat capacity $(\mathrm{J} / \mathrm{kg} / \mathrm{K}), T$ is the tissue temperature $(\mathrm{K}), k$ is the thermal conductivity $(\mathrm{W} / \mathrm{m} / \mathrm{K}), \rho_{b}$ is the density of blood $\left(\mathrm{kg} / \mathrm{m}^{3}\right), c_{b}$ is the specific heat capacity of blood $(\mathrm{J} / \mathrm{kg} / \mathrm{K}), \omega_{b}$ is the blood perfusion rate $(1 / \mathrm{s}), T_{b}$ is the temperature of blood entering the tissue, the term $\left[\rho_{b} c_{b} \omega_{b}\left(T-T_{b}\right)\right]$ models the heat sink effect caused by the small capillary vasculature, $Q_{m}$ is the heat generated by metabolism $\left(\mathrm{W} / \mathrm{m}^{3}\right)$, which is normally ignored due to its minimal impact compared to other heat sources and $Q_{p}$ $\left(\mathrm{W} / \mathrm{m}^{3}\right)$ is the heat generation (or source term) during thermal ablative procedures and is tremendously dependent on the type of therapy under consideration and is discussed as follows.

\subsubsection{Modelling of heat source for MWA and RFA}

During the RFA and MWA procedures, electromagnetic energy is used to heat the biological tissues. The propagation and interaction effects of electromagnetic fields in a lossy media such as biological tissues are well-described by a source-free, time-harmonic form of Maxwell's equations as (Chiang et al., 2013): 


$$
\begin{aligned}
& \nabla \cdot \boldsymbol{D}=0 ; \\
& \nabla \cdot \boldsymbol{B}=0 ; \\
& \nabla \times \boldsymbol{E}=-j \omega \mu \boldsymbol{H} ; \\
& \nabla \times \boldsymbol{H}=\boldsymbol{J}+j \omega \varepsilon \boldsymbol{E},
\end{aligned}
$$

where $\boldsymbol{E}$ is the electric field intensity $(\mathrm{V} / \mathrm{m}), \boldsymbol{D}$ is the electric flux density $\left(\mathrm{C} / \mathrm{m}^{2}\right), \boldsymbol{H}$ is the magnetic field intensity $(\mathrm{A} / \mathrm{m}), \boldsymbol{B}$ is the magnetic flux density $\left(\mathrm{Wb} / \mathrm{m}^{2}\right), \boldsymbol{J}$ is the current density $\left(\mathrm{A} / \mathrm{m}^{2}\right), \omega$ is an angular frequency $(\mathrm{rad} / \mathrm{s}), \mu$ is the magnetic permeability $(\mathrm{H} / \mathrm{m}), \varepsilon$ is the complex permittivity or dielectric constant $(\mathrm{F} / \mathrm{m})$ and $j=\sqrt{-1}$.

Most of the MWA studies reported in the previous literature have been conducted utilizing the electromagnetic wave frequency of $915 \mathrm{MHz}$ or $2.45 \mathrm{GHz}$, with a few studies also reported at higher frequencies (see e.g. (Sawicki et al., 2017, Luyen et al., 2014, Sawicki et al., 2018, Yoon et al., 2011)). The electric and magnetic fields related to the time-varying transverse electromagnetic wave can be computed from the Helmholtz harmonic wave equation derived from Maxwell's equation and is given by:

$$
\nabla \times \mu_{r}^{-1}(\nabla \times \mathbf{E})-k_{0}^{2}\left(\varepsilon_{r}-\frac{j \sigma}{\omega \varepsilon_{0}}\right) \mathbf{E}=0,
$$

where $\mathbf{E}$ is the electric field vector $(\mathrm{V} / \mathrm{m}), \mu_{r}$ is the relative magnetic permeability, $\varepsilon_{r}$ is the relative permittivity, $\sigma$ is the electrical conductivity $(\mathrm{S} / \mathrm{m}), \varepsilon_{0}$ is the permittivity of free space, $\omega$ is an angular frequency $(\mathrm{rad} / \mathrm{s}), k_{0}$ is the free space wave number $\left(\mathrm{m}^{-1}\right)$ and $j=\sqrt{-1}$.

Further, in the lower frequency range of $\approx 500 \mathrm{kHz}$, as is being used during RFA, the electromagnetic field wave length is several orders of magnitude larger than the size of the active electrode, i.e. $600 \mathrm{~m}$ at about $500 \mathrm{kHz}$. Thus, the biological medium can be considered to be almost totally resistive, whereby the displacement current is negligibly small in comparison to the resistive current. Hence, the quasi-static approximation of Maxwell's equations can be used to solve the electromagnetic problem without compromising accuracy (Berjano, 2006, Zhang et al., 2016). Quasi-static electromagnetic field theory presumes that the extent of variation of electric and magnetic fields is negligible and is very similar in characteristic to the static fields, although the fields vary with time. Thus, the electric field distribution during RFA can be obtained by solving generalized Laplace equation instead of solving full-fledged Maxwell's equations, as given by:

$$
\nabla \cdot[(\sigma \nabla V]=0,
$$

where $V$ is the applied electric potential $(\mathrm{V}), \sigma$ is the electrical conductivity of biological tissue $(\mathrm{S} / \mathrm{m})$ and the electric field vector ' $\mathbf{E}$ ' $(\mathrm{V} / \mathrm{m})$ for the quasi-static approximation of Maxwell's equations during RFA is computed from:

$$
\mathbf{E}=-\nabla V \text {. }
$$


Further, the external heating source term to be fed in the bioheat transfer model for MWA and RFA is computed from:

$$
Q_{p}=\rho \cdot S A R=\frac{1}{2} \sigma|\mathbf{E}|^{2}
$$

where $\rho$ is the density of biological tissue $\left(\mathrm{kg} / \mathrm{m}^{3}\right), S A R$ is the specific absorption rate $(\mathrm{W} / \mathrm{kg})$, $\sigma$ is the electrical conductivity of biological tissue $(\mathrm{S} / \mathrm{m})$ and $\mathbf{E}$ is the electric field vector given by Eq. 3 and Eq. 5 for MWA and RFA, respectively.

\subsubsection{Modelling of heat source for laser ablation}

The heat source term during laser ablation i.e. the absorption of laser energy along the tissue depth $(z)$ within the biological tissue is mostly modelled utilizing the Beer-Lambert's law (Sahoo et al., 2014, Wongchadakul et al., 2018), as given by:

$$
\begin{aligned}
Q_{p} & =\alpha \cdot I \\
& =\alpha \cdot\left(I_{0} e^{\left(-r^{2} / 2 \sigma^{2}\right)} \cdot e^{(\beta z)} \cdot e^{-(\alpha+\beta) z}\right),
\end{aligned}
$$

where $I$ is the laser irradiation intensity $\left(\mathrm{W} / \mathrm{m}^{2}\right), I_{0}$ is the irradiation intensity at the tissue surface $\left(\mathrm{W} / \mathrm{m}^{2}\right), \alpha$ is the absorption coefficient $\left(\mathrm{m}^{-1}\right), \beta$ is the scattering coefficient $\left(\mathrm{m}^{-1}\right), z$ is the depth of tissue and $\sigma$ is the width of the irradiated area.

\subsubsection{Modelling of heat source for ultrasound ablation}

Acoustic heat deposition with an interstitial ultrasound transducer is mostly modelled as (Jiang et al., 2012, Prakash and Diederich, 2012, Prakash et al., 2012, Scott et al., 2014):

$$
\begin{aligned}
Q_{p} & =2 \alpha I \\
& =2 \alpha \tau I_{s} \frac{r_{t}}{r} e^{-2 \int_{r_{t}}^{r} \mu d r^{\prime}},
\end{aligned}
$$

where $\alpha$ is the ultrasound absorption coefficient $(\mathrm{Np} / \mathrm{m}), I$ is acoustic intensity $\left(\mathrm{W} / \mathrm{m}^{2}\right), \tau$ is the transmission coefficient, $I_{s}$ is the acoustic intensity on the transducer surface $\left(\mathrm{W} / \mathrm{m}^{2}\right), r_{t}$ is the radius of transducer $(\mathrm{m}), r$ is the radial distance from the transducer's central axis $(\mathrm{m})$, and $\mu$ is the ultrasound attenuation coefficient $(\mathrm{Np} / \mathrm{m})$. 


\subsection{Modelling of induced thermal damage during thermal ablative procedures}

Several techniques have been used to quantify the size of ablation volume attained during the computational modelling of thermal ablative procedures, viz., isotherm contour, thermal isoeffective dose (TID) and Arrhenius model (Zhang et al., 2016). A comparative analysis and critical review regarding the different mathematical models used in literature for quantifying cell death during thermal ablative procedures has been provided in (Pearce, 2013). The simplest approach to evaluate the tissue death in computational models is to use a $50{ }^{\circ} \mathrm{C}$ isotherm contour approach (Qadri et al., 2017, Singh, 2018, Singh et al., 2016, Singh et al., 2019), and recently $55^{\circ} \mathrm{C}$ and $59^{\circ} \mathrm{C}$ isotherm contours have also been used (Zhang et al., 2016). Importantly, this approach considers that the death of tissue during thermal ablative procedures is dependent only on the local temperature and does not take into account the dependence of target tissue type and heating duration, and thus the use of other models (e.g., TID and Arrhenius models) have also been explored to address this issue (Zhang et al., 2016, Qadri et al., 2017). The TID model is a normalizing method to convert various timetemperature exposures to cumulative equivalent minutes at a reference temperature of $43{ }^{\circ} \mathrm{C}$ $\left(C E M_{43}\right)$, and is computed using

$$
C E M_{43}=\int_{0}^{t} R^{(43-T)} d t(\mathrm{~min}),
$$

where $T$ represents the constant temperature applied for the time $t(\min )$ and $R$ is the factor to compensate for a $1{ }^{\circ} \mathrm{C}$ temperature change. The factor $R$ is considered to be 0.5 for temperature exceeding $43{ }^{\circ} \mathrm{C}$, i.e., the equivalent time doubles per degree temperature increase and 0.25 for temperature below $43{ }^{\circ} \mathrm{C}$, i.e., the equivalent time decreases by a factor of four per degree temperature decrease (van Rhoon, 2016). The critical thermal dosage representing complete damage of tissue is considered to be $C E M_{43}=120$ or $240 \mathrm{~min}$. Although this model is widely used to predict the tissue death during hyperthermia, i.e. for lower temperature range between 40 and $45{ }^{\circ} \mathrm{C}$, for higher temperatures (i.e. above $50{ }^{\circ} \mathrm{C}$ ) attained during thermal ablation this approach is considered to be inapplicable as this parameter normalizes treatment thermal histories rather than predicting treatment results (Zhang et al., 2016, Pearce, 2013, Reddy et al., 2013).

The Arrhenius model provides a simple, straightforward and widely applied method for predicting the ablation volume in the computational modelling of thermal ablation (Zhang et al., 2016, Qadri et al., 2017). The tissue damage during thermal ablation is associated with the different irreversible process of protein denaturation that can be characterized by a firstorder irreversible kinetic equation (Zhang et al., 2016) and is given by:

$$
\Omega(t)=\int_{0}^{t} A e^{\frac{-E_{a}}{R T}} d t,
$$


where $\Omega(t)$ is the degree of tissue death (or damage integral), $t$ is the ablation time (s), $A$ is a frequency factor $\left(\mathrm{s}^{-1}\right), E_{a}$ is the activation energy barrier $(\mathrm{J} / \mathrm{mol}), R$ is the universal gas constant $(8.314 \mathrm{~J} / \mathrm{mol} \mathrm{K})$ and $T$ is the tissue temperature inside the computational domain $(\mathrm{K})$ at a specified time. $A$ and $E_{a}$ are the kinetic parameters that account for the morphological changes in the biological tissue due to the thermal degradation of proteins and their values are tremendously dependent on the type of tissue under consideration. In the context of tissue damage, a damage integral of $\Omega(t)=1$ corresponds to a probability of $63 \%$ cell death and damage integral of $\Omega(t)=4.6$ corresponds to a probability of $99 \%$ cell death at a specific location (Zhang et al., 2016).

Although the Arrhenius damage model has become a yardstick for comparing the efficacy of newly proposed damage models during the thermal ablative procedure (O'Neill et al., 2011, Pearce, 2013, Reddy et al., 2013, Wright, 2015), there are several limitations associated with it too. Importantly, the Arrhenius damage model considers only two states of biological tissues, viz., either all alive or all dead cells, and the transition between the two states is modelled with a single irreversible reaction. However, actual cell death mechanisms during thermal ablation can comprise of multiple reversible and interacting processes and accordingly several multi-parameter fit methods have also been employed for modelling cell survival data (Pearce, 2013, Reddy et al., 2013). A new three-state model has been proposed by (O’Neill et al., 2011) that also considers an intermediate stage between the completely alive and dead state of cells, i.e. vulnerable state representing the potential of cells to recover and return to the alive state. This three-state cell death model has been recently used in some of the computational studies of thermal ablation to more accurately quantify the protein denaturation within the biological tissue (Liu et al., 2017, Park et al., 2016, Qadri et al., 2017, Park et al., 2018). The model assumes that there are three states (viz., native $(N)$, unfolded $(U)$ and denatured $(D)$ ), and the cells in the unfolded state have the potential to recover and return in the native (or alive) state. The reaction equation, grouping all the different intermediates states into one overall state, is given by:

$$
N \underset{k_{3}}{\stackrel{k_{1}}{\rightleftarrows}} U \stackrel{k_{2}}{\rightarrow} D
$$

where $N, U, D$ are the proportion of cells that are in native (alive), unfolded (vulnerable) and denatured (dead) states, respectively, and $k_{i}$ 's are the reaction rates that describe the forward or backward rates of change in cell states and are assumed to be governed by first-order Arrhenius equation given by:

$$
k_{i}(T)=A_{i} e^{\frac{-\Delta E_{i}}{R T}}
$$


where $A_{i}$ and $\Delta E_{i}$ are the frequency factor and the activation energy, respectively, associated with different reaction rates $\left(k_{i}:=k_{1}, k_{2}, k_{3}\right), R$ is the universal gas constant and $T$ is the temperature computed from bioheat transfer model. With the constraint that the sum of all the three states is equal to one (i.e., $N+U+D=1$ ), the three-state death model can be mathematically described by the following system of ordinary differential equations (Park et al., 2018):

$$
\frac{d N}{d t}=-k_{1} N+k_{3} U ; \quad \frac{d U}{d t}=k_{1} N-k_{3} U-k_{2} U ; \quad \frac{d D}{d t}=k_{2} U .
$$

To quantify the coagulation volume using the three-state cell death model, a tissue viability parameter $G=N+U$ (or, 1-D) is determined that represents the proportion of the tissues that are not dead. Importantly, the tissue is considered to be completely destroyed in the computational models if the viability is less than the threshold value of 0.8 (O'Neill et al., 2011, Qadri et al., 2017).

\section{Current trends in the improvements of mathematical models of RFA and MWA}

The continuous development in the area of computational modelling of minimally invasive thermal ablative procedures has contributed in a vital way to our better understanding of the nuances of bio-physical factors that help or hinder the efficacy of these procedures. In the past decade, numerous generalizations and model refinements have been made in the computational modelling approach of thermal ablative procedures, such as, consideration/inclusion of two-compartment models, temperature-dependent thermo-electric and bio-physical parameters, tissue vaporization models (beyond $100{ }^{\circ} \mathrm{C}$ ), non-Fourier effects, mechanical deformations, solid-fluid interaction, porous media models etc. This section highlights some of these notable refinements and generalizations in the computational modelling approach, as applied to MWA and RFA, along with the associated challenges.

\subsection{Modelling of bio-physical parameters}

The accuracy of computational models of thermal ablation is tremendously dependent on the accuracy of modelling bio-physical parameters of the considered tissue. Several studies (Ahmed et al., 2008, Hall et al., 2015, Lopresto et al., 2017a, Sebek et al., 2016, Singh and Repaka, 2017c, Singh et al., 2019) have already highlighted the fact that consideration of temperature-dependent bio-physical parameters during the computational modelling of thermal ablation results is a more accurate and realistic prediction of treatment outcomes as compared to treating these parameters as constant. 
The phase change occurrence due to vaporization of the water inside the biological tissue beyond $100{ }^{\circ} \mathrm{C}$ is frequently modelled using the apparent heat capacity model (Muhieddine et al., 2009, Xu et al., 2019). Incorporation of the water vaporization model in the computational model of thermal ablation would result in a more accurate prediction of the physical changes occurring during such procedures. The left-hand side term of bioheat transfer Eq. (1) is modified to take into account the dramatic increase in the thermal capacity of the biological tissue subjected to the evaporation of water when the temperature in the tissue approaches $100{ }^{\circ} \mathrm{C}$ as (Abraham and Sparrow, 2007, Yang et al., 2006, Yang et al., 2007):

$$
\rho c \frac{\partial T}{\partial t}=\frac{\partial T}{\partial t} \cdot\left\{\begin{array}{cc}
\rho_{l} c_{l} & 0 \leq T \leq 99{ }^{\circ} \mathrm{C} \\
H_{f g} C & 99<T \leq 100{ }^{\circ} \mathrm{C} \\
\rho_{g}{ }^{c}{ }_{g} & T>100{ }^{\circ} \mathrm{C}
\end{array}\right\},
$$

where $\rho_{i}$ and $c_{i}$ are the density and specific heat of tissue that varies due to phase-change, i.e., at temperatures below $100{ }^{\circ} \mathrm{C}(i=l$ refers to liquid tissue phase) and at temperature above $100{ }^{\circ} \mathrm{C}\left(i=g\right.$ refers to gas tissue phase), $H_{f g}$ is the latent heat, i.e., the product of water latent heat of vaporization and water density at $100{ }^{\circ} \mathrm{C}$, and $C$ is the tissue water content inside the tissue.

The temperature-dependent thermal conductivity of the tissue is mostly modelled as a linearly increasing function of temperature (up to $100{ }^{\circ} \mathrm{C}$ ) in the computational models of thermal ablation and is given by

$$
k(T)=\left\{\begin{array}{ll}
k_{0}+\Delta k\left(T-T_{r e f}\right) & \text { for } T \leq 10{ }^{\circ} C \\
k_{0}+\Delta k\left(100{ }^{\circ} C-T_{r e f}\right) & \text { for } T>100{ }^{\circ} C
\end{array}\right\},
$$

where $k_{0}(\mathrm{~W} / \mathrm{m} / \mathrm{K})$ is the thermal conductivity of the tissue measured at baseline temperature $T_{\text {ref }}=37^{\circ} \mathrm{C}$ (core body temperature).

Blood perfusion is one of the most critical parameters that significantly affect the accuracy of the computational model, especially with the Pennes bioheat transfer model that accounts for microvascular tissue perfusion in absence of the large blood vessels. In most of the computational studies on thermal ablation available in literature (Ewertowska et al., 2018a, Ewertowska et al., 2018b, Ooi et al., 2018, Ooi et al., 2019, Qadri et al., 2017, Singh et al., 2019, Xu et al., 2019, Zhang et al., 2017), a thermal damage-dependent piecewise model of blood perfusion is used, whereby complete cessation of the blood perfusion rate is assumed to occur at the threshold of different damage models due to the collapse of microvasculature within the tissue (Hall et al., 2015) and is given by 


$$
\omega_{b}=\left\{\begin{array}{ll}
\omega_{b, 0} & \text { if damage is below the threshold value } \\
0 & \text { beyond the threshold value of damage }
\end{array}\right\}
$$

where $\omega_{b, 0}$ is the baseline blood perfusion rate of the tissue.

The effects of variation in the perfusion rates and perfusion models during computational studies of RFA were studied by Schutt and Haemmerich (Schutt and Haemmerich, 2008) considering: (a) piecewise model, (b) linear decreasing model, and (c) nonlinear decreasing model. It was found that the blood perfusion model significantly affects the final ablation zone dimensions of the computational model of RFA. The nonlinear decreasing model derived from the in vivo study in renal tissue, in which the blood perfusion initially increases due to hyperaemia and later decreases with coagulation due to damage to the microvasculature, was able to more accurately and realistically quantify the damage dependent variation in the blood perfusion rate during RFA. Thus, most of the recent studies reported in the literature have utilized a non-linear piecewise decreasing model of blood perfusion rate in the computational models of thermal ablation (Abraham and Sparrow, 2007, Shao et al., 2017a, Singh and Repaka, 2017c, Singh and Repaka, 2017a, Singh and Repaka, 2018c), as given by

$$
\omega_{b}=\left\{\begin{array}{cc}
\omega_{b, 0} & \text { for } \Omega(t) \leq 0 \\
\omega_{b, 0}\left[1+25 \Omega(t)-260 \Omega(t)^{2}\right] & \text { for } 0<\Omega(t) \leq 0.1 \\
\omega_{b, 0} \exp [-\Omega(t)] & \text { for } \Omega(t)>0.1
\end{array}\right\}
$$

where $\omega_{b, 0}$ is the baseline blood perfusion and $\Omega(t)$ is the induced thermal damage.

Since RFA and MWA procedures are performed at different frequencies of 450-550 $\mathrm{kHz}$ and $2.45 \mathrm{GHz}$ (or $915 \mathrm{MHz}$ ), respectively, the electrical parameter's value and its variation are different in both scenarios. Table 1 presents the electrical properties among various tissues at the frequency of RFA $(500 \mathrm{kHz})$ and MWA $(2.45 \mathrm{GHz})$ procedures (Hasgall et al., 2015). The relative permittivity and electrical conductivity of the biological tissue subjected to MWA are mostly modelled utilizing sigmoidal functions to include the effects of temperature dependence and water vaporization at the elevated temperatures ( $\mathrm{Ji}$ and Brace, 2011, Liu and Brace, 2017, Lopresto et al., 2014) using Eqs. 18 and 19, respectively:

$$
\begin{aligned}
& \varepsilon_{r}(T)=s_{1}\left(1-\frac{1}{1+\exp \left(s_{2}-s_{3} T\right)}\right)+s_{4}, \\
& \sigma(T)=r_{1}\left(1-\frac{1}{1+\exp \left(r_{2}-r_{3} T\right)}\right),
\end{aligned}
$$

where $s_{1}-s_{4}$ and $r_{1}-r_{3}$ are the regression coefficients, refer ( $\mathrm{Ji}$ and Brace, 2011, Liu and Brace, 2017, Lopresto et al., 2014) for more details. 
For computational modelling of RFA, various temperature-dependent models of electrical conductivity have been reported in the previous literature (Hall et al., 2014, Trujillo and Berjano, 2013, Hall et al., 2015). All of them describe a similar behavior with an increase in the electrical conductivity as a linear or exponential function of temperature until the tissue temperature reaches the threshold for water vaporization that is being followed by a rapid drop of two orders of magnitude due to the water vaporization and charring. Albeit some slight variations in the reported models of temperature-dependent electrical conductivity are present, but such variations have shown negligible effects on the predicted ablation volume during RFA. The most widely used model of temperature-dependent electrical conductivity during computational modelling of RFA is given by (Ewertowska et al., 2018b, GonzálezSuárez et al., 2018, Ooi et al., 2019)

$$
\sigma(T)=\left\{\begin{array}{ll}
\sigma_{0} \exp ^{0.015\left(T-T_{r e f}\right)} & \text { for } T \leq 99{ }^{0} C \\
2.5345 \sigma_{0} & \text { for } 99{ }^{\circ} C<T \leq 100{ }^{\circ} C \\
2.5345 \sigma_{0}-0.50183 \sigma_{0}\left(T-100{ }^{\circ} C\right) & \text { for } 100{ }^{\circ} C<T \leq 105^{\circ} C \\
0.025345 \sigma_{0} & \text { for } T>105{ }^{\circ} C
\end{array}\right\},
$$

where $\sigma_{0}(\mathrm{~S} / \mathrm{m})$ is the electrical conductivity of the tissue at baseline temperature $T_{r e f}=37^{\circ} \mathrm{C}$ (core body temperature).

\subsection{Incorporation of non-Fourier effects}

The majority of studies available in earlier works on the computational modelling of thermal ablation utilizes the Pennes bioheat transfer model for predicting the thermal response. However, the Pennes bioheat equation has been developed based on the classical Fourier's law of heat conduction [i.e., $\boldsymbol{q}(\boldsymbol{r}, t)=-k \nabla T(\boldsymbol{r}, t)$; where $\boldsymbol{q}$ is heat flux, $k$ is thermal conductivity and $T(\boldsymbol{r}, t)$ is the temperature at point $\boldsymbol{r}$ at time $t$ ]. It presumes an infinitely fast propagation of thermal signals or equivalently, any thermal disturbance on a medium will be felt instantaneously throughout the medium. Such assumptions are reasonable in majority of the practical applications but fail, especially in particular heat conduction media having nonhomogenous inner structures such as biological tissues. Importantly, the heat conduction in a biological tissue always occurs with a lagging behaviour due to its anisotropic and heterogeneous structures, and suggests the existence of non-Fourier conduction. This leads to the propagation of thermal disturbance at a finite speed, i.e. results in a delayed response between the heat flux vector and the temperature gradient. The lagging behaviour induced due to non-Fourier behaviour has been incorporated in the linear extension of the Fourier heat transfer model by introducing a thermal relaxation time [i.e., $\boldsymbol{q}\left(\boldsymbol{r}, t+\tau_{q}\right)=-k \nabla T(\boldsymbol{r}, t)$ : where 
$\tau_{q}$ is the thermal relaxation time], as independently proposed by (Cattaneo, 1958) and (Vernotte, 1958). The introduced thermal relaxation time $\tau_{q}$ represents the time delay between the heat flux vector and the temperature gradient, and the constitutive relation is known as single-phase-lag (SPL) non-Fourier heat transfer model, as given by:

$$
\begin{aligned}
& \rho c \tau_{q} \frac{\partial^{2} T}{\partial t^{2}}+\left(\rho c+\tau_{q} \rho_{b} c_{b} \omega_{b}\right) \frac{\partial T}{\partial t}= \\
& k \nabla^{2} T-\rho_{b} c_{b} \omega_{b}\left(T-T_{b}\right)+Q_{m}+Q_{p}+\tau_{q}\left(\frac{\partial Q_{m}}{\partial t}+\frac{\partial Q_{p}}{\partial t}\right) .
\end{aligned}
$$

(Tzou, 1995) added another relaxation time $\tau_{T}\left[\boldsymbol{q}\left(\boldsymbol{r}, t+\tau_{q}\right)=-k \nabla T\left(\boldsymbol{r}, t+\tau_{T}\right)\right]$ known as a phase lag due to temperature gradient, to take into account the effects of micro-structural interaction along with fast transient effects of heat transport, an effect that was absent in the SPL non-Fourier heat transfer model. The constitutive model is referred to as the dual-phaselag (DPL) non-Fourier heat transfer model as given by:

$$
\begin{aligned}
& \rho c \tau_{q} \frac{\partial^{2} T}{\partial t^{2}}+\left(\rho c+\tau_{q} \rho_{b} c_{b} \omega_{b}\right) \frac{\partial T}{\partial t}= \\
& k \nabla^{2} T+\tau_{T} k \nabla^{2} \frac{\partial T}{\partial t}-\rho_{b} c_{b} \omega_{b}\left(T-T_{b}\right)+Q_{m}+Q_{p}+\tau_{q}\left(\frac{\partial Q_{m}}{\partial t}+\frac{\partial Q_{p}}{\partial t}\right) .
\end{aligned}
$$

Several pertinent models have been reported (Askarizadeh and Ahmadikia, 2014, Kumar et al., 2015, Kumar et al., 2016, Liu and Chen, 2010) and developed using first and secondorder Taylor expansions of the DPL non-Fourier heat transfer model proposed by Tzou (Tzou, 1995). The fully coupled thermo-mechanical models of hyperbolic thermoelasticity, studies in (Strunin et al., 2001), included also non-linear effects.

The biological tissue consists of non-homogeneous media, containing microscopic inhomogeneities such as macromolecules and cell organelles organized in cellular structures, resulting in higher relaxation time compared to the engineering materials. Unfortunately, due to these associated complexities of biological materials, the exact value of thermal relaxation time for both the heat flux and the temperature gradient is still unclear. (Vedavarz et al., 1994) estimated that the value of $\tau_{q}$ for biological tissues lies in the range of 1-100 s at room temperature. (Kaminski, 1990) found the relaxation time for heat flux in the range of 20-30 s for the meat products. (Mitra et al., 1995) found that in a processed meat $\tau_{q}=16 \mathrm{~s}$ and $\tau_{T}=$ $0.043 \mathrm{~s}$, while (Roetzel et al., 2003) found $\tau_{q}=1.77$ s. (Jaunich et al., 2008) found the values of thermal relaxation time in the range of $10-20 \mathrm{~s}$ on the inhomogeneous tissue phantoms that simulated skin tissue. (Liu and Chen, 2010) reported $\tau_{q}=7.4-8.9 \mathrm{~s}$ and $\tau_{T}=14.5-21.4 \mathrm{~s}$, while (Sahoo et al., 2014) reported $\tau_{q}=2-8 \mathrm{~s}$ and $\tau_{T}=0.045 \mathrm{~s}$. Thus, there prevails a huge 
variability among the thermal relaxation time of biological tissues reported in previous literature. The comparison of different values of non-Fourier lags in biological tissues reported in the previous experimental studies has been presented in Table 2. Recently, (Maillet, 2019) reported a short review highlighting the shortcomings in the experimental validation of the non-Fourier models reported in previous literature. The study reported that one of the serious flaws of the reported studies was that the non-Fourier heat transfer models were not validated at the meso-scale in heterogeneous materials. Other shortcomings include, non-validation of the experimental boundary conditions by direct simulations along with uncertainty in the quantification of experimental source term, deviations in the origin of time reported for the experimental configuration, assumption of a uniform temperature field that is not confirmed by temperature measurement in experimental studies before time $t=0$, errors in the thermo-physical parameters, ignorance of the modern parameter estimation techniques and non-existent or deficient analysis of the errors during experimental measurements. Thus, there remains a great demand of conducting more rigorous experimental studies on biological tissues with a very critical hindsight to validate the non-Fourier models on a sound basis and characterize the thermal relaxation times associated with such phenomena among different tissues. Although several computational studies have already been reported in literature utilizing the non-Fourier approach for highlighting the differences in the predicted temperature distribution and ablation volumes during percutaneous thermal ablative procedures (Askarizadeh and Ahmadikia, 2014, Kabiri and Talaee, 2019, Kumar et al., 2018, Kumar et al., 2015, Kumar et al., 2016, Li et al., 2017, López-Molina et al., 2008, Singh and Repaka, 2018e, Zhang et al., 2015). Hitherto, most of these studies are limited to computational modelling of RFA, with a very scarce application of non-Fourier phenomena in MWA (Kabiri and Talaee, 2019). At the same time, the consideration of non-Fourier behavior becomes more vital in MWA, where a high amount of energy is deposited within the biological tissues in shorter time spans as compared to RFA. It is also true for several other treatment modalities such as laser ablation.

\subsection{Incorporation of the mechanical deformation model}

The physical problem of mechanical deformation caused by the high-temperature during thermal ablation of soft biological tissues is mostly modelled using the stress-strain equation (Eq. 23) and the thermo-elastic wave equation (Eq. 24) (González-Suárez et al., 2015, Keangin et al., 2011, Wongchadakul et al., 2018):

$$
\bar{\sigma}_{i j}=2 \mu \varepsilon_{i j}+\lambda \varepsilon_{k k} \delta_{i j}-(3 \lambda+2 \mu) \varepsilon^{t h} \delta_{i j}
$$




$$
\rho \frac{\partial^{2} \boldsymbol{u}}{\partial t^{2}}=\bar{\sigma}_{i j, j}+\boldsymbol{F}
$$

where $\bar{\sigma}$ is the stress tensor and $\varepsilon=\left[\left(\nabla \boldsymbol{u}^{T}+\nabla \boldsymbol{u}\right) / 2\right]$ is the strain tensor $(i, j=1,2,3$ are the tensor indices representing geometry's coordinate axes and $k k$ subindices indicate the trace of the strain tensor), $\mu=[E / 2(1+v)]$ and $\lambda=[v E /(1+v)(1-2 v)]$ are the Lame's constants, $E$ is the Young's modulus, $v$ is the Poisson's ratio, $\boldsymbol{u}$ is mechanical displacement vector, $\varepsilon^{\text {th }}=\int_{T_{\text {ref }}}^{T} \alpha d T$ is the thermal strain, $\alpha$ is the thermal expansion coefficient, $T$ is the temperature computed from bioheat transfer model, $T_{r e f}$ is the baseline temperature, $\rho$ is the density, $t$ is the time, $\boldsymbol{F}$ is the body mechanical force vector and $\delta$ is the Kronecker delta function given by:

$$
\delta_{i j}=\left\{\begin{array}{ll}
1 & \text { for } i=j \\
0 & \text { for } i \neq j
\end{array} .\right.
$$

It is noteworthy to mention that both RFA and MWA utilizes elevated temperatures $\left(>60{ }^{\circ} \mathrm{C}\right)$ to attain cellular injury to the deceased tissue. The exposure of biological tissue to such hightemperature results in thermo-elastic deformation, including both the mechanical deformation induced due to thermal expansion and the tissue shrinkage/contraction. Importantly, the tissue shrinkage is a consequence of many interlinked complex effects associated to occur at elevated temperatures during thermal ablation, viz., protein denaturation, contraction of collagen and dehydration. To date, the underlying mechanism of these processes that results in the shrinkage of biological tissues when exposed to high temperatures is not fully understood. Recently, there has been a significant increase in the research related to the quantification of the tissue shrinkage spatially or temporally among different organs during thermal ablative procedures (Liu and Brace, 2017). Notably, previous ex vivo thermal ablative studies have reported the ablation zone volume contraction up to 40-50\% in liver, 50-60\% in lung and 26-42\% in the kidney (Brace et al., 2010, Farina et al., 2014, Liu and Brace, 2014, Sommer et al., 2013). Furthermore, tissue shrinkage of up to $62 \%$ has also been observed in actual clinical studies on hepatic hemangiomas and renal cell carcinomas (Moreland et al., 2014, Ziemlewicz et al., 2014). Previously reported studies have highlighted that the relative shrinkage during thermal ablative modalities increases with increasing the exposed temperature and/or treatment time (Liu and Brace, 2017, Amabile et al., 2017, Farina et al., 2018, Rossmann et al., 2013). Moreover, this relative shrinkage has been found to be higher in the tissue closer to the applicator and is observed more frequently in MWA as compared to RFA (Liu and Brace, 2017, Amabile et al., 2017, Farina et al., 2018, Rossmann et al., 2013). 
Most of the computational studies of thermal ablation available in the literature are based on coupled thermo-electric analysis (Barauskas et al., 2008, Ewertowska et al., 2018b, Ooi et al., 2018, Ooi et al., 2019, Qadri et al., 2017, Singh et al., 2016, Singh and Repaka, 2017c, Zhang et al., 2017, Zhang et al., 2015, Zorbas and Samaras, 2014, Zorbas and Samaras, 2015) and clearly neglects or underestimates the induced thermo-elastic deformations due to elevated temperature within the biological tissue. As mentioned earlier, the exposure of biological tissue to elevated temperatures during thermal ablative procedures can result in mechanical deformations, including both contractions and expansions. Several computational studies have recently tried to capture such mechanical deformations but mainly focused on capturing mechanical deformations induced due to thermal expansion alone (González-Suárez et al., 2015, Keangin et al., 2011, Wongchadakul et al., 2018, Chaichanyut and Tungjitkusolmun, 2016, Karaki et al., 2018, Keangin and Rattanadecho, 2018, Li et al., 2014, Li et al., 2017). Importantly, ignoring the impact of tissue contraction could result in a significant underestimation of the ablation volume predicted by the computational models as compared to the actual dimensions of the destroyed tissue (Brace et al., 2010, Rossmann et al., 2013). Henceforth, incorporation of the thermally induced contraction phenomenon in the computational models of thermal ablation would warrant a more accurate prediction and assessment of the dimensions of ablation zone.

More recently, few studies have also proposed mathematical models to predict the tissue shrinkage during thermal ablation (Liu and Brace, 2017, Rossmann et al., 2013), but the incorporation of such predictive models in the actual numerical simulations of the ablation procedures is still missing. (Rossmann et al., 2013) performed an ex vivo, isothermal shrinkage studies for quantifying the shrinkage dynamics in the porcine liver tissue subjected to 15 minutes of heating utilizing bipolar RF system. Five target temperatures were used from $60{ }^{\circ} \mathrm{C}$ to a maximum temperature of $95{ }^{\circ} \mathrm{C}$, so as to avoid explosive evaporation and combustion of the tissue samples. A $40 \mathrm{~W}$ power was applied for heating the samples until the pre-defined target temperature was reached and later manually controlled to maintain the tissue temperature to be constant. Two markers were inserted parallel in the center of the heating zone and their motion was recorded via digital video camera. The relative percentage shrinkage is thus defined by the movement of markers relative to their initial position after 15 min of heating, and is given by:

$$
\xi_{\text {rel }}=\left(1-\frac{L}{L_{0}}\right) \cdot 100,
$$

where $L$ is the final distance between the markers and $L_{0}$ is the initial distance between the markers. After 15 minutes of heating, the estimated relative shrinkages were reported to be 
$12.3 \%, 13.8 \%, 16.6 \%, 19.2 \%$ and $21.7 \%$ at a temperature of $60,65,75,85$ and $95{ }^{\circ} \mathrm{C}$, respectively. A mathematical model was further developed for predicting the time and temperature-dependent shrinkage dynamics of tissue, and is given by:

$$
\xi_{i j}(t, T)=a_{0}+a_{1} \ln (t)+a_{2}\left(\frac{1}{T(K)}\right)+\beta_{3} I(\text { days }=1)+\beta_{4} I(\text { days }=2)+b_{i}+\varepsilon_{i j},
$$

where $\xi_{i j}$ is the shrinkage for the $j_{t h}$ observation of experiment $i ; a_{0}, a_{1}$ and $a_{2}$ are the material parameters; $\beta_{3}$ and $\beta_{4}$ accounts for time since sacrifice of the sample; $b_{i}$ accounts for the experiment level effect for experiment $i ; \varepsilon_{i j}$ is the residual; $I($ days $=k)$ is an indicator taking a value of 1 if it was $k$ days since sacrifice for the sample in experiment $i$; $T$ is the temperature, and $t$ is the time.

(Liu and Brace, 2014) reported an ex vivo study to analyze the spatio-temporal distribution of liver tissue contraction during MWA utilizing intraprocedural computed tomography (CT) imaging. A 10-minute MWA procedure was performed at $100 \mathrm{~W}$ and 2.45 $\mathrm{GHz}$ on the bovine liver samples. In order to capture the contraction, a total of 46 aluminum fiducial markers were positioned around the microwave ablation antenna and CT data were acquired every $30 \mathrm{~s}$ during the MWA procedure. The tissue contraction and contraction rates were quantified from the fiducial motion posttreatment. It was found that after the MWA procedure, the ablation zone was $\sim 20 \%$ smaller in the radial direction and $\sim 10 \%$ smaller in the longitudinal direction as compared to the pretreatment dimensions. Accordingly, this leads to a reduction of around $45 \%$ of the ablation volume as compared to its pre-ablation volume. Further, the study reported that the greatest contraction occurred at the ablation zone center and the contraction rate peaks early and decays over time. In another study, (Liu and Brace, 2017) reported a numerical model that integrates the temperature and time-dependent model of tissue contraction with a negative thermal coefficient which is further coupled to the electromagnetic and heat transfer models for predicting the thermo-mechanical response during MWA. The proposed simulation model showed a good agreement of the temperature and contraction-induced displacement with the experimental in vitro results. More recently, (Liu and Brace, 2019) reported an experimental study on bovine liver to quantitatively analyze the tissue deformation during RFA and MWA. It was reported that the tissue dimensions contracted by 5\% post RFA and 20-65\% post MWA procedures. Thus, the present experimental ex vivo study proved that the mechanical deformations induced during thermal ablative procedures could underestimate the original ablation zone by $30-60 \%$ with varying energy sources. (Park et al., 2016) developed and reported a mathematical framework to describe the protein denaturation that results in tissue contraction when exposed to elevated temperature during thermal ablation. A three-state model of globular protein with 
first-order kinetics as described in Eqs. 11-13 was used for computing the shrinkage and a sensitivity analysis was performed for determining the different parameters of the model. The change in the protein state to tissue length was modelled assuming the total length of the tissue, $L$, to be equal to the linear sum of the different states of proteins (i.e. $L=N L_{N}+U L_{U}+$ $D L_{D}$ ). Assuming that all the protein is in the native state initially prior to the application of thermal ablative procedures, i.e. $L_{0}=N$, the relative shrinkage described in Eq. 24 can be rewritten as:

$$
\xi_{r e l}=\left(1-N-U \frac{L_{U}}{L_{N}}-D \frac{L_{D}}{L_{N}}\right),
$$

where $N, U, D$ are the proportion of cells that are in native (alive), unfolded (vulnerable) and denatured (dead) states, respectively, and $L$ is the length of proteins with the subscripts representing different states. Thus, the proportions of proteins in each state, viz., native $(N)$, unfolded $(U)$ and denatured state $(D)$, and the length ratios, $L_{U} / L_{N}$ and $L_{D} / L_{N}$ will affect the tissue length and thus the relative shrinkage within the tissue. The different parameters utilized in the study were derived from the previously reported ex vivo study on isothermal free shrinkage of bovine pericardium tissue samples. Utilizing this mathematical framework, (Park et al., 2018) recently reported a mathematical model of the thermo-elastic deformation for an elastic isotropic material coupled with a three-state thermal denaturation model to determine the contraction of tissue during thermal ablative modalities. The results reported in the study showed that the tissue displacement was not bound to the heated regions only and that both the tissue expansion and the contraction were observed at different stages of the thermal ablative procedures. Further, this study reports that the tissue displacement was significantly dependent on the Poisson's ratio (i.e. the mechanical property of the tissue defined by the negative of the ratio of transverse strain to axial strain) and the applicator temperature during thermal ablation. It was found that the magnitude of the peak value of tissue contraction decreases with decreasing the Poisson's ratio. More recently, (Singh and Melnik, 2019b) reported a coupled thermo-electro-mechanical model for more accurate prediction of the treatment outcomes during thermal ablative procedures. Importantly, the effects of heat relaxation time effects were also quantified considering both SPL and DPL models. The study reported significant deviations in the ablation volume predicted with and without mechanical coupling during MWA. These recent results have emphasized the need of incorporating the mechanical deformation model, considering both thermal expansion and tissue contraction, by coupling the solid mechanics model to the existing bio-electromagnetic and bioheat transfer models for more accurate and precise predictions of the ablation volume. Such coupled thermo-electro-mechanical models take a significant step towards a more 
realistic description of the biophysical phenomenon during thermal ablation and will reduce the mismatch between treatment outcomes obtained from the experimental and numerical findings.

\subsection{Solid-fluid interaction, blood vessel models and biological networks}

Several studies have been reported in the literature considering porous media theory for modelling the heat transport in the biological tissue (Chaichanyut and Tungjitkusolmun, 2016, Karaki et al., 2018, Keangin and Rattanadecho, 2018, Keangin and Rattanadecho, 2013, Khaled and Vafai, 2003, Nield and Bejan, 2017, Rattanadecho and Keangin, 2013). A typical description of such established models of porous media can be found, e.g., in (Khaled and Vafai, 2003, Nield and Bejan, 2017). Importantly, such studies consider the biological tissue as a complex porous structure that comprises of three compartments, viz., blood vessels, cells and interstitial space. For sake of simplicity, most of the previous studies have divided the biological tissue into two different regions, namely, the vascular region (comprising of blood vessels) and the extravascular region (comprising of cells and the interstitial space). Since such models require quite detailed anatomical information, their implementation is complex and tremendously dependent on the characterization of different values of interest among different tissues. The modelling of heat transfer utilizing a porous media approach results in fewer assumptions and hence better prediction of the temperature distribution as compared to the Pennes bioheat transfer equation. Further, two different formulations, i.e. local thermal equilibrium (LTE) and local thermal non-equilibrium (LTNE) are mostly used for predicting the heat transport through porous biological tissues (Keangin and Rattanadecho, 2018, Keangin and Rattanadecho, 2013, Rattanadecho and Keangin, 2013, Wang et al., 2015). The LTE formulation assumes that the temperature of the tissue phase is locally equal to that of the blood phase everywhere inside the porous medium. Such an assumption is only valid when the capillary bed of the tissue has a large number of smaller diameter micro-vessels along with a large area of heat transfer. Whereas, this assumption does not hold good for some physical situations where the fluid is flowing at a high speed through the porous medium and the temperature difference is not negligible between the two phases. Accordingly, for those cases, the LTNE formulation is utilized for investigating the changes in blood temperature as a result of convective heat exchange between the two phases. Some of the pioneer work in regard to modelling of MWA utilizing porous media approach with LTE and LTNE formulations has been reported by (Keangin and Rattanadecho, 2018, Keangin and Rattanadecho, 2013, Rattanadecho and Keangin, 2013). (Wang et al., 2015) developed an analytical model utilizing the LTNE formulation of porous 
media theory for predicting the blood and tissue temperature distributions along with overall heat exchange correlations during RFA. The study also investigated the effects of physiological parameters, viz., metabolic heat generation, the volume fraction of the vascular space and effective blood to tissue conductivities, different biological media and the rate of heat exchange between the lumen and the tissue.

We note also that the heat sink (or cooling) effect caused by the large blood vessel, e.g. in close proximity of tumor, can significantly influence the success rate of complete tumor eradication during thermal ablation (Fang et al., 2017, Pillai et al., 2015). Importantly, this effect is more pronounced for the blood vessel greater than $2 \mathrm{~mm}$ in diameter (Shih et al., 2006), and is more significant in RFA as compared to MWA (Lopresto et al., 2017b, Ward et al., 2013). Several computational studies have been reported in the literature for evaluating the influence of heat sink effect caused by large blood vessels by coupling the additional fluid flow model (i.e. Navier-Stokes equations) to the existing bio-electromagnetic and bioheat transfer models of thermal ablation (Chaichanyut and Tungjitkusolmun, 2016, Haemmerich et al., 2003, Horng et al., 2007, Huang, 2013, Jain and Wolf, 2000, Rossmann et al., 2012, Singh et al., 2015, Wang et al., 2016, Zorbas and Samaras, 2015, Khademi et al., 2019, Shao et al., 2017a, Shao et al., 2017c). Importantly, in these studies, the blood vessel is incorporated by including a cylinder or a vascular tree within the computational domain, either derived from the patient image data or selected arbitrarily. (Hassanpour and Saboonchi, 2016) reported a study to evaluate the role of small vessels on the heat transfer mechanism during intensive heating of biological tissue. The cylindrical small parallel vessels were modelled as a co- and counter-current vascular networks within the computational domain. Recently, (Audigier et al., 2017) reported a computational study of RFA for treating a liver tumor that incorporates the computational fluid dynamics (CFD) solver with the conventional electro-thermal model. In this study, the computational domain was derived from the realistic animal-specific models of pigs, inclusive of hepatic venous and arterial circulation systems, acquired from the computed tomography images. To address and avoid the anisotropic resolution issue of the segmented vessels obtained from the preoperative images along with an unstable solution of CFD solver, smooth vessel trees were generated in a piecewise fashion from the extracted centrelines and computed the mean radius of the vessels. Moreover, the inputs required for modelling the blood flow in the RFA model, such as blood flow entering the vena cava, the portal vein and the hepatic artery, were actually acquired from the phase-contrast magnetic resonance images, instead of fixing nominal values from the literature. Furthermore, the blood pressure inputs to be prescribed at the boundaries of the blood vessels were acquired from the invasive measurements in pigs. The developed model 
not only considered the heat sink effect of all hepatic vessels (veins and arteries) during RFA procedures but also the blood flow within the parenchyma by utilizing the porous media approach. Figure 3 presents the schematic of blood vessels and bio-network modelling during RFA procedures (Audigier et al., 2017). (Salimpour and Shirani, 2017) reported a study to quantify the effects of thermally significant blood vessels on the temperature distribution in a skin subjected to thermal therapy. In this study, the counter-current multilevel vessel network of the circular cross-section was embedded within the three-dimensional triple-layered skin structure. The blood was modelled assuming a non-Newtonian power-law viscosity model and the study reported that both micro and macrovascular blood perfusions have an enormous effect on the tissue temperature distribution (i.e. a difference of $8{ }^{\circ} \mathrm{C}$ between the zero and maximum perfusion rate conditions at the end of the procedure). Importantly, the microvascular perfusion refers to the perfusion that occurs at the capillary level, while the macrovascular perfusion refers to the heat sink effect caused by the large blood vessels (Singh and Repaka, 2017b). The effects of boundary conditions, relaxation time, thermal properties, perfusion rate, metabolism and pulse heat flux on the temperature distribution were also investigated in (Salimpour and Shirani, 2017). Again, the major focus of such studies was only limited to evaluating the vascular cooling effect on RFA, since MWA is generally less susceptible to such heat sink effects as compared to RFA.

\subsection{Image-based multiscale modelling}

Traditionally, computational studies of the thermal ablation are performed on either onecompartment (having homogeneous properties) or two-compartment models (e.g., having different properties for healthy and tumorous tissues). In these studies, instead of modelling the entire tissue, only a small control volume of the tissue is modelled with a simplified geometry, such as a cylinder or a sphere, in either three-dimensional or two-dimensional axisymmetric coordinates. This approach assumes that the target zone for performing thermal ablation is located far from the boundary of that organ, with the ablation zone dimensions significantly less than the actual size of that organ, such that any boundary effects are negated (Ooi et al., 2019). Figure 4 presents the reduction of tissue-level model to the simplified axisymmetric model along with associated boundary conditions for MWA and RFA procedures. The outer boundaries of the computational domain of thermal ablative models are specified with electrical and thermal boundary conditions. Most often, ground (to mimic the ground pad) and constant body temperature conditions (that assumes ablation zone to be sufficiently isolated from the surrounding healthy tissues such that normo-thermoregulation can maintain the external boundaries of the domain at body temperature) are prescribed as the 
electrical and thermal boundary conditions, respectively (Ewertowska et al., 2018b, González-Suárez et al., 2018, Ooi et al., 2019, Singh and Repaka, 2017c, He et al., 2013). Some researchers have adopted other boundary conditions, such as, the Robin type electrical boundary conditions to mimic the outflow of electric current to an infinite space and the thermal insulation condition to allow temperature at external boundary to increase in response to the heating induced during thermal ablation, etc. (Altrogge et al., 2007, Kröger et al., 2010, Ooi et al., 2018, Qadri et al., 2017). Recently, (Ooi et al., 2019) reported a computational study of RFA for treating liver cancer by considering geometrically-accurate models of the liver. Importantly, in this study, the geometrically-accurate model of the liver was constructed using publically-available CT scan dataset of the liver in which ellipsoid shaped artificial tumor domain was inserted to represent the tumor. The prime motive of this study was to investigate the effects of different electrical and thermal boundary conditions prescribed at the outer boundaries of the computational domain of RFA models, specifically for cases where the tumor is located close to the liver boundary. The different types of boundary conditions considered for the electrical field were ground and Robin type, while constant body temperature and thermal insulation conditions were imposed for the thermal field. It was found that the different electrical and thermal boundary conditions imposed at the computational domain of RFA resulted in significant differences in the predicted electrical potential, temperature and coagulation volume distributions. The use of ground or body temperature conditions resulted in a reduction of the predicted coagulation volume as compared to the case when the Robin type or the thermal insulation condition is prescribed. Although this study could not firmly identify the correct boundary condition to be prescribed in RFA models, it certainly highlights the concern about the selection of proper boundary conditions at the outer domain of the computational models, e.g., when the tumor is located at the peripheral region of the liver. Furthermore, the consideration of the ambient room temperature conditions, by incorporating the convective cooling boundary condition at the outer surfaces of the computational domain, also becomes vital if the treated tissue is directly exposed to the ambience, such as for treating cancer in skin or breast (Singh and Repaka, 2018e).

The ultimate goal of the computational models is to reach a stage where these tools can be easily integrated into the clinical workflow in such a way that based on the individual patient imaging data an optimal heating protocol can be readily provided in advance of the therapy. The attainment of this goal is tremendously dependent on the combination of mathematical modelling, computational efficiency and accurate image analysis (Payne et al., 2011). Moreover, extensive validation of the developed models is required before it can be 
integrated into clinical settings in order to provide precise treatment outcomes with confidence. Image-based multiscale modelling is the next step to attain the goal of complete transformation of computational models of MWA and RFA into clinical practices. In a nutshell, the image-based computational modelling of thermal ablation can typically be subdivided into three main steps: (a) generation of patient-specific model, (b) computation of electromagnetic power deposited within the tissue, and (c) prediction of the temperature distribution and damage volume for better planning and optimization of the treatment protocols (Paulides et al., 2013). The first step is most challenging and time-consuming task whereby a three-dimensional patient-specific model is built by segmenting the medical images captured using the computed tomography (CT) or magnetic resonance image (MRI) of the patient (Wu et al., 2017, Wu et al., 2016, Zhang et al., 2018). The accurate and quick reconstruction of the three-dimensional surface models from CT and/or MRI data significantly relies on the advanced segmentation algorithms (Audigier et al., 2017, Lebre et al., 2019, Neal and Kerckhoffs, 2009, Schumann et al., 2010, Soler et al., 2014, Zygomalas and Kehagias, 2019). The next step is related to the percutaneous insertion of the electrode/applicator within the target tissue. Importantly, the precise and accurate insertion of the electrode during clinical practices is tremendously dependent on the personal experience (e.g., excellent hand-eye coordination) of the clinicians. To address this issue and assist the clinicians in a better way, use of computer-assisted electrode trajectory planning techniques has also been extensively explored, particularly for reducing the number of re-insertion attempts (Seitel et al., 2011, Singh and Repaka, 2018d). Recently, (Zhang et al., 2019b) reported an extensive review on computer-assisted needle trajectory planning for RFA and MWA of liver tumors, highlighting different algorithms used for needle trajectory planning along with their shortcomings. The last step in a computational modelling approach of thermal ablation is the prediction of the heating protocol outcome (i.e. ablation volume). This outcome is generally predicted utilizing the coupled thermo-electro-mechanical simulations and is based on the input requirements of the heating profile, blood flow field, bioheat transfer model and thermal damage model. The practical difficulties associated with choosing different parameter values have been discussed in a review article by Payne et al. (Payne et al., 2010).

Several studies have been reported in the past on the three-dimensional image-based patient-specific model of RFA for treating tumor (Audigier et al., 2017, Audigier et al., 2015, Audigier et al., 2013, Payne et al., 2011, Payne et al., 2010, Rieder et al., 2011, Chen et al., 2018, Mariappan et al., 2017, Reinhardt et al., 2017, Voglreiter et al., 2018, Zorbas and Samaras, 2014, Jin et al., 2014, Moche et al., 2020). Figure 6 presents a generalized technical 
workflow adopted during the patient-specific modelling and simulation of RFA for treating liver tumor (Voglreiter et al., 2018). (Payne et al., 2011) developed a multiscale mathematical model for simulating the RFA process in treating liver tumors based on patient-specific data and images. In this study, a split-volume porous bioheat transfer model has been used for modelling the heat transfer in the vascularized tissue instead of using uniformly distributed blood perfusion rate within the whole tissue. This modelling approach was adopted to avoid the deviations between the Pennes model predictions and the actual temperature fields. Further, the heat sink effect caused by the large blood vessels, having a diameter greater than $10 \mathrm{~mm}$, was quantified by modelling the convective heat transfer on the vessel wall using Newton's law of cooling. While, the cooling effects caused by small blood vessels (having a diameter less than $0.1 \mathrm{~mm}$ ) was neglected due to their minor contribution to the vasculature cooling. Moreover, to mimic the blood flow in the patient-specific vascular geometry, continuum porous media flow field was constructed by applying the appropriate sources and sinks at the boundaries of the blood vessel tree that was reconstructed from a vessel-enhanced X-ray CT image. Furthermore, the outcomes of the developed simulation tool kit were compared with the in vivo outcomes of RFA in pig animal and the likely sources of error along with routes towards their clinical implementations were discussed. The greatest sources of error were associated with the thermo-electric and bio-physical properties considered in the model that can have huge variability not only among different patients but also spatially within the considered tissue. Further, the material properties can vary significantly with a disease (for e.g., cirrhosis of the liver can strongly affect the flow field). In addition, the blood flow within the tumor is highly abnormal and any incorrect assumptions on the blood flow velocity within the computational model can significantly overestimate the heat sink effect thereby predicting an incorrect lesion volume. Moreover, tumor hypoxia is an additional factor that can lead to the tumor response quite different as compared to that of the surrounding healthy tissue. Further, toxins are released as the tumor cells die during thermal ablation that can also significantly affect the remainder of the tumor. The study further highlights that the importance of conducting a sensitivity analysis for examining the effects of such errors on the treatment outcome of the computational model, once the accurate clinical data from the human patients is available. (Zorbas and Samaras, 2014) computationally simulated the RFA treatment employing realistic anatomy of three different body sites, namely, liver, lung and kidney, with an embedded spherical tumor. These anatomically realistic computational domains of different tissues were actually derived from the high-resolution region-specific models developed by IT'IS Foundation (Christ et al., 2009). The study reports significant deviations in the treatment outcomes of RFA while 
considering the complex tissue anatomical model as compared to the infinite homogeneous tissue model. (Audigier et al., 2017) reported a computational framework for the validation of a subject-specific multi-physics model of RFA for treating the liver tumor. In this study, a comprehensive experimental setup was utilized by combining the multimodal, pre- and postoperative anatomical and functional images along with the interventional monitoring of intra-operative signals, namely, temperature and delivered power. In order to validate the proposed framework, twelve experimental ablations were performed on the pig liver. Further, the computational model of RFA was developed taking into account the main biophysical phenomena, viz., heat transfer, cellular necrosis, hepatic blood flow and the advection effect of porous circulation. (Voglreiter et al., 2018) reported a software framework for the highperformance patient-specific simulation of RFA for treating liver tumors. The graphics processing unit (GPU) based software was reported to provide a fast and accurate prediction of the treatment outcomes along with their advanced visualization during RFA intervention. This was attained by combining a large number of high-performance image processing, biomechanical simulation and visualization techniques into the generalized clinical workflow.

\section{Application of laser ablation to biological tissues, neural interfaces, multiphysics and smaller-scale effects}

Like radiofrequency and microwave energy, laser also induces electromagnetic heating to elevate the tissue temperature to cytotoxic level within the biological tissues. Laser irradiation is monochromatic, coherent and collimated, and has vast application in the biomedical engineering, in particular thermal therapies (Makropoulou et al., 2019). Lasers have been widely and successfully used over the past three decades for therapeutic treatment of the superficial cancers (typically, basal cell skin cancer) and the early stages of cervical, vaginal, penile, vulvar and non-small cell lung cancer . Importantly, the interaction of lasers with the biological tissues can be characterized into several mechanisms, viz., photo-thermal, photo-mechanical (or photo-acoustical), photo-chemical and plasma-mediated ablation (photo-ablation) (Okuno et al., 2013, Jaunich et al., 2008). Amongst these four mechanisms, the photo-thermal effect is the most commonly observed and easily quantified mechanism that has been successfully used in the localized heating of cancerous tissues during laserinduced interstitial thermotherapy (LITT), laser-induced hyperthermia (HT) and interstitial laser photocoagulation therapy (ILP). The application of lasers utilizing the (NIR) region (750-100 nm) of electromagnetic spectrum has been extensively used by the researchers in clinical diagnosis and thermal therapies. Laser ablation is performed utilizing either continuous and/or pulsed mode, whereby the absorptivity of laser energy within the 
biological tissue is significantly dependent on the optical properties of the target tumor and surrounding healthy tissue (Mooney et al., 2017, Stafford et al., 2010). Selection of the proper delivery technique of laser beam within the target tissue plays a vital role in initiating the photo-thermal or photo-ablative effects for attaining successful ablation (Jaunich et al., 2008). Particularly for treating deep-rooted tumors, the laser beam (either collimated or diffused) with a high optical penetration depth is delivered using a fiber-optic delivery system. While, for treating skin or subsurface tumors there is no need of perforation as instead of the fiberoptic system, a converging laser beam is used that is directly focused at the target site. Furthermore, treatment outcomes of the laser therapy procedures are significantly dependent on the tissue properties along with the irradiation time, intensity and spot size of the laser (Jaunich et al., 2008).

One of the major limitations of laser ablation is the non-specific overheating of the surrounding healthy tissue. A recent improvement in the laser ablation strategies has shown that this problem can be effectively tackled by incorporating the nanoparticles within the target tissue. Importantly, the localization of the nanoparticles within the tumor increases the absorption of light within them, leading to more selective and pronounced heating of the target tissue along with minimizing the morbidity caused by off-target heating. The efficacy of different types of nanoparticles, namely, gold, carbon and graphene with different shapes (e.g., nanospheres, nanorods and nanoshells) have been previously explored during the laser ablative procedures (Mooney et al., 2017). The major focus has been given to the gold nanoparticles due to their chemical stability and higher compatibility with the biomaterial (Paul et al., 2016). Several studies have been reported to improve the efficacy of gold nanoparticles mediated laser ablation by developing new materials, overcoming their toxicity concerns and improving their intra-tumoral distribution (Feng et al., 2015, Khlebtsov and Dykman, 2011, Mooney et al., 2014, Zhao et al., 2015). Although, the early reported results utilizing different types of nanoparticles in collaboration with the laser ablation are quite promising, further progress needs to be made through the close research collaboration between the clinical experts, physicists, bioengineers and material scientists to improve and translate this research to the clinical practices (Almekkawy et al., 2019, Chen et al., 2019, Schena et al., 2017, Sheng et al., 2017).

More recently, the application of minimally invasive laser ablation therapy has also been explored in treating the variety of neurosurgical conditions, e.g., deep-seated gliomas, brain metastasis, epilepsy, radiation necrosis, pediatric brain tumors as well as other lesional intracranial pathologies (Ashraf et al., 2018, Medvid et al., 2015, Missios et al., 2015, Rahmathulla et al., 2014, Silva et al., 2016, Silva et al., 2017, Shukla et al., 2017, Lagman et 
al., 2017). Importantly, the adoption of laser ablation in neurosurgery is the result of recent advances in the probe design, cooling mechanism and real-time magnetic resonance thermography that have resulted in addressing the earlier technical difficulties related to the inability to precisely monitor and control the extent of thermal damage (Ashraf et al., 2018). Although with the advent of real-time monitoring and thermal damage estimation, laser therapy has gained ground as an appealing treatment option in neurosurgery (Ashraf et al., 2018), there is an immediate need of further investigation by performing the large scale studies and clinical trials for developing standardized protocols and demonstrate their safety and efficacy over the traditional approaches.

The role of neural interfaces in the field of thermal ablation is crucial. The use of minimally invasive monitoring techniques utilizing the biocompatible micro/nano electrodes has also been extensively explored in neurotechnology (Woeppel et al., 2017). Importantly, such non-invasive monitoring techniques using the neural electrodes can significantly assist in enhancing the understanding of nuances of the electrophysiological response of neural tissue during nonpharmacological treatments of neurological disorders. A recent review article reported by (Won et al., 2018) provides the latest advances in the materials, devices and systems for the neural interfaces.

Several mathematical studies have been reported in the past on thermal therapies utilizing the laser (Bhowmik et al., 2014, Bhowmik et al., 2016, Kumar and Srivastava, 2015, Nirgudkar et al., 2017, Truong et al., 2018, Wang et al., 2006a, Wang et al., 2006b, Zhang et al., 2008, Li et al., 2020). Importantly, the source term of bioheat transfer model is modified by either Beer-Lambert's law or diffusion approximation while modelling the laser ablation. Recently, (Wongchadakul et al., 2018) reported a thermo-mechanical model to simulate the laser-induced thermotherapy by incorporating the coupled heat transfer and mechanical deformation model of biological tissue. Also, the effects of laser irradiation time, wavelength, laser intensity, laser beam radius and blood perfusion rate on the treatment outcomes were systematically investigated. (Kessentini and Barchiesi, 2012) reported a numerical study to optimize the absorption efficiency of silica-gold nanoshell, hollow nanosphere and nanorod utilizing the particle swarm optimization algorithm. (Soni et al., 2015a, Soni et al., 2015b) reported several studies to quantify the heat confinement and the effects of tumor blood perfusion variability during nanoparticle-assisted laser therapy. (Paul et al., 2014) reported a parametric study to investigate the thermal effects of large blood vessels on the temperature evolution within the tissue during laser-assisted thermal therapy. Both single vessel and countercurrent vessel transisting tissue were considered and the effects of blood vessels depth, tissue blood perfusion rate and laser specifications on the tissue surface temperature 
were analysed. In another study reported by (Paul et al., 2016), subsurface thermal behaviour of tissue phantom embedded with the large blood vessels subjected to plasmonic photothermal therapy was investigated, considering gold mesoflowers and graphene nanostructures. The study reported that the spatio-temporal temperature distribution was significantly dependent on the presence of the nanoparticles and the position of blood vessel. Importantly, the gold nanostructures resulted in the temperature rise of $9{ }^{\circ} \mathrm{C}$, while graphene nanostructures resulted in the temperature rise of $18{ }^{\circ} \mathrm{C}$, as compared to bare tissue without nanoparticles. It was further reported that the addition of nanostructures can significantly compensate the heat sink effect caused by large blood vessels. (Ren et al., 2017) studied the laser-tissue interaction involved in the process of gold nanoparticle enhanced photothermal therapy. In this study, Monte Carlo and Beer's law methods were used to compute the heat generation of tissue and gold nanoparticles irradiated by the laser. Furthermore, the influence of period heating, gold nanoparticle volume fraction, laser irradiation and tumor aspect ratio on the treatment outcomes were also investigated. (Sahoo et al., 2018) reported a study to quantify the rise in the internal temperature of the tissue subjected to photothermal therapy, with and without the application of gold nanostructures. Both the numerical and experimental findings of this study highlighted the importance of consideration of micro-scale non-Fourier heat transfer model for accurate prediction of the temperature within the bio-tissue mimicking tumor that is incubated with the plasmonic nanostructures. Recently, (Paul and Paul, 2018) reported a computational study to analyse the effect of intratumoral and intravenous loading scheme of the silica-gold nanoshells during laser-assisted thermal therapy. In addition, the heat sink effect caused by the large blood vessel and dual-phase-lag non-Fourier effects were also investigated. More recently, (Wang et al., 2018a) employed a two-energy equation model (i.e. porous media model) to numerically compute the temperature distribution within the biological tissue exposed to gold nanoparticles assisted thermal therapy. In this study, the effects of incident light intensity, gold nanoparticle volume fraction, periodic heating and cooling time, and incident light position on the temperature distributions of the multi-layer structure of human skin were also investigated. With regards to the application of laser therapy in neurosurgery, (Fahrenholtz et al., 2018) recently reported a computational study for predicting and optimizing the maximum extent of ablation during the surgical planning of magnetic resonance-guided laser ablation in brain. (Mitchell et al., 2018) reported a study to model magnetic resonance-guided laser therapy in heterogeneous tissue, considering four different tissue types with independent optical properties, for predicting the treatment outcomes in brain. 
Furthermore, the elevated temperature produced within the biological tissue during thermal ablative procedures can also result in the induction of painful sensation. The sensation of nociceptive pain simulated due to mechanical $(\sim 0.2 \mathrm{MPa})$, chemical and/or thermal $\left(\sim 43{ }^{\circ} \mathrm{C}\right)$ energy is transducted through the nociceptors, the first cells in the series of the neuron that resides at the end of long axons. Basically, nociceptors are one of the three kinds of peripheral nerves: myelinated afferent $\mathrm{A} \delta$ and $\mathrm{A} \alpha$ fibers, and unmyelinated C-fibers. The thermal pain sensation is mainly mediated by the relatively fast myelinated $\mathrm{A} \delta$ fiber, and relatively slow and thin unmyelinated C-fibers (Zhu and $\mathrm{Lu}, 2010)$. There have been a rapid surge in the development of mathematical models and theoretical frameworks for transduction, transmission, perception and modulation of pain at different levels: molecular, cellular and neuron networks (Argüello et al., 2015, Kucyi and Davis, 2015, Moayedi and Davis, 2012, Ortiz-Catalan, 2018, Seth and de Gray, 2016, Tiemann et al., 2018).

(Xu et al., 2010, Xu et al., 2008) developed the mathematical model for quantifying the skin thermal pain sensation during thermal therapies by coupling the thermal model to the neural model of nociceptors. The developed thermo-neural model was used for the prediction of thermal pain intensity induced due to the high temperature attained during thermal therapies and accordingly the treatment was classified to be painful or not. (Dezhdar et al., 2015) proposed a probabilistic model taking into account the associated uncertainties and potential noise in the system for providing the estimates of depth and threshold temperature of C-fiber nociceptors during the transduction of thermal pain in the skin. The proposed model predicted the realistic estimates of both, the threshold and the depth at which transduction happens within the skin for all measured neurons, when compared with the in vitro data, even without detailed knowledge of the bio-thermal properties of the system. Recently, (Lin et al., 2017) proposed a three-state model for simulating the kinetics of temperature-sensitive ion channels for understanding the molecular basis of nociceptor signalling during thermal pain sensation in a heated dental tooth. The mathematical model was developed by coupling the nociceptor transduction with irreversible thermal desensitization of the ion channels. It was found that the proposed model was capable enough to capture the prediction of postoperative pain that is comparable to the essence of experimental in vivo observations. These findings can assist the medical practitioners in designing local anesthesia regimens during the thermal ablative procedures, so that the treatment can be performed with reduced anesthesia.

\section{Modelling of non-invasive thermal ablation utilizing nanoparticles}


Each thermal ablative modalities possess their individual advantages and limitations and have already met with some success based on the initial clinical trials and feasibility studies reported in the past several decades. However, one of the underlying problem associated with most of the available thermal ablative modalities is that they are still minimally invasive (not completely non-invasive). Furthermore, these therapies may also lead to collateral thermal damage to the surrounding healthy tissue and critical structures in close proximity of tumor, specifically for deep-seated tumors (LeBrun and Zhu, 2018). Thus, there is a tremendous need for exploring methods that can provide better control and confine heating only to the tumorous tissue, sparing the surrounding healthy tissue.

The use of nanoparticle technology in oncologic applications has opened many new doors in this field of cancer research. One such growing area of interest is the application of magnetic nanoparticle hyperthermia (developed in the 1950s for treating lymph nodes in recurrent breast cancer) that has emerged as a promising non-invasive heating method, overcoming the associated limitations of traditional hyperthermia methods (Deatsch and Evans, 2014). Importantly, this approach uses biocompatible iron-based magnetic nanoparticles that ranges from 10 to $100 \mathrm{~nm}$ in diameter (i.e. approximately 1000 times smaller than most human cells) for inducing localized heating within the target tumor by the application of an external alternating magnetic field. The iron-based nanoparticles are often mixed with a suspending medium such as water (forming a ferrofluid) for delivery within the target tumorous tissue using either intravenous or intra-tumoral injections (LeBrun and Zhu, 2018). Furthermore, these nanoparticles can be coated depending on the application, for e.g., during intravenous delivery these nanoparticles are often coated with antibodies (i.e. drugs or proteins) that have an affiliation for cancer cells. These nanoparticles are also coated with a surfactant so as to prevent particle agglomeration within the target tissue (LeBrun and Zhu, 2018). The major mechanisms by virtue of which heat is generated during magnetic nanoparticles assisted hyperthermia include Néel relaxation and Brownian motion of the particles. Apart from these, other mechanisms may also contribute to heating such as hysteresis and eddy currents, based on the effective diameter of nanoparticles (Deatsch and Evans, 2014, Dennis and Ivkov, 2013, Kumar and Mohammad, 2011). Furthermore, it has been well documented that the concentration of iron-based nanoparticles typically used during magnetic hyperthermia will not lead to any toxicity within the human body, since after treatment the majority of the injected nanoparticles are cleared by the body within several weeks (LeBrun and Zhu, 2018). Moreover, clinical and animal studies previously reported in literature utilizing magnetic nanoparticles assisted hyperthermia have shown significant temperature rise above the baseline temperature (Attaluri et al., 2011, Evans et al., 2018, 
LeBrun et al., 2016a, Ma et al., 2018, Salloum et al., 2008a, Salloum et al., 2008b). Previous investigations have also demonstrated that the amount of heat generated during magnetic nanoparticles assisted hyperthermia is tremendously dependent on the magnetic field strength and frequency, spatial distribution of the nanoparticles, size and coating, etc. (Attaluri et al., 2011, Evans et al., 2018, LeBrun et al., 2016a, Ma et al., 2018, Salloum et al., 2008a, Salloum et al., 2008b, Deatsch and Evans, 2014, LeBrun and Zhu, 2018). Furthermore, magnetic nanoparticles assisted hyperthermia can also be useful for treating deep-seated tumors even with irregular geometries, since the heating induced due to magnetic field is only confined to the region having nanoparticle, which was difficult to attain during traditional hyperthermia methods.

Despite the great potential and numerous advantages over current cancer treatment options, magnetic nanoparticle assisted hyperthermia is still not a standard treatment protocol for treating cancer. There are a number of associated challenges that need to be thoroughly addressed for this modality to become more clinically acceptable for treating cancer. Importantly, these challenges are associated with: (a) controlling and repeating the nanoparticles deposition patterns to the desired location (as nanoparticle dispersion patterns are often non-uniform and uncontrollable), and (b) accurately predicting the temperature-time history for estimating the appropriate thermal dosage. The uncertainty of nanoparticle deposition patterns can basically result in poor treatment outcomes owing to inadequate temperature elevations within the target tissue and/or overheating of the surrounding healthy tissue, which can further lead to tumor recurrence and/or metastasis post-treatment (LeBrun and Zhu, 2018). Such variations can be easily tackled by developing mathematical models of magnetic nanoparticle assisted hyperthermia. Importantly, the heat transfer during such procedures can be quantified using the Pennes bioheat transfer model given by Eq. 1, whereby the heat source $Q_{p}\left(\mathrm{~W} / \mathrm{m}^{3}\right)$ induced due to magnetic hyperthermia is computed as:

$$
\begin{aligned}
& Q_{p}=\left.\rho_{f} c_{f} \frac{\partial T}{\partial t}\right|_{t=0} \text { or } \rho_{f} \cdot \mathrm{SAR} \\
& \mathrm{SAR}=\mathrm{SLP}=\left.\mathrm{c}_{f} \frac{m_{f}}{m_{N P}} \frac{\partial T}{\partial t}\right|_{t=0},
\end{aligned}
$$

where $\rho_{f}$ is the density of the ferrofluid $\left(\mathrm{kg} / \mathrm{m}^{3}\right), c_{f}$ is the specific heat of the ferrofluid $(\mathrm{J} / \mathrm{kg} / \mathrm{K})$, SAR is the specific absorption rate $(\mathrm{W} / \mathrm{kg})$ that represents the heat generation and $\frac{\partial T}{\partial t}$ represents the initial slope of time-dependent rise in the temperature obtained from experimental studies, SLP is the specific loss of power carrying the same meaning and unit as 
of SAR. For a single-domain nanoparticles exposed to an alternating magnetic field, SLP is computed as (LeBrun and Zhu, 2018):

$$
\begin{aligned}
& \mathrm{SLP}=\frac{\mathrm{SAR}}{\rho_{F e} \phi}=\frac{\pi \mu_{0}^{2} H_{0}^{2} f M_{d}^{2} V_{m}}{\xi k_{B} T \rho_{F e}} \frac{2 \pi f \tau}{1+(2 \pi f \tau)^{2}}\left[\operatorname{coth} \xi-\frac{1}{\xi}\right] \\
& \text { where, } \xi=\frac{\mu_{0} H_{0} M_{d} V_{m}}{k_{B} T}
\end{aligned}
$$

where $\rho_{F e}$ is the density of iron nanoparticles, $\phi$ is the volume fraction, $M_{d}$ is the domain magnetization of the suspended particle $\left(M_{d}=M_{s} / \phi\right.$ where $M_{s}$ is the saturation magnetization of the ferrofluid), $H_{m}$ and $f$ represents the magnitude and frequency of magnetic field applied to the magnetic nanoparticles, respectively, $V_{m}$ is the volume of each particle, $T$ is the absolute temperature of magnetic nanoparticles, $k_{B}$ is the Boltzmann constant and $\tau$ is the relaxation time of magnetic nanoparticles that depends upon the nanoparticle size for given values of anisotropy constant, temperature and viscosity of the magnetic suspensions. Eq. (30) provides a theoretical basis for optimizing the nanoparticles material, size, applied magnetic field strength and frequency for attaining a desirable heat generation rate within a non-interacting and monodispersed particles (Deatsch and Evans, 2014, LeBrun and Zhu, 2018).

Unfortunately due to the uncontrollable nature and the practical difficulties associated with the exact quantification of the nanoparticle deposition distribution within the target tissue during magnetic nanoparticle assisted hyperthermia, the early attempts for predicting the spatio-temporal temperature distributions have shown significant deviation between the numerically simulated and experimentally measured results obtained from animal and clinical trials (LeBrun and Zhu, 2018). The major reason for such deviation could be related to the consideration of simplified tumor geometries that results in different nanoparticle distribution (often difficult to accurately quantify) as compared to actual clinical scenarios and the idealized heat generation rate assumptions of the nanoparticles that are fed into the multiscale model of magnetic nanoparticles assisted hyperthermia. Furthermore, strong evidence about the unpredictability of nanoparticle distributions within tumors has been recently reported based on the microCT imaging-based experimental studies (LeBrun et al., 2016a, LeBrun et al., 2016b). The nanoparticles distribution has been found to be tremendously dependent on the heterogeneous microstructure of different shapes and sizes of tumors that includes, vascular permeability, local blood perfusion, tumor porosity, random nature of nanoparticle interactions and aggregation (LeBrun and Zhu, 2018). Thus, it becomes extremely important to develop more accurate numerical models of magnetic nanoparticles assisted hyperthermia based on the image-generated tumor geometry and nanoparticle 
distribution. Such numerical models would provide more precise a priori estimate of the spatio-temporal temperature distribution, so as to assist the clinical practitioners in optimizing the thermal dosage that will further lead to designing tumor-specific treatment planning of magnetic nanoparticles assisted hyperthermia and its successful clinical translation.

Among the different percutaneous thermal ablative modalities, RFA has already proven to be an effective therapy for the treatment of various soft tissue tumors. However, minimally invasive RFA has a number of limitations including the requirement for painful procedure of invasive needle placement, precise image-guidance, size of tumor and collateral damage to adjacent healthy regions and surrounding tissues. Therefore, tremendous attention has been given to replace invasive needle placements by injecting metallic nanoparticles into the cancerous tumor. This concept was demonstrated by the scientists by utilizing the wellknown 'Kanzius machine', where radiofrequency (RF) current passes through a medium without physical contact between the medium and the transmitter-receiver pair but at higher frequencies $(13.56 \mathrm{MHz})$ as compared to that being used in conventional RFA (450-500 kHz) (Cardinal et al., 2008). Later, few in vitro studies attempted to utilize the non-invasive RFA approach with promising results (Cherukuri and Curley, 2010, Corr et al., 2013, Curley et al., 2014a, Curley et al., 2014b, Gannon et al., 2007, Gannon et al., 2008, Glazer et al., 2010a, Glazer et al., 2010b, Raoof et al., 2012, Raoof et al., 2014, Raoof and Curley, 2011, Rejinold et al., 2016, Rejinold et al., 2015, Rejinold et al., 2014a, Rejinold et al., 2014b). Importantly, during such non-invasive RFA procedures, the RF responsive nanobiomaterials, viz., gold (Au-NPs), iron oxide, cobalt, carbon-based nanomaterials, and QDs (Quantum dots) are directly injected into the tumor (Rejinold et al., 2015). Radiofrequency field is applied over the injection site that dramatically increases absorption of RF energy that is dissipated in the form of heat, thus killing the tumor injected with nanoparticles. An increase in RF generator output power and exposure time can further increase the amount of heat dissipated by the nanoparticles (Cardinal et al., 2008). RF fields readily penetrate through human body with minimal perturbations and side-effects (as compared to Laser and X-rays) until the RF fields interact with nanoparticles that absorb RF energy and quickly release heat to the surrounding region. Due to the size and quantum characteristics, nanoparticles (specifically metal nanoparticles) can absorb even more energy (and release even more heat) (Glazer and Curley, 2011). Hence, these nanotechnology-based localized, targeted cancer modalities have potential advantages such as enhanced efficacy, improved cosmesis, reduced side effects, and improved quality of patient life. The computational modelling approach for modelling such therapies will involve the integration of nanoparticle model with the previously reported thermo-electric models for quantifying the temperature distribution and thermal damage to 
both the tumorous and the surrounding healthy tissue during RFA procedures. Importantly, the effective thermal conductivity and the heat capacity of the target tissue embedded with spherical nanoparticles during nanoparticles assisted RFA can be easily quantified using Eqs. 31 and 32, respectively (Leong et al., 2006, Shao et al., 2017b):

$$
\begin{gathered}
k_{e f f}(T)=k_{t}(T) \cdot \frac{k_{p}+2 k_{t}(T)-2 \eta\left(k_{t}(T)-k_{p}\right)}{k_{p}+2 k_{t}(T)+\eta\left(k_{t}(T)-k_{p}\right)} . \\
c_{e f f}(T) \rho_{\text {eff }}=c_{t}(T) \rho_{t}(1-\eta)+c_{p} \rho_{p} \eta .
\end{gathered}
$$

where $\eta$ is the content of nanoparticle volume and the subscript eff, $p, t$ represents the effective value, loaded particle and biological tissue, respectively.

Moreover, the effective thermal conductivity of biological tissue injected with nonspherical particles nanoparticles (e.g. carbon nanotubes (CNT)) can be quantified from (Glory et al., 2008, Shao et al., 2017b):

$$
k_{\text {eff }}(T)=k_{t}(T) \cdot \frac{k_{t}(T)+(n-1) k_{p}-(n-1) \eta\left(k_{t}(T)-k_{p}\right)}{k_{t}(T)+(n-1) k_{p}+\eta\left(k_{t}(T)-k_{p}\right)} .
$$

where $\eta$ is the content of nanoparticle volume and $n(=3 / \psi)$ is the empirical shape factor, $\psi$ represents the particle sphericity (i.e. the ratio of the surface area of the sphere with its volume equivalent to the non-spherical particle to surface area of particle). For nanotubes $n$ can be computed from: $\left[n=(12 L / d)^{1 / 3}\right.$ ], where $d$ is diameter and $L$ is the length of nanotubes. The effective electrical conductivity of the biological tissue injected with nanoparticles during RFA procedure can be computed from (Ganguly et al., 2009, Shao et al., 2017b):

$$
\sigma_{e f f}(T)=\sigma_{t}(T) \cdot \frac{3 \eta\left(\sigma_{p}(T)-\sigma_{t}(T)\right)}{\left(\sigma_{p}(T)+2 \sigma_{t}(T)\right)-\eta\left(\sigma_{p}(T)-\sigma_{t}(T)\right)} .
$$

where $\eta$ is the content of nanoparticle volume and $\sigma_{\text {eff }}, \sigma_{t}, \sigma_{p}$ are the effective value of electrical conductivities, biological tissue and nanoparticles, respectively.

\section{Modelling of RFA application in treating chronic pain}

The application of RF (radiofrequency) is well pronounced for treating different types of tumors in liver, kidney, lung, prostate, bones and breast. Moreover, RF has also been gaining increasing popularity among the pain management therapists for mitigating various types of chronic pain, namely, low back pain, knee pain, hip pain and migraine, etc. The power delivery during the RF application in pain management is usually done using either continuous or pulsed modes (Chua et al., 2011). In the conventional continuous power delivery mode, RF generator delivers the high-frequency alternating current to the electrode placed close to the target nerve for heating the neural tissue $\left(80-90^{\circ} \mathrm{C}\right)$. This process stops the 
transmission of nociceptive signals from the periphery of nerve by causing protein denaturation and destruction of the axons. In the another approach of pulsed RF utilized in the clinical practices for treating chronic pain, brief 'pulses' of RF signals are applied to the neural tissue from the RF generator that is followed by the silent phases for allowing time for heat dissemination. Figure 5 presents the different components of the pulsed RF procedure utilized for management of chronic neural pain (Chua et al., 2011). Moreover, the pulsed RF can produce far stronger electrical fields (5-10 times more) as compared to the continuous RF (Cosman Jr and Cosman Sr, 2005). Initially, the pulsed RF procedure was thought to be a completely non-destructive in nature, but recent research advances suggests the occurrence of both the thermal and non-thermal effects during such procedures (Chua et al., 2011, Soloman et al., 2010). Although, the exact explanation of the complete mechanisms of action involved in the pulsed RF still remains elusive, some associated effects have been speculated (Calodney et al., 2016, Chang, 2018). What currently known is that, the electric field generated during pulsed RF results in structural changes in the neural cells, along with genetic changes and inhibition of nociceptive firing. Importantly, the pulsed RF procedure is less destructive when compared to the continuous RF, as there have been no previous reports of the associated neurological side effects (Erdine et al., 2009).

A very limited progress has been made in this direction utilizing a computational modelling approach. (Cosman Jr and Cosman Sr, 2005) reported the numerical study to quantify the electric and thermal field distributions in the tissue around the RF electrode utilizing continuous and pulsed RF applications during pain therapy. The results obtained with numerical studies were found to closely reproduce the thermal and electrical features of both continuous and pulsed RF when compared with ex vivo studies on liver and egg-white phantom. In another study by (Cosman Jr et al., 2014), the comparison of the lesion size produced with different configurations of RF electrodes and different generator settings were reported during interventional pain management. The heat lesions produced with monopolar configuration were found to be significantly affected by the cannula diameters, active tip lengths, set temperatures and set times. The study revealed that the average lesion width increases by 58-65\% (3-4 mm) with increase of the cannula diameter from 22 to 16 gauge at preset temperature and time of $80{ }^{\circ} \mathrm{C}$ and 2 minutes, respectively. It was further reported that with increase in preset temperature from $60{ }^{\circ} \mathrm{C}$ to $90{ }^{\circ} \mathrm{C}$, the average lesion width increases by $108-152 \%$ after 2 minutes of RFA procedure. (Pérez et al., 2014) reported a computational study for quantifying the thermal and electrical field distributions during bipolar pulsed RF application for pain relief. This study highlighted the noteworthy differences between the electrical and thermal performance of the bipolar pulsed RF as 
compared to the bipolar continuous RF for pain relief. Importantly, in this study a coupled thermo-electric model was developed to assess the damage caused due to both thermal ablative (induced due to temperature spikes) and possible electroporation effects (induced due to electrical field) during bipolar pulsed RF. The effects of changing electrode dimensions (length and diameter), inter-electrode distance, a relative position between electrodes (offset and angle), treatment time and blood perfusion rate were thoroughly discussed from both the thermal and electrical performance aspects. The results obtained from the computational models were compared with the previous experimental studies reported in literature and a reasonable agreement among them was found. The study reported that shorter the distance between the two electrodes, higher will be the temperature spike amplitude during pulsed RF procedure. The temperature distribution around the electrodes was found to be completely different for short distances (2 and $5 \mathrm{~mm}$ ) whereby the tissue between the electrode become quite heated and leads to considerable thermal ablation as compared to longer distances $(10,15$ and $20 \mathrm{~mm}$ ), where the heating was confined only around the tip of the electrode. Further, it was found that the maximum temperature attained within the tissue increases from $45.6{ }^{\circ} \mathrm{C}$ to $49.1{ }^{\circ} \mathrm{C}$ as the electrode dimensions were reduced from 18 gauge to 22 gauge. It was also reported that the accidental change in electrodes intertip angle and intertip offset has negligible effect on the temperature spike, but can alter the ablation volume between the electrodes. A comparative study was also conducted for analyzing the deviations between the continuous and pulsed RF at the same energy level and it was found that the damage volume is same for both the cases but with lower temperature value for continuous RF. Furthermore, it was found that the inclusion of blood perfusion term in the bioheat transfer model results in $1.5^{\circ} \mathrm{C}$ drop in the maximum temperature during pulsed bipolar RF procedure. It was also reported that the electric field distribution was exclusively dependent on the maximum value of the applied voltage and is not altered by procedure duration. Moreover, the results suggested that the possible irreversible electroporation zone during the pulsed RF procedure was confined only to a very small zone of tissue around the electrode tip. Recently, (Ewertowska et al., 2018a) reported a computer modelling study of the RF application in pain relief to quantify the effect of applied voltage, duration and repetition frequency of RF pulses on the temperature spikes and electrical field distributions. Importantly, a computational model was developed to compare the thermal and electrical performance of the standard clinical protocol typically used during the pulsed RF procedures (i.e., $45 \mathrm{~V}$ pulses, $20 \mathrm{~ms}$ duration and $2 \mathrm{~Hz}$ repetition frequency) with a new protocol having higher applied electric field ( $55 \mathrm{~V}$ instead of $45 \mathrm{~V})$, shorter pulses $(5 \mathrm{~ms}$ instead of $20 \mathrm{~ms}$ ) and higher pulse frequency repetition $(5 \mathrm{~Hz}$ instead of $2 \mathrm{~Hz}$ ). The study 
reported that the new protocol of the pulsed RF increased the electric field magnitude by $20 \%$, without increasing the temperature and thus can be more effective in providing chronic pain relief. Furthermore, the effect of incorporation of the temperature controller was also studied and it was found that the temperature controller can play vital role in minimizing the thermal damage to the tissue by keeping the electric field magnitude at same level by reducing the total number of delivered pulses by around $67 \%$. The developed model was further validated utilizing an in vitro agar-based experimental model and was found to match moderately well with the experimental findings. More recently, (Singh and Melnik, 2019a, Singh and Melnik, 2019d, Singh and Melnik, 2019c) reported the first preliminary results highlighting the importance of consideration of heterogeneous surroundings in the computational domain during continuous and pulsed RF application for mitigating chronic pain. A comparative analysis was conducted to highlight the deviations in the treatment outcome of the continuous RF considering a three-dimensional computational domain. Importantly, computational simulations were performed for three cases, viz., (a) completely homogenous domain comprising of only muscle tissue (similar to most of the studies reported in literature), (b) computational domain comprising of muscle and target nerve, and (c) completely heterogeneous domain comprising of muscle, nerve and bone tissues to model more realistic scenario. The results reported in the study highlighted $30.64 \%$ decline in the ablation volume for completely heterogeneous domain comprising of muscle, target nerve and bone tissue as compared to homogeneous domain comprising of muscle alone. Further, the results revealed a strong dependence of the ablation volume on the target nerve location from the bone and it was found that the ablation volume decreases for the target nerve located closer to bone and vice versa.

\section{Multiscale modelling of neurological disorders and machine learning algorithms}

A wide interest has been growing in the scientific community for developing computational models of thermal ablation for treating different types of neurological disorders. Such computational models of the brain and the nervous system not only assist in explaining the data or bio-physical behaviour that already exist but also helps in predicting the behaviour of a system under new conditions and generating new hypothesis (Gerardo-Giorda and Kroos, 2017, Holt and Netoff, 2013, Jirsa et al., 2017, Miga, 2016). Importantly, the associated complexity of linkages that produces pathophysiology in neurology requires a multiscale modelling for combining the molecular and cellular-level processes occurring at the neuron level (microscopic scale) to the whole brain tissue (macroscopic scale). For e.g., epilepsy is a multiscale disease that involves changes at multiple spatial and temporal scales, i.e., changes 
in cellular level (microscale) can bring about seizures that actually occurs at a macroscopic scale and is actually identified by a patient's behaviour and recorded with electroencephalography (EEG) (Holt and Netoff, 2013, Lytton et al., 2017). Thus, a multiscale approach in computational modelling is often required to bridge the gap between different scales, like, cellular, network, cortical region and brain scales, such as in the case of modelling epilepsy. More recently, a review article has been reported highlighting the perspective, challenges and opportunities of integration of machine learning and multiscale modelling in biomedical, biomedical and behavioural sciences (Alber et al., 2019). Although, simulation and analysis methods utilizing multiscale models have recently made a major leap forward, determining the relevant scales for a particular problem and their efficient coupling still remains challenging (Widmer and Stelling, 2018).

The application of machine learning algorithms and models have also been explored in the thermal ablative procedures, either for the accurate and precise placement of the electrode or for the real-time monitoring of ablation volume (Besler et al., 2019a, Li et al., 2019, Lötsch and Ultsch, 2018, Wang et al., 2018b, Yildiz and Özdemir, 2019, Zhang et al., 2019a, Besler et al., 2019b, Hajimolahoseini et al., 2018, Negro et al., 2019, Zhang and Chauhan, 2019). (Wang et al., 2018b) reported the application of an artificial neural network (ANN) for real-time estimation of the lesion depth and control of RFA within ex vivo animal tissue. Recently, (Besler et al., 2019a), reported a machine learning approach for prediction of the lesion depth during RFA utilizing a Random Forest and Adaptive Boosting model to reduce the monitoring time as compared to conventional methods. (Li et al., 2019) reported a study that incorporates the machine learning techniques with computer-assisted planning for optimizing the electrode trajectory during laser therapy of neurological disorder. Figure 7 presents the complete flowchart generally adopted in the clinical practices utilizing machine learning algorithms for optimizing the electrode trajectory during laser-assisted thermal therapy of brain disorder (Li et al., 2019). More recently, (Yildiz and Özdemir, 2019) reported an ANN modelling of the laser-induced thermal damage on ex vivo liver. Importantly, in this study feedforward ANN models with different learning algorithms were developed and compared for finding the optimum structure for prediction of the thermal damage degree as a function of laser parameters, viz., treatment time, power, laser spot size, penetration depth and wavelength. (Lötsch and Ultsch, 2018) reported a review highlighting the recent applications and the associated challenges of machine learning in pain research. Thus, the application of machine learning could play a vital role in optimizing the needle trajectory and thermal dosage to be delivered in the target tissue, so as to ensure safe and reliable treatment outcomes. However, the development of effective and efficient machine 
learning algorithms are based on the availability of quality data from clinical studies which at least at this stage is quite scarce for the research pertaining to thermal ablation. More recently, the application of machine learning-based reversed modelling approach has been presented in (Surleraux et al., 2020) for rapid tool shape optimization during thermal ablation process. Although this study was related to the application of thermal ablation in the field of manufacturing science, such approaches can be readily integrated in the field of biomedical engineering, especially thermal therapies.

\section{Current challenges and future perspectives in modelling of RFA and MWA}

Thermal ablative therapies have demonstrated rapid progress over the past decade in providing a viable and safe alternative to surgery. Among different hyperthermic ablative modalities that utilize electromagnetic heating, RFA is a well-established and extensively studied modality for treating: (a) different types of cancer (e.g., liver, kidney, bone, lung, breast, prostate and adrenal), (b) cardiac arrhythmia and some types of atrial fibrillation, and (c) chronic nerve pain by providing rapid pain relief. While, MWA and nanoparticles mediated laser therapy being rapidly progressing modalities mainly focused on treating tumors. Additionally, the application of laser therapy has also been explored in neurosurgery for treating different types of pathological disorders in brain. Computational modelling has become an important tool that not only assists in providing a priori estimates of the treatment outcomes with better visualizations but can also be used for educational purposes, e.g., providing training and online support to the physicians.

Among others, numerous computational studies have been published in the last decades on mathematical modelling of RFA for treating tumors. The models available in literature are either one-compartment models or two-compartment models, utilizing different protocols of RF energy delivery, viz., continuous (Barauskas et al., 2008, Zorbas and Samaras, 2013, Singh et al., 2016, Singh and Repaka, 2015), temperature-controlled (Shao et al., 2017a, Singh, 2018, Singh and Repaka, 2017a, Singh and Repaka, 2018a, Singh and Repaka, 2018c, Singh and Repaka, 2018b, Zhang et al., 2017, Singh and Repaka, 2016) and impedance-controlled (Cheong et al., 2019, Trujillo et al., 2017, Trujillo et al., 2016). Further, modifications in the electrode design have also been reported in the quest for attaining an increase in the coagulation volume during RFA procedures. Such modifications include the use of multi-tine electrodes, bipolar electrodes and saline-infused cooled electrodes. However, most of the available computational studies of RFA for treating tumor are mainly limited to the treatment of early-stage of tumor only (e.g., for liver it is less than 3 $\mathrm{cm}$ in diameter). The need to address the issues related to incorporation and evaluation of the 
impact of inhomogeneity on the treatment outcomes among different biological tissues is still prevalent in this direction. These typical shortcomings can be effectively tackled by incorporating the image-based realistic geometries along with consideration of the temperature-dependent electrical and thermal properties during modelling of RFA for treating tumor in different tissues and sites. Further, to guarantee a more accurate prediction of the treatment outcomes during RFA procedure, the incorporation of convective cooling between the heated tissue and the nearby large blood vessels become quite essential, apart from incorporating the porous media model for modelling the heat transport at microscale. Another future direction in the computational modelling of RFA would be the development and realization of models for the fast prediction of treatment outcomes as compared to the frequently used finite element models that require long computation times limiting their usage in clinical practices (see, e.g., (Audigier et al., 2017, Chen et al., 2018, Voglreiter et al., 2018)). Moreover, the combination of RFA with conventional treatment, viz., chemotherapy and radiotherapy for attaining higher ablation volume have also been explored (Rao and Deng, 2010, Zhang et al., 2016). The development of mathematical models can be explored in this research direction as well to understand the underlying physics and conducting parametric studies for quantifying the effects of various critical parameters on treatment outcomes.

Further, most of the computational studies on the application of RF in treating chronic pain reported till date have been conducted on homogeneous tissues (Ewertowska et al., 2018a, Pérez et al., 2014, Singh and Melnik, 2019a). It often means that although the goal during such procedures was to attain nerve ablation, the nerve itself was not part of the computational domain. Although, the reported computational studies of pain management utilizing RF currents have resulted in addressing different concerns and in progressing the field by providing a quantitative prediction of electrical and thermal fields along with the damage volume, some of them could have resulted in introducing severe inaccuracies in the simulated model. To address these concerns, computational models with heterogeneous surroundings need to be developed, incorporating the muscle, nerve and bones along with other critical structures, to provide more qualitative prediction of the treatment outcomes during RF application in treating chronic pain. Recently, a preliminary study, highlighting the deviations in the treatment outcomes during the continuous RF procedure has been reported in (Singh and Melnik, 2019d), when the target nerve was considered in the computational domain of chronic pain models. Further refinements in the chronic pain management models can be attained by using multiscale modelling approaches, whereby the damage caused due to high-alternating electric current can be quantified at a cellular level. This can be 
accomplished by integrating the Hodgkin-Huxley neural model with the thermo-electromechanical model of RFA. The incorporation of such models in the computational analysis will assist in providing a better understanding of the molecular changes affecting the neuronal behaviour during the development of corresponding treatment therapies. More realistic models can be made by integrating the actual physiological geometries of the neuron along with modelling the biophysical phenomena at the membrane layer (e.g., modelling changes in sodium, potassium, calcium and magnesium concentrations (Kosik-Bogacka et al., 2018, Kroos et al., 2017, Li et al., 2016, Mercadal et al., 2018, Srebro et al., 2017)). A more accurate future modelling strategy would be incorporating other multiphysics effects, such as piezoelectric (e.g., (Mahapatra and Melnik, 2006, Melnik and Melnik, 1998, Melnik, 2000, Mosgaard et al., 2015, Lee et al., 2017)). Note that the well-posedness of mathematical models of coupled piezoelectricity, along with rigorous energy bounds, were derived in a series of earlier papers (Melnik, 2000). This was done for the first time in a general dynamic setting. Recently, one such study (although with a different application) has been reported by (Cinelli et al., 2017) that proposed an electro-thermal equivalent three-dimensional model of a single neuron whereby the nerve membrane was modelled as a piezoelectric material.

There has been a tremendous focus on improving the computational models of MWA. These improvements include: temperature-dependent dielectric and thermal properties, incorporation of water vaporization and tissue contraction model, etc. Such improvements have significantly benefited the design, optimization and characterization of new microwave antenna applicators, apart from providing the optimal microwave power to be radiated from antenna for attaining complete destruction of tumor with minimum damage to the surrounding healthy tissue and critical structures. But, again most of these reported computational studies of MWA have been performed on the homogenous tissue (Cavagnaro et al., 2015a, Cavagnaro et al., 2015b, Keangin and Rattanadecho, 2013, Liu and Brace, 2017, Rattanadecho and Keangin, 2013, Sebek et al., 2016, Singh et al., 2019, Xu et al., 2019), with very limited studies reported considering both the tumorous and healthy tissue (Chaichanyut and Tungjitkusolmun, 2016, Keangin and Rattanadecho, 2018). The consideration of the tumor in the tissue could significantly influence the treatment outcomes of the MWA procedure. Thus, there seems to be a great need of developing the computational models of MWA utilizing the image-based patient-specific models among different tissues to bridge the gap between the results predicted from computational models and the clinically obtained results. 
Although, RFA (and recently MWA) applications in clinical practices is more widespread compared to laser ablation for treating a tumor in soft tissues, recently there has been a surge in the application of laser therapy for treating different types of neurological disorders, e.g., brain tumors, epilepsy. Importantly, the application of magnetic resonance (MR)-guided laser therapy in treating brain disorders results in higher efficacy, improved real-time intraoperative monitoring of the ablation zone, low risk of complications, shorter hospitalization time and no damage of the tissue beyond the ablation zone as compared to the conventional treatments (Mitchell et al., 2018). The computational modelling utilizing multiscale approaches in laser therapy for treating neurological disorders can significantly assist in better treatment planning by providing a priori information about the optimal trajectory of the needle placement along with the optimal radiation dosage to minimize the damage to the critical structures of brain. Incorporation of Artificial Intelligence (AI) and machine learning algorithms can further assist in bridging the different scales of the multiscale model of brain during MR-guided laser therapy.

Furthermore, the accuracy of the computational models of thermal ablation is significantly dependent on the tissue's biophysical parameters and thus accurate characterization of such parameters. However, accurate characterization of these biophysical properties is an extremely challenging task due to the associated variability among patients, tissue/disease state and non-linear changes associated with the elevated temperature during thermal ablative procedures (Lopresto et al., 2014, Lopresto et al., 2017a, Zhang et al., 2016). Henceforth, there is a strong need in developing characterization techniques for estimating these biophysical properties that can be readily integrated with the therapeutic procedure workflow. The computational models should also focus on addressing and reporting the associated uncertainty in the treatment outcomes by virtue of these varying biophysical properties, so as to provide more concrete evidence for integrating the computational models of thermal ablation into the clinical practices.

Further, it is extremely important to experimentally validate the developed computational models to evaluate their accuracy and efficacy. The validation studies of thermal ablation available in the previous studies have been generally conducted performing the ex vivo procedures on the excised biological tissue. In most of such studies, the ablation zone dimensions obtained by the macroscopic visual inspection post-procedure are compared with the numerically predicted dimensions of the ablation zone for quantifying the aptness of the developed model. Studies have also been reported incorporating the histological analysis, viz., microscopic examination, enzyme histochemistry and transmission electron microscopy, 
for providing a more accurate comparison between computationally predicted and experimental obtained ablation zone, apart from providing distinct zones of ablation (Amabile et al., 2017, Chiang et al., 2013, Zhang et al., 2016). Alternative to the experimental validation based on ablation zone quantification, studies have also been reported on the comparison between the spatio-temporal temperature distribution utilizing an array of thermocouples, thermistors or fibre-optic based sensors around the applicator. Importantly, there has been tremendous research focus on developing thermometric (both invasive and non-invasive) techniques for real-time visualization/monitoring of the tissue temperature and ablation volume during thermal ablative procedures (Eyerly et al., 2015, Almekkawy et al., 2019, Gao et al., 2019b, Gao et al., 2019c, Quirk and Lu, 2019). However, special care should be taken to address the mechanical deformation induced by the elevated temperatures during the thermal ablative procedures. This can be done by either recalibrating the evaluation points of temperature measurements or incorporating the mechanical deformation model for providing an accurate comparison between the temperature distributions obtained from computational and experimental studies (Liu and Brace, 2017). The assessment of the minimally invasive 3D dosimetry during hyperthermic ablation based on patient-specific temperature simulations and sensory feedback has been presented in (Verhaart et al., 2015), highlighting the importance of both the patient-specific tissue properties and models for enhancing the accuracy of temperature prediction. Recently, a new parameter feedback method based on sensitivity analysis and single-thermometry measurements has been reported in (Gao et al., 2019a) for improving the accuracy of temperature predictions for MWA simulations.

One of the severe limitations of utilizing the ex vivo experimental validation study is the absence of the blood perfusion rate that can significantly influence the predicted ablation zone or temperature distribution. The next step could be conducting the in vivo experimental studies for accounting the effect of blood perfusion rate on the ablation zone or the temperature distribution and consequently addressing the discrepancies between the numerical and experimental findings. The conjugation of the imaging techniques such as CT scan or MRI in the experimental validation studies would definitely result in establishing broader applicability of the computational models and raising the faith among clinicians about the predicted treatment outcomes. This would result in clinical translation of the developed models to patient-specific planning by assisting the physicians in decision-making process such as the need of repositioning the applicator or terminating the ablative procedure at critical point to avoid any procedural complications. Thus, the AI and machine learning 
algorithms can play a significant role during such decision-making processes and treatment planning stage of the thermal ablative procedures.

\section{Conclusions}

The purpose of this paper is to provide a current state-of-the-art review in the computational modelling of the most widely applied thermal ablative techniques in clinical practices, in particular, RFA and MWA, with a touch upon on different avenues of laser ablation, noninvasive nanoparticle assisted hyperthermic ablation and RF application for treating chronic pain. The different complexities associated with the modelling of these hyperthermic ablative techniques have also been highlighted. We emphasize multiscale, multiphysics nature of the models and related challenges. Finally, future promising research directions on improving the existing computational models of RFA and MWA have been provided. The authors believe that the continuous expansion of the interdisciplinary research in the area of thermal ablation that includes medical, engineering, computational, mathematical and biological sciences is very timely for the success of clinical translation and further adaptation of the thermal ablative modalities in actual clinical practices worldwide.

\section{Acknowledgements}

Authors are grateful to the NSERC and the CRC Program for their support. RM is also acknowledging support of the BERC 2018-2021 program and Spanish Ministry of Science, Innovation and Universities through the Agencia Estatal de Investigacion (AEI) BCAM Severo Ochoa excellence accreditation SEV-2017-0718, and the Basque Government fund Artificial Intelligence in BCAM EXP. 2019/00432.

\section{References}

National Cancer Institute, "Lasers in Cancer Treatment", https://www.cancer.gov/aboutcancer/treatment/types/surgery/lasers-fact-sheet (Accessed 11 June 2019) [Online].

ABRAHAM, J. \& SPARROW, E. 2007. A thermal-ablation bioheat model including liquid-to-vapor phase change, pressure-and necrosis-dependent perfusion, and moisture-dependent properties. International Journal of Heat and Mass Transfer, 50, 2537-2544.

AHMED, M., BRACE, C. L., LEE JR, F. T. \& GOLDBERG, S. N. 2011. Principles of and advances in percutaneous ablation. Radiology, 258, 351-369.

AHMED, M., LIU, Z., HUMPHRIES, S. \& NAHUM GOLDBERG, S. 2008. Computer modeling of the combined effects of perfusion, electrical conductivity, and thermal conductivity on tissue heating patterns in radiofrequency tumor ablation. International Journal of Hyperthermia, 24, 577-588.

ALBER, M., TEPOLE, A. B., CANNON, W. R., DE, S., DURA-BERNAL, S., GARIKIPATI, K., KARNIADAKIS, G., LYTTON, W. W., PERDIKARIS, P. \& PETZOLD, L. 2019. Integrating machine learning and multiscale modeling-perspectives, challenges, and opportunities in the biological, biomedical, and behavioral sciences. npj Digital Medicine, 2, 1-11. 
ALMEKKAWY, M., CHEN, J., ELLIS, M., HAEMMERICH, D., HOLMES, D., LINTE, C., PANESCU, D., PEARCE, J., PRAKASH, P. \& ZDERIC, V. 2019. Therapeutic Systems and Technologies: State-ofthe-Art, Applications, Opportunities and Challenges. IEEE Reviews in Biomedical Engineering.

ALTROGGE, I., PREUSSER, T., KRÖGER, T., BÜSKENS, C., PEREIRA, P. L., SCHMIDT, D. \& PEITGEN, H.-O. 2007. Multiscale optimization of the probe placement for radiofrequency ablation. Academic radiology, 14, 1310-1324.

AMABILE, C., FARINA, L., LOPRESTO, V., PINTO, R., CASSARINO, S., TOSORATTI, N., GOLDBERG, S. N. \& CAVAGNARO, M. 2017. Tissue shrinkage in microwave ablation of liver: an ex vivo predictive model. International Journal of Hyperthermia, 33, 101-109.

ANDREOZZI, A., BRUNESE, L., IASIELLO, M., TUCCI, C. \& VANOLI, G. P. 2019. Modeling Heat Transfer in Tumors: A Review of Thermal Therapies. Annals of biomedical engineering, 47, 676-693.

ARGÜELLO, E. J., SILVA, R. J., HUERTA, M. K. \& AVILA, R. S. 2015. Computational modeling of peripheral pain: a commentary. Biomedical engineering online, 14, 56.

ASHRAF, O., PATEL, N. V., HANFT, S. \& DANISH, S. F. 2018. Laser-induced thermal therapy in neurooncology: a review. World neurosurgery, 112, 166-177.

ASKARIZADEH, H. \& AHMADIKIA, H. 2014. Analytical analysis of the dual-phase-lag model of bioheat transfer equation during transient heating of skin tissue. Heat and Mass Transfer, 50, 16731684.

ATTALURI, A., MA, R., QIU, Y., LI, W. \& ZHU, L. 2011. Nanoparticle distribution and temperature elevations in prostatic tumours in mice during magnetic nanoparticle hyperthermia. International Journal of Hyperthermia, 27, 491-502.

AUDIGIER, C., MANSI, T., DELINGETTE, H., RAPAKA, S., MIHALEF, V., CARNEGIE, D., BOCTOR, E., CHOTI, M., KAMEN, A. \& AYACHE, N. 2015. Efficient lattice boltzmann solver for patientspecific radiofrequency ablation of hepatic tumors. IEEE Transactions on Medical Imaging, 34, 1576-1589.

AUDIGIER, C., MANSI, T., DELINGETTE, H., RAPAKA, S., MIHALEF, V., SHARMA, P., CARNEGIE, D., BOCTOR, E., CHOTI, M. \& KAMEN, A. Lattice Boltzmann method for fast patient-specific simulation of liver tumor ablation from CT images. International Conference on Medical Image Computing and Computer-Assisted Intervention, 2013. Springer, 323-330.

AUDIGIER, C., MANSI, T., DELINGETTE, H., RAPAKA, S., PASSERINI, T., MIHALEF, V., JOLLY, M.-P., POP, R., DIANA, M. \& SOLER, L. 2017. Comprehensive preclinical evaluation of a multi-physics model of liver tumor radiofrequency ablation. International journal of computer assisted radiology and surgery, 12, 1543-1559.

BARAUSKAS, R., GULBINAS, A., VANAGAS, T. \& BARAUSKAS, G. 2008. Finite element modeling of cooled-tip probe radiofrequency ablation processes in liver tissue. Computers in biology and medicine, 38, 694-708.

BERJANO, E. J. 2006. Theoretical modeling for radiofrequency ablation: state-of-the-art and challenges for the future. Biomedical engineering online, 5, 24.

BESLER, E., CURTIS WANG, Y., C. CHAN, T. \& V. SAHAKIAN, A. 2019a. Real-time monitoring radiofrequency ablation using tree-based ensemble learning models. International Journal of Hyperthermia, 36, 428-437.

BESLER, E., WANG, Y. C. \& SAHAKIAN, A. V. 2019b. Early and Late Fusion Machine Learning on MultiFrequency Electrical Impedance Data to Improve Radiofrequency Ablation Monitoring. IEEE journal of biomedical and health informatics.

BHOWMIK, A., REPAKA, R., MISHRA, S. C. \& MITRA, K. 2014. Analysis of radiative signals from normal and malignant human skins subjected to a short-pulse laser. International Journal of Heat and Mass Transfer, 68, 278-294.

BHOWMIK, A., REPAKA, R., MISHRA, S. C. \& MITRA, K. 2016. Thermal assessment of ablation limit of subsurface tumor during focused ultrasound and laser heating. Journal of Thermal Science and Engineering Applications, 8, 011012.

BHOWMIK, A., SINGH, R., REPAKA, R. \& MISHRA, S. C. 2013. Conventional and newly developed bioheat transport models in vascularized tissues: A review. Journal of Thermal Biology, 38, 107-125.

BRACE, C. 2011. Thermal tumor ablation in clinical use. IEEE pulse, 2, 28-38. 
BRACE, C. L., DIAZ, T. A., HINSHAW, J. L. \& LEE JR, F. T. 2010. Tissue contraction caused by radiofrequency and microwave ablation: a laboratory study in liver and lung. Journal of Vascular and Interventional Radiology, 21, 1280-1286.

CALODNEY, A., ROSENTHAL, R., GORDON, A. \& WRIGHT, R. E. 2016. Targeted radiofrequency techniques. Techniques of neurolysis. Springer.

CARDINAL, J., KLUNE, J. R., CHORY, E., JEYABALAN, G., KANZIUS, J. S., NALESNIK, M. \& GELLER, D. A. 2008. Noninvasive radiofrequency ablation of cancer targeted by gold nanoparticles. Surgery, 144, 125-132.

CATTANEO, C. 1958. A form of heat-conduction equations which eliminates the paradox of instantaneous propagation. Comptes Rendus, 247, 431.

CAVAGNARO, M., AMABILE, C., CASSARINO, S., TOSORATTI, N., PINTO, R. \& LOPRESTO, V. 2015a. Influence of the target tissue size on the shape of ex vivo microwave ablation zones. International Journal of Hyperthermia, 31, 48-57.

CAVAGNARO, M., PINTO, R. \& LOPRESTO, V. 2015b. Numerical models to evaluate the temperature increase induced by ex vivo microwave thermal ablation. Physics in Medicine \& Biology, 60, 3287.

CHAICHANYUT, M. \& TUNGJITKUSOLMUN, S. 2016. Microwave ablation using four-tine antenna: effects of blood flow velocity, vessel location, and total displacement on porous hepatic cancer tissue. Computational and mathematical methods in medicine, 2016.

CHANG, M. C. 2018. Efficacy of pulsed radiofrequency stimulation in patients with peripheral neuropathic pain: a narrative review. Pain physician, 21, E225-E234.

CHEN, J., NING, C., ZHOU, Z., YU, P., ZHU, Y., TAN, G. \& MAO, C. 2019. Nanomaterials as photothermal therapeutic agents. Progress in materials science, 99, 1-26.

CHEN, R., LU, F., WU, F., XIE, L. \& KONG, D. 2018. An analytical solution for temperature distributions in hepatic radiofrequency ablation incorporating the heat-sink effect of large vessels. Physics in Medicine \& Biology, 63, 235026.

CHEONG, J. K., YAP, S., OOI, E. T. \& OOI, E. H. 2019. A computational model to investigate the influence of electrode lengths on the single probe bipolar radiofrequency ablation of the liver. Computer methods and programs in biomedicine, 176, 17-32.

CHERUKURI, P. \& CURLEY, S. A. 2010. Use of nanoparticles for targeted, noninvasive thermal destruction of malignant cells. Cancer nanotechnology. Springer.

CHIANG, J., WANG, P. \& BRACE, C. L. 2013. Computational modelling of microwave tumour ablations. International Journal of Hyperthermia, 29, 308-317.

CHRIST, A., KAINZ, W., HAHN, E. G., HONEGGER, K., ZEFFERER, M., NEUFELD, E., RASCHER, W., JANKA, R., BAUTZ, W. \& CHEN, J. 2009. The Virtual Family-development of surface-based anatomical models of two adults and two children for dosimetric simulations. Physics in Medicine \& Biology, 55, N23.

CHU, K. F. \& DUPUY, D. E. 2014. Thermal ablation of tumours: biological mechanisms and advances in therapy. Nature Reviews Cancer, 14, 199.

CHUA, N. H., VISSERS, K. C. \& SLUIJTER, M. E. 2011. Pulsed radiofrequency treatment in interventional pain management: mechanisms and potential indications-a review. Acta neurochirurgica, 153, 763-771.

CINELLI, I., DESTRADE, M., DUFFY, M. \& MCHUGH, P. 2017. Electrothermal equivalent threedimensional finite-element model of a single neuron. IEEE Transactions on Biomedical Engineering, 65, 1373-1381.

CORR, S. J., CISNEROS, B. T., GREEN, L., RAOOF, M. \& CURLEY, S. A. 2013. Protocols for assessing radiofrequency interactions with gold nanoparticles and biological systems for non-invasive hyperthermia cancer therapy. JoVE (Journal of Visualized Experiments), e50480.

COSMAN JR, E. R. \& COSMAN SR, E. R. 2005. Electric and thermal field effects in tissue around radiofrequency electrodes. Pain Medicine, 6, 405-424.

COSMAN JR, E. R., DOLENSKY, J. R. \& HOFFMAN, R. A. 2014. Factors that affect radiofrequency heat lesion size. Pain Medicine, 15, 2020-2036. 
CURLEY, S., PALALON, F., SANDERS, K. \& KOSHKINA, N. 2014a. The effects of non-invasive radiofrequency treatment and hyperthermia on malignant and nonmalignant cells. International journal of environmental research and public health, 11, 9142-9153.

CURLEY, S. A., PALALON, F., LU, X. \& KOSHKINA, N. V. 2014b. Noninvasive radiofrequency treatment effect on mitochondria in pancreatic cancer cells. Cancer, 120, 3418-3425.

DEATSCH, A. E. \& EVANS, B. A. 2014. Heating efficiency in magnetic nanoparticle hyperthermia. Journal of Magnetism and Magnetic Materials, 354, 163-172.

DENNIS, C. L. \& IVKOV, R. 2013. Physics of heat generation using magnetic nanoparticles for hyperthermia. International Journal of Hyperthermia, 29, 715-729.

DEZHDAR, T., MOSHOURAB, R. A., FRÜND, I., LEWIN, G. R. \& SCHMUKER, M. 2015. A probabilistic model for estimating the depth and threshold temperature of C-fiber nociceptors. Scientific reports, 5, 17670.

ERDINE, S., BILIR, A., COSMAN, E. R. \& COSMAN JR, E. R. 2009. Ultrastructural changes in axons following exposure to pulsed radiofrequency fields. Pain Practice, 9, 407-417.

EVANS, B. A., BAUSCH, M. D., SIENERTH, K. D. \& DAVERN, M. J. 2018. Non-monotonicity in the influence of nanoparticle concentration on SAR in magnetic nanoparticle hyperthermia. Journal of Magnetism and Magnetic Materials, 465, 559-565.

EWERTOWSKA, E., MERCADAL, B., MUÑOZ, V., IVORRA, A., TRUJILLO, M. \& BERJANO, E. 2018a. Effect of applied voltage, duration and repetition frequency of RF pulses for pain relief on temperature spikes and electrical field: a computer modelling study. International Journal of Hyperthermia, 34, 112-121.

EWERTOWSKA, E., QUESADA, R., RADOSEVIC, A., ANDALUZ, A., MOLL, X., ARNAS, F. G., BERJANO, E., BURDÍO, F. \& TRUJILLO, M. 2018b. A clinically oriented computer model for radiofrequency ablation of hepatic tissue with internally cooled wet electrode. International Journal of Hyperthermia, 35, 194-204.

EYERLY, S. A., VEJDANI-JAHROMI, M., DUMONT, D. M., TRAHEY, G. E. \& WOLF, P. D. 2015. The evolution of tissue stiffness at radiofrequency ablation sites during lesion formation and in the peri-ablation period. Journal of cardiovascular electrophysiology, 26, 1009-1018.

FAHRENHOLTZ, S. J., MADANKAN, R., DANISH, S., HAZLE, J. D., STAFFORD, R. J. \& FUENTES, D. 2018. Theoretical model for laser ablation outcome predictions in brain: calibration and validation on clinical MR thermometry images. International Journal of Hyperthermia, 34, 101-111.

FANG, Z., ZHANG, B. \& ZHANG, W. 2017. Current Solutions for the Heat-Sink Effect of Blood Vessels with Radiofrequency Ablation: A Review and Future Work. Advanced Computational Methods in Life System Modeling and Simulation. Springer.

FARINA, L., NISSENBAUM, Y., CAVAGNARO, M. \& GOLDBERG, S. N. 2018. Tissue shrinkage in microwave thermal ablation: comparison of three commercial devices. International Journal of Hyperthermia, 34, 382-391.

FARINA, L., WEISS, N., NISSENBAUM, Y., CAVAGNARO, M., LOPRESTO, V., PINTO, R., TOSORATTI, N., AMABILE, C., CASSARINO, S. \& GOLDBERG, S. N. 2014. Characterisation of tissue shrinkage during microwave thermal ablation. International Journal of Hyperthermia, 30, 419-428.

FENG, W., NIE, W., CHENG, Y., ZHOU, X., CHEN, L., QIU, K., CHEN, Z., ZHU, M. \& HE, C. 2015. In vitro and in vivo toxicity studies of copper sulfide nanoplates for potential photothermal applications. Nanomedicine: Nanotechnology, Biology and Medicine, 11, 901-912.

GANGULY, S., SIKDAR, S. \& BASU, S. 2009. Experimental investigation of the effective electrical conductivity of aluminum oxide nanofluids. Powder Technology, 196, 326-330.

GANNON, C. J., CHERUKURI, P., YAKOBSON, B. I., COGNET, L., KANZIUS, J. S., KITTRELL, C., WEISMAN, R. B., PASQUALI, M., SCHMIDT, H. K. \& SMALLEY, R. E. 2007. Carbon nanotube-enhanced thermal destruction of cancer cells in a noninvasive radiofrequency field. Cancer: Interdisciplinary International Journal of the American Cancer Society, 110, 2654-2665.

GANNON, C. J., PATRA, C. R., BHATTACHARYA, R., MUKHERJEE, P. \& CURLEY, S. A. 2008. Intracellular gold nanoparticles enhance non-invasive radiofrequency thermal destruction of human gastrointestinal cancer cells. Journal of nanobiotechnology, 6, 2. 
GAO, H., WANG, X., WU, S., ZHOU, Z. \& BAI, Y. 2019a. 2450-MHz microwave ablation temperature simulation using temperature-dependence feedback of characteristic parameters. International Journal of RF and Microwave Computer-Aided Engineering, 29, e21488.

GAO, H., WANG, X., WU, S., ZHOU, Z., BAI, Y. \& Al, H. 2019b. Characterization of 2450-MHz microwave thermal coagulation zone based on characteristic length growth model and shape variation factor. International Journal of RF and Microwave Computer-Aided Engineering, 29, e21705.

GAO, H., WANG, X., WU, S., ZHOU, Z., BAI, Y. \& WU, W. 2019c. Conformal coverage of liver tumors by the thermal coagulation zone in $2450-\mathrm{MHz}$ microwave ablation. International Journal of Hyperthermia, 36, 591-605.

GERARDO-GIORDA, L. \& KROOS, J. M. 2017. A computational multiscale model of cortical spreading depression propagation. Computers \& Mathematics with Applications, 74, 1076-1090.

GLAZER, E. S. \& CURLEY, S. A. 2011. Non-invasive radiofrequency ablation of malignancies mediated by quantum dots, gold nanoparticles and carbon nanotubes. Therapeutic delivery, 2, 13251330.

GLAZER, E. S., MASSEY, K. L., ZHU, C. \& CURLEY, S. A. 2010a. Pancreatic carcinoma cells are susceptible to noninvasive radio frequency fields after treatment with targeted gold nanoparticles. Surgery, 148, 319-324.

GLAZER, E. S., ZHU, C., MASSEY, K. L., THOMPSON, C. S., KALUARACHCHI, W. D., HAMIR, A. N. \& CURLEY, S. A. 2010b. Noninvasive radiofrequency field destruction of pancreatic adenocarcinoma xenografts treated with targeted gold nanoparticles. Clinical Cancer Research, 16, 5712-5721.

GLORY, J., BONETTI, M., HELEZEN, M., MAYNE-L'HERMITE, M. \& REYNAUD, C. 2008. Thermal and electrical conductivities of water-based nanofluids prepared with long multiwalled carbon nanotubes. Journal of applied physics, 103, 094309.

GONZÁLEZ-SUÁREZ, A., PÉREZ, J. J. \& BERJANO, E. 2018. Should fluid dynamics be included in computer models of RF cardiac ablation by irrigated-tip electrodes? Biomedical engineering online, 17, 43.

GONZÁLEZ-SUÁREZ, A., GUTIERREZ-HERRERA, E., BERJANO, E., JIMENEZ LOZANO, J. N. \& FRANCO, W. 2015. Thermal and elastic response of subcutaneous tissue with different fibrous septa architectures to RF heating: numerical study. Lasers in surgery and medicine, 47, 183-195.

HAEMMERICH, D., WRIGHT, A., MAHVI, D., LEE, F. \& WEBSTER, J. 2003. Hepatic bipolar radiofrequency ablation creates coagulation zones close to blood vessels: a finite element study. Medical and Biological Engineering and Computing, 41, 317-323.

HAJIMOLAHOSEINI, H., HASHEMI, J., GAZOR, S. \& REDFEARN, D. 2018. Inflection point analysis: A machine learning approach for extraction of IEGM active intervals during atrial fibrillation. Artificial intelligence in medicine, 85, 7-15.

HALL, S. K., OOI, E. H. \& PAYNE, S. J. 2014. A mathematical framework for minimally invasive tumor ablation therapies. Critical Reviews ${ }^{T M}$ in Biomedical Engineering, 42.

HALL, S. K., OOI, E. H. \& PAYNE, S. J. 2015. Cell death, perfusion and electrical parameters are critical in models of hepatic radiofrequency ablation. International Journal of Hyperthermia, 31, 538-550.

hasgall, P., DI GenNaRo, F., BAUMgartner, C., NeUfeld, E., GOSSEliN, M., PAYNe, D., KLINGENBÖCK, A. \& KUSTER, N. 2015. IT'IS Database for thermal and electromagnetic parameters of biological tissues. Version 3.0.

HASSANPOUR, S. \& SABOONCHI, A. 2016. Modeling of heat transfer in a vascular tissue-like medium during an interstitial hyperthermia process. Journal of thermal biology, 62, 150-158.

HE, Z. Z., XUE, X. \& LIU, J. 2013. An effective finite difference method for simulation of bioheat transfer in irregular tissues. Journal of heat transfer, 135, 071003.

HOLT, A. B. \& NETOFF, T. I. 2013. Computational modeling of epilepsy for an experimental neurologist. Experimental neurology, 244, 75-86.

HORNG, T. L., LIN, W. L., LIAUH, C. T. \& SHIH, T. C. 2007. Effects of pulsatile blood flow in large vessels on thermal dose distribution during thermal therapy. Medical physics, 34, 13121320. 
HUANG, H.-W. \& HORNG, T.-L. 2015. Bioheat Transfer and Thermal Heating for Tumor Treatment. Heat Transfer and Fluid Flow in Biological Processes. Elsevier.

HUANG, H. W. 2013. Influence of blood vessel on the thermal lesion formation during radiofrequency ablation for liver tumors. Medical physics, 40, 073303.

JAIN, M. K. \& WOLF, P. D. 2000. A three-dimensional finite element model of radiofrequency ablation with blood flow and its experimental validation. Annals of biomedical engineering, 28, 1075-1084.

JAUNICH, M., RAJE, S., KIM, K., MITRA, K. \& GUO, Z. 2008. Bio-heat transfer analysis during short pulse laser irradiation of tissues. International Journal of Heat and Mass Transfer, 51, 55115521.

JI, Z. \& BRACE, C. L. 2011. Expanded modeling of temperature-dependent dielectric properties for microwave thermal ablation. Physics in Medicine \& Biology, 56, 5249.

JIANG, C.-P., WU, M.-C. \& WU, Y.-S. 2012. Inducing occlusion effect in Y-shaped vessels using highintensity focused ultrasound: finite element analysis and phantom validation. Computer methods in biomechanics and biomedical engineering, 15, 323-332.

JIN, C., HE, Z. \& LIU, J. 2014. MRI-based finite element simulation on radiofrequency ablation of thyroid cancer. Computer methods and programs in biomedicine, 113, 529-538.

JIRSA, V. K., PROIX, T., PERDIKIS, D., WOODMAN, M. M., WANG, H., GONZALEZ-MARTINEZ, J., BERNARD, C., BÉNAR, C., GUYE, M. \& CHAUVEL, P. 2017. The virtual epileptic patient: individualized whole-brain models of epilepsy spread. Neuroimage, 145, 377-388.

KABIRI, A. \& TALAEE, M. R. 2019. Theoretical investigation of thermal wave model of microwave ablation applied in prostate Cancer therapy. Heat and Mass Transfer, 1-10.

KAMINSKI, W. 1990. Hyperbolic heat conduction equation for materials with a nonhomogeneous inner structure. Journal of Heat Transfer, 112, 555-560.

KARAKI, W., LOPEZ, C. A., BORCA-TASCIUC, D.-A. \& DE, S. 2018. A continuum thermomechanical model of in vivo electrosurgical heating of hydrated soft biological tissues. International journal of heat and mass transfer, 127, 961-974.

KEANGIN, P. \& RATTANADECHO, P. 2013. Analysis of heat transport on local thermal non-equilibrium in porous liver during microwave ablation. International Journal of Heat and Mass Transfer, 67, 46-60.

KEANGIN, P. \& RATTANADECHO, P. 2018. A numerical investigation of microwave ablation on porous liver tissue. Advances in Mechanical Engineering, 10, 1687814017734133.

KEANGIN, P., WESSAPAN, T. \& RATTANADECHO, P. 2011. Analysis of heat transfer in deformed liver cancer modeling treated using a microwave coaxial antenna. Applied Thermal Engineering, 31, 3243-3254.

KESSENTINI, S. \& BARCHIESI, D. 2012. Quantitative comparison of optimized nanorods, nanoshells and hollow nanospheres for photothermal therapy. Biomedical optics express, 3, 590-604.

KHADEMI, R., MOHEBBI-KALHORI, D. \& RAZMINIA, A. 2019. Thermal analysis of a tumorous vascular tissue during pulsed-cryosurgery and nano-hyperthermia therapy: Finite element approach. International Journal of Heat and Mass Transfer, 137, 1001-1013.

KHALED, A.-R. \& VAFAI, K. 2003. The role of porous media in modeling flow and heat transfer in biological tissues. International Journal of Heat and Mass Transfer, 46, 4989-5003.

KHANAFER, T. K. \& VAFAI, K. 2009. Synthesis of mathematical models representing bioheat transport. Advances in Numerical Heat Transfer, Volume 3. CRC Press.

KHLEBTSOV, N. \& DYKMAN, L. 2011. Biodistribution and toxicity of engineered gold nanoparticles: a review of in vitro and in vivo studies. Chemical Society Reviews, 40, 1647-1671.

$\mathrm{KIM}, \mathrm{C}$. 2018. Understanding the nuances of microwave ablation for more accurate post-treatment assessment. Future Oncology, 14, 1755-1764.

KOSIK-BOGACKA, D. I., LANOCHA-ARENDARCZYK, N., KOT, K., ZIETEK, P., KARACZUN, M., PROKOPOWICZ, A., KUPNICKA, P. \& CIOSEK, Z. 2018. Calcium, magnesium, zinc and lead concentrations in the structures forming knee joint in patients with osteoarthritis. Journal of Trace Elements in Medicine and Biology, 50, 409-414. 
KRÖGER, T., PANNIER, S., KALISKE, M., ALtROGGE, I., GRAF, W. \& PREUSSER, T. 2010. Optimal applicator placement in hepatic radiofrequency ablation on the basis of rare data. Computer methods in biomechanics and biomedical engineering, 13, 431-440.

KROOS, J. M., MARINELLI, I., DIEZ, I., CORTES, J. M., STRAMAGLIA, S. \& GERARDO-GIORDA, L. 2017. Patient-specific computational modeling of cortical spreading depression via diffusion tensor imaging. International journal for numerical methods in biomedical engineering, 33, e2874.

KUCYI, A. \& DAVIS, K. D. 2015. The dynamic pain connectome. Trends in neurosciences, 38, 86-95.

KUMAR, C. S. \& MOHAMMAD, F. 2011. Magnetic nanomaterials for hyperthermia-based therapy and controlled drug delivery. Advanced drug delivery reviews, 63, 789-808.

KUMAR, D., SINGH, S., SHARMA, N. \& RAI, K. 2018. Verified non-linear DPL model with experimental data for analyzing heat transfer in tissue during thermal therapy. International Journal of Thermal Sciences, 133, 320-329.

KUMAR, P., KUMAR, D. \& RAI, K. 2015. A numerical study on dual-phase-lag model of bio-heat transfer during hyperthermia treatment. Journal of thermal biology, 49, 98-105.

KUMAR, P., KUMAR, D. \& RAI, K. 2016. Non-linear dual-phase-lag model for analyzing heat transfer phenomena in living tissues during thermal ablation. Journal of thermal biology, 60, 204-212.

KUMAR, S. \& SRIVASTAVA, A. 2015. Thermal analysis of laser-irradiated tissue phantoms using dual phase lag model coupled with transient radiative transfer equation. International Journal of Heat and Mass Transfer, 90, 466-479.

LAGMAN, C., ChUNG, L. K., PELARGOS, P. E., UNG, N., BUI, T. T., LEE, S. J., VOTH, B. L. \& YANG, I. 2017. Laser neurosurgery: A systematic analysis of magnetic resonance-guided laser interstitial thermal therapies. Journal of Clinical Neuroscience, 36, 20-26.

LEBRE, M.-A., VACAVANT, A., GRAND-BROCHIER, M., ROSITI, H., ABERGEL, A., CHABROT, P. \& MAGNIN, B. 2019. Automatic segmentation methods for liver and hepatic vessels from CT and MRI volumes, applied to the Couinaud scheme. Computers in biology and medicine, 110, 42-51.

LEBRUN, A., JOGLEKAR, T., BIEBERICH, C., MA, R. \& ZHU, L. 2016a. Identification of infusion strategy for achieving repeatable nanoparticle distribution and quantification of thermal dosage using micro-CT Hounsfield unit in magnetic nanoparticle hyperthermia. International Journal of Hyperthermia, 32, 132-143.

LEBRUN, A., MA, R. \& ZHU, L. 2016b. MicroCT image based simulation to design heating protocols in magnetic nanoparticle hyperthermia for cancer treatment. Journal of thermal biology, 62, 129-137.

LEBRUN, A. \& ZHU, L. 2018. Magnetic Nanoparticle Hyperthermia in Cancer Treatment: History, Mechanism, Imaging-Assisted Protocol Design, and Challenges. Theory and Applications of Heat Transfer in Humans, 2, 631-667.

LEE, W., GUILAK, F. \& LIEDTKE, W. 2017. Role of piezo channels in joint health and injury. Current topics in membranes. Elsevier.

LEONG, K., YANG, C. \& MURSHED, S. 2006. A model for the thermal conductivity of nanofluids-the effect of interfacial layer. Journal of nanoparticle research, 8, 245-254.

LI, K., VAKHARIA, V. N., SPARKS, R., FRANÇA, L. G., GRANADOS, A., MCEVOY, A. W., MISEROCCHI, A., WANG, M., OURSELIN, S. \& DUNCAN, J. S. 2019. Optimizing trajectories for cranial laser interstitial thermal therapy using computer-assisted planning: a machine learning approach. Neurotherapeutics, 16, 182-191.

LI, X., QIN, Q.-H. \& TIAN, X. 2020. Thermo-viscoelastic analysis of biological tissue during hyperthermia treatment. Applied Mathematical Modelling, 79, 881-895.

LI, X., ZHONG, Y., JAZAR, R. \& SUBIC, A. 2014. Thermal-mechanical deformation modelling of soft tissues for thermal ablation. Bio-medical materials and engineering, 24, 2299-2310.

LI, X., ZHONG, Y., SMITH, J. \& GU, C. 2017. Non-Fourier based thermal-mechanical tissue damage prediction for thermal ablation. Bioengineered, 8, 71-77.

LI, Y., YUE, J. \& YANG, C. 2016. Unraveling the role of Mg++ in osteoarthritis. Life sciences, 147, 2429. 
LIN, M., LIU, S. B., GENIN, G. M., ZHU, Y., SHI, M., JI, C., LI, A., LU, T. J. \& XU, F. 2017. Melting Away Pain: Decay of Thermal Nociceptor Transduction during Heat-Induced Irreversible Desensitization of Ion Channels. ACS Biomaterials Science \& Engineering, 3, 3029-3035.

LIU, C., PARK, C. S., HALL, S. K. \& PAYNE, S. J. 2017. Mathematical model of the post-ablation enhancement zone as a tissue-level oedematic response. International Journal of Hyperthermia, 33, 111-121.

LIU, D. \& BRACE, C. L. 2014. CT imaging during microwave ablation: analysis of spatial and temporal tissue contraction. Medical physics, 41, 113303.

LIU, D. \& BRACE, C. L. 2017. Numerical simulation of microwave ablation incorporating tissue contraction based on thermal dose. Physics in Medicine \& Biology, 62, 2070.

LIU, D. \& BRACE, C. L. 2019. Evaluation of tissue deformation during radiofrequency and microwave ablation procedures: Influence of output energy delivery. Medical Physics, 46, 4127-4134.

LIU, K.-C. \& CHEN, H.-T. 2010. Investigation for the dual phase lag behavior of bio-heat transfer. International Journal of Thermal Sciences, 49, 1138-1146.

LÓPEZ-MOLINA, J. A., RIVERA, M. J., TRUJILLO, M., BURDÍO, F., LEQUERICA, J. L., HORNERO, F. \& BERJANO, E. J. 2008. Assessment of hyperbolic heat transfer equation in theoretical modeling for radiofrequency heating techniques. The open Biomedical engineering journal, 2, 22.

LOPRESTO, V., PINTO, R. \& CAVAGNARO, M. 2014. Experimental characterisation of the thermal lesion induced by microwave ablation. International Journal of Hyperthermia, 30, 110-118.

LOPRESTO, V., PINTO, R., FARINA, L. \& CAVAGNARO, M. 2017a. Microwave thermal ablation: effects of tissue properties variations on predictive models for treatment planning. Medical engineering \& physics, 46, 63-70.

LOPRESTO, V., PINTO, R., FARINA, L. \& CAVAGNARO, M. 2017b. Treatment planning in microwave thermal ablation: clinical gaps and recent research advances. International Journal of Hyperthermia, 33, 83-100.

LÖTSCH, J. \& ULTSCH, A. 2018. Machine learning in pain research. Pain, 159, 623.

LUYEN, H., GAO, F., HAGNESS, S. C. \& BEHDAD, N. 2014. Microwave ablation at $10.0 \mathrm{GHz}$ achieves comparable ablation zones to $1.9 \mathrm{GHz}$ in ex vivo bovine liver. IEEE Transactions on Biomedical Engineering, 61, 1702-1710.

LYTTON, W. W., ARLE, J., BOBASHEV, G., JI, S., KLASSEN, T. L., MARMARELIS, V. Z., SCHWABER, J., SHERIF, M. A. \& SANGER, T. D. 2017. Multiscale modeling in the clinic: diseases of the brain and nervous system. Brain informatics, 4, 219.

MA, M., ZHANG, Y. \& GU, N. 2018. Estimation the tumor temperature in magnetic nanoparticle hyperthermia by infrared thermography: Phantom and numerical studies. Journal of thermal biology, 76, 89-94.

MAHAPATRA, D. R. \& MELNIK, R. 2006. Modelling and analysis of collagen piezoelectricity in human cornea. DYNAMICS OF CONTINUOUS DISCRETE AND IMPULSIVE SYSTEMS-SERIES AMATHEMATICAL ANALYSIS, 13, 377-384.

MAILLET, D. 2019. A review of the models using the Cattaneo and Vernotte hyperbolic heat equation and their experimental validation. International Journal of Thermal Sciences, 139, 424-432.

MAKROPOULOU, M., KARELIOTIS, G., SPYRATOU, E., DRAKAKI, E., SERAFETINIDES, A. \& EFSTATHOPOULOS, E. 2019. Non-ionizing, laser radiation in Theranostics: The need for dosimetry and the role of Medical Physics. Physica Medica, 63, 7-18.

MARIAPPAN, P., WEIR, P., FLANAGAN, R., VOGLREITER, P., ALHONNORO, T., POLLARI, M., MOCHE, M., BUSSE, H., FUTTERER, J. \& PORTUGALLER, H. R. 2017. GPU-based RFA simulation for minimally invasive cancer treatment of liver tumours. International journal of computer assisted radiology and surgery, 12, 59-68.

MEDVID, R., RUIZ, A., KOMOTAR, R. J., JAGID, J., IVAN, M., QUENCER, R. \& DESAI, M. 2015. Current applications of MRI-guided laser interstitial thermal therapy in the treatment of brain neoplasms and epilepsy: a radiologic and neurosurgical overview. American Journal of Neuroradiology, 36, 1998-2006.

MELNIK, R. \& MELNIK, K. 1998. A note on the class of weakly coupled problems of non-stationary piezoelectricity. Communications in numerical methods in engineering, 14, 839-847. 
MELNIK, R. V. 2000. Generalised solutions, discrete models and energy estimates for a 2D problem of coupled field theory. Applied Mathematics and Computation, 107, 27-55.

MERCADAL, B., VICENTE, R. \& IVORRA, A. 2018. Pulsed Radiofrequency for Chronic Pain: An Electroporation Mediated Calcium Signaling Process? Biophysical Journal, 114, 287 a.

MIGA, M. I. 2016. Computational modeling for enhancing soft tissue image guided surgery: an application in neurosurgery. Annals of biomedical engineering, 44, 128-138.

MISSIOS, S., BEKELIS, K. \& BARNETT, G. H. 2015. Renaissance of laser interstitial thermal ablation. Neurosurgical focus, 38, E13.

MITCHELL, D., FAHRENHOLTZ, S., MACLELLAN, C., BASTOS, D., RAO, G., PRABHU, S., WEINBERG, J., HAZLE, J., STAFFORD, J. \& FUENTES, D. 2018. A heterogeneous tissue model for treatment planning for magnetic resonance-guided laser interstitial thermal therapy. International Journal of Hyperthermia, 34, 943-952.

MITRA, K., KUMAR, S., VEDEVARZ, A. \& MOALLEMI, M. 1995. Experimental evidence of hyperbolic heat conduction in processed meat. Journal of Heat Transfer, 117, 568-573.

MOAYEDI, M. \& DAVIS, K. D. 2012. Theories of pain: from specificity to gate control. Journal of neurophysiology, 109, 5-12.

MOCHE, M., BUSSE, H., FUTTERER, J. J., HINESTROSA, C. A., SEIDER, D., BRANDMAIER, P., KOLESNIK, M., JENNISKENS, S., SEQUEIROS, R. B. \& KOMAR, G. 2020. Clinical evaluation of in silico planning and real-time simulation of hepatic radiofrequency ablation (CliniclMPPACT Trial). European radiology, 30, 934-942.

MOONEY, R., ROMA, L., ZHAO, D., VAN HAUTE, D., GARCIA, E., KIM, S. U., ANNALA, A. J., ABOODY, K. S. \& BERLIN, J. M. 2014. Neural stem cell-mediated intratumoral delivery of gold nanorods improves photothermal therapy. ACS nano, 8, 12450-12460.

MOONEY, R., SCHENA, E., SACCOMANDI, P., ZHUMKHAWALA, A., ABOODY, K. \& BERLIN, J. M. 2017. Gold nanorod-mediated near-infrared laser ablation: in vivo experiments on mice and theoretical analysis at different settings. International Journal of Hyperthermia, 33, 150-159.

MORELAND, A. J., ZIEMLEWICZ, T. J., BEST, S. L., HINSHAW, J. L., LUBNER, M. G., ALEXANDER, M. L., BRACE, C. L., KITCHIN, D. R., HEDICAN, S. P. \& NAKADA, S. Y. 2014. High-powered microwave ablation of t1a renal cell carcinoma: safety and initial clinical evaluation. Journal of endourology, 28, 1046-1052.

MOSGAARD, L. D., ZECCHI, K. A. \& HEIMBURG, T. 2015. Mechano-capacitive properties of polarized membranes. Soft Matter, 11, 7899-7910.

MUHIEDDINE, M., CANOT, E. \& MARCH, R. 2009. Various approaches for solving problems in heat conduction with phase change.

NEAL, M. L. \& KERCKHOFFS, R. 2009. Current progress in patient-specific modeling. Briefings in bioinformatics, 11, 111-126.

NEGRO, R., RUCCO, M., CREANZA, A., MORMILE, A., LIMONE, P. P., GARBEROGLIO, R., SPIEZIA, S., MONTI, S., CUGINI, C. \& EL DALATI, G. 2019. Machine Learning Prediction of Radiofrequency Thermal Ablation Efficacy: A New Option to Optimize Thyroid Nodule Selection. European Thyroid Journal, 1-8.

NIELD, D. A. \& BEJAN, A. 2017. Heat transfer through a porous medium. Convection in Porous Media. Springer.

NIRGUDKAR, H., KUMAR, S. \& SRIVASTAVA, A. 2017. Thermal analysis of laser-irradiated tissue phantoms using a novel separation of the variables-based discrete transfer method. Numerical Heat Transfer, Part A: Applications, 71, 575-589.

O'NEILL, D. P., PENG, T., STIEGLER, P., MAYRHAUSER, U., KOESTENBAUER, S., TSCHELIESSNIGG, K. \& PAYNE, S. J. 2011. A three-state mathematical model of hyperthermic cell death. Annals of biomedical engineering, 39, 570-579.

OKUNO, T., KATO, S., HATAKEYAMA, Y., OKAJIMA, J., MARUYAMA, S., SAKAMOTO, M., MORI, S. \& KODAMA, T. 2013. Photothermal therapy of tumors in lymph nodes using gold nanorods and near-infrared laser light. Journal of controlled release, 172, 879-884.

OOI, E. H., JY CHIA, N., OOI, E. T., FOO, J. J., LIAO, I. Y., R. NAIR, S. \& MOHD ALI, A. F. 2018. Comparison between single-and dual-porosity models for fluid transport in predicting lesion 
volume following saline-infused radiofrequency ablation. International Journal of Hyperthermia, 34, 1142-1156.

OOI, E. H., LEE, K. W., YAP, S., KHATTAB, M. A., LIAO, I. Y., OOI, E. T., FOO, J. J., NAIR, S. R. \& ALI, A. F. M. 2019. The effects of electrical and thermal boundary condition on the simulation of radiofrequency ablation of liver cancer for tumours located near to the liver boundary. Computers in biology and medicine, 106, 12-23.

ORTIZ-CATALAN, M. 2018. The stochastic entanglement and phantom motor execution hypotheses: a theoretical framework for the origin and treatment of PLP. Frontiers in neurology, 9, 748.

PARK, C. S., HALL, S. K., LIU, C. \& PAYNE, S. J. 2016. A model of tissue contraction during thermal ablation. Physiological measurement, 37, 1474.

PARK, C. S., LIU, C., HALL, S. K. \& PAYNE, S. J. 2018. A thermoelastic deformation model of tissue contraction during thermal ablation. International Journal of Hyperthermia, 34, 221-228.

PAUL, A., NARASIMHAN, A., DAS, S. K., SENGUPTA, S. \& PRADEEP, T. 2016. Subsurface thermal behaviour of tissue mimics embedded with large blood vessels during plasmonic photothermal therapy. International Journal of Hyperthermia, 32, 765-777.

PAUL, A., NARASIMHAN, A., KAHLEN, F. J. \& DAS, S. K. 2014. Temperature evolution in tissues embedded with large blood vessels during photo-thermal heating. Journal of thermal biology, 41, 77-87.

PAUL, A. \& PAUL, A. 2018. Computational study of photo-thermal ablation of large blood vessel embedded tumor using localized injection of gold nanoshells. Journal of thermal biology, 78, 329-342.

PAULIDES, M. M., STAUFFER, P. R., NEUFELD, E., MACCARINI, P. F., KYRIAKOU, A., CANTERS, R. A., DIEDERICH, C. J., BAKKER, J. F. \& VAN RHOON, G. C. 2013. Simulation techniques in hyperthermia treatment planning. International Journal of Hyperthermia, 29, 346-357.

PAYNE, S., FLANAGAN, R., POLLARI, M., ALHONNORO, T., BOST, C., O'NEILL, D., PENG, T. \& STIEGLER, P. 2011. Image-based multi-scale modelling and validation of radio-frequency ablation in liver tumours. Philosophical Transactions of the Royal Society A: Mathematical, Physical and Engineering Sciences, 369, 4233-4254.

PAYNE, S. J., PENG, T. \& O'NEILL, D. 2010. Mathematical modeling of thermal ablation. Critical Reviews ${ }^{T M}$ in Biomedical Engineering, 38.

PEARCE, J. A. 2013. Comparative analysis of mathematical models of cell death and thermal damage processes. International Journal of Hyperthermia, 29, 262-280.

PENNES, H. H. 1948. Analysis of tissue and arterial blood temperatures in the resting human forearm. Journal of applied physiology, 1, 93-122.

PÉREZ, J. J., PÉREZ-CAJARAVILLE, J. J., MUÑOZ, V. \& BERJANO, E. 2014. Computer modeling of electrical and thermal performance during bipolar pulsed radiofrequency for pain relief. Medical physics, 41, 071708.

PILLAI, K., AKHTER, J., CHUA, T. C., SHEHATA, M., ALZAHRANI, N., AL-ALEM, I. \& MORRIS, D. L. 2015. Heat sink effect on tumor ablation characteristics as observed in monopolar radiofrequency, bipolar radiofrequency, and microwave, using ex vivo calf liver model. Medicine, 94.

PRAKASH, P. 2010. Theoretical modeling for hepatic microwave ablation. The open biomedical engineering journal, 4, 27.

PRAKASH, P. \& DIEDERICH, C. J. 2012. Considerations for theoretical modelling of thermal ablation with catheter-based ultrasonic sources: Implications for treatment planning, monitoring and control. International journal of hyperthermia, 28, 69-86.

PRAKASH, P., SALGAONKAR, V. A., CLIF BURDETTE, E. \& DIEDERICH, C. J. 2012. Multiple applicator hepatic ablation with interstitial ultrasound devices: Theoretical and experimental investigation. Medical physics, 39, 7338-7349.

QADRI, A. M., CHIA, N. J. \& OOI, E. H. 2017. Effects of saline volume on lesion formation during saline-infused radiofrequency ablation. Applied Mathematical Modelling, 43, 360-371.

QUIRK, M. T. \& LU, D. S. 2019. Noninvasive Assessment of Hepatocellular Carcinoma Tumor Thrombus: Is It All in Vein? Liver Transplantation, 25, 201-202. 
RAAYMAKERS, B., KOTTE, A. \& LAGENDIJK, J. 2009. Discrete vasculature (DIVA) model simulating the thermal impact of individual blood vessels for in vivo heat transfer. Advances in Numerical Heat Transfer, Volume 3. CRC Press.

RAHMATHULLA, G., RECINOS, P. F., KAMIAN, K., MOHAMMADI, A. M., AHLUWALIA, M. S. \& BARNETT, G. H. 2014. MRI-guided laser interstitial thermal therapy in neuro-oncology: a review of its current clinical applications. Oncology, 87, 67-82.

RAO, W. \& DENG, Z.-S. 2010. A review of hyperthermia combined with radiotherapy/chemotherapy on malignant tumors. Critical Reviews ${ }^{T M}$ in Biomedical Engineering, 38.

RAOOF, M., CORR, S. J., KALUARACHCHI, W. D., MASSEY, K. L., BRIGGS, K., ZHU, C., CHENEY, M. A., WILSON, L. J. \& CURLEY, S. A. 2012. Stability of antibody-conjugated gold nanoparticles in the endolysosomal nanoenvironment: implications for noninvasive radiofrequency-based cancer therapy. Nanomedicine: Nanotechnology, Biology and Medicine, 8, 1096-1105.

RAOOF, M., CORR, S. J., ZHU, C., CISNEROS, B. T., KALUARACHCHI, W. D., PHOUNSAVATH, S., WILSON, L. J. \& CURLEY, S. A. 2014. Gold nanoparticles and radiofrequency in experimental models for hepatocellular carcinoma. Nanomedicine: Nanotechnology, Biology and Medicine, 10, 1121-1130.

RAOOF, M. \& CURLEY, S. A. 2011. Non-invasive radiofrequency-induced targeted hyperthermia for the treatment of hepatocellular carcinoma. International journal of hepatology, 2011.

RATTANADECHO, P. \& KEANGIN, P. 2013. Numerical study of heat transfer and blood flow in twolayered porous liver tissue during microwave ablation process using single and double slot antenna. International Journal of Heat and Mass Transfer, 58, 457-470.

REDDY, G., DREHER, M. R., ROSSMANN, C., WOOD, B. J. \& HAEMMERICH, D. 2013. Cytotoxicity of hepatocellular carcinoma cells to hyperthermic and ablative temperature exposures: in vitro studies and mathematical modelling. International Journal of Hyperthermia, 29, 318-323.

REINHARDT, M., BRANDMAIER, P., SEIDER, D., KOLESNIK, M., JENNISKENS, S., SEQUEIROS, R. B., EIBISBERGER, M., VOGLREITER, P., FLANAGAN, R. \& MARIAPPAN, P. 2017. A prospective development study of software-guided radio-frequency ablation of primary and secondary liver tumors: Clinical intervention modelling, planning and proof for ablation cancer treatment (clinicimppact). Contemporary clinical trials communications, 8, 25-32.

REJINOLD, N. S., JAYAKUMAR, R. \& KIM, Y.-C. 2015. Radio frequency responsive nano-biomaterials for cancer therapy. Journal of controlled release, 204, 85-97.

REJINOLD, N. S., RANJUSHA, R., BALAKRISHNAN, A., MOHAMMED, N. \& JAYAKUMAR, R. 2014a. Gold-chitin-manganese dioxide ternary composite nanogels for radio frequency assisted cancer therapy. RSC Advances, 4, 5819-5825.

REJINOLD, N. S., THOMAS, R. G., MUTHIAH, M., CHENNAZHI, K., PARK, I.-K., JEONG, Y. Y., MANZOOR, K. \& JAYAKUMAR, R. 2014b. Radio frequency triggered curcumin delivery from thermo and $\mathrm{pH}$ responsive nanoparticles containing gold nanoparticles and its in vivo localization studies in an orthotopic breast tumor model. Rsc Advances, 4, 39408-39427.

REJINOLD, N. S., THOMAS, R. G., MUTHIAH, M., LEE, H. J., JEONG, Y. Y., PARK, I.-K. \& JAYAKUMAR, R. 2016. Breast tumor targetable $\mathrm{Fe} 3 \mathrm{O} 4$ embedded thermo-responsive nanoparticles for radiofrequency assisted drug delivery. Journal of biomedical nanotechnology, 12, 43-55.

REN, Y., QI, H., CHEN, Q. \& RUAN, L. 2017. Thermal dosage investigation for optimal temperature distribution in gold nanoparticle enhanced photothermal therapy. International Journal of Heat and Mass Transfer, 106, 212-221.

RIEDER, C., KROEGER, T., SCHUMANN, C. \& HAHN, H. K. 2011. GPU-based real-time approximation of the ablation zone for radiofrequency ablation. IEEE transactions on visualization and computer graphics, 17, 1812-1821.

ROETZEL, W., PUTRA, N. \& DAS, S. K. 2003. Experiment and analysis for non-Fourier conduction in materials with non-homogeneous inner structure. International Journal of Thermal Sciences, 42, 541-552.

ROSSMANN, C., GARRETT-MAYER, E., RATTAY, F. \& HAEMMERICH, D. 2013. Dynamics of tissue shrinkage during ablative temperature exposures. Physiological measurement, 35, 55. 
ROSSMANN, C., RATTAY, F. \& HAEMMERICH, D. 2012. Platform for patient-specific finite-element modeling and application for radiofrequency ablation. Visualization, Image Processing and Computation in Biomedicine, 1.

SAHOO, N., GHOSH, S., NARASIMHAN, A. \& DAS, S. K. 2014. Investigation of non-Fourier effects in bio-tissues during laser assisted photothermal therapy. International Journal of Thermal Sciences, 76, 208-220.

SAHOO, N., NARASIMHAN, A., DHAR, P. \& DAS, S. K. 2018. Non-Fourier thermal transport induced structural hierarchy and damage to collagen ultrastructure subjected to laser irradiation. International Journal of Hyperthermia, 34, 229-242.

SALIMPOUR, M. R. \& SHIRANI, E. 2017. Heat transfer analysis of skin during thermal therapy using thermal wave equation. Journal of thermal biology, 64, 7-18.

SALLOUM, M., MA, R., WEEKS, D. \& ZHU, L. 2008a. Controlling nanoparticle delivery in magnetic nanoparticle hyperthermia for cancer treatment: experimental study in agarose gel. International Journal of Hyperthermia, 24, 337-345.

SALLOUM, M., MA, R. \& ZHU, L. 2008b. An in-vivo experimental study of temperature elevations in animal tissue during magnetic nanoparticle hyperthermia. International Journal of Hyperthermia, 24, 589-601.

SAWICKI, J. F., LUYEN, H., MOHTASHAMI, Y., SHEA, J. D., BEHDAD, N. \& HAGNESS, S. C. 2018. The Performance of Higher Frequency Microwave Ablation in the Presence of Perfusion. IEEE Transactions on Biomedical Engineering, 66, 257-262.

SAWICKI, J. F., SHEA, J. D., BEHDAD, N. \& HAGNESS, S. C. 2017. The impact of frequency on the performance of microwave ablation. International Journal of Hyperthermia, 33, 61-68.

SCHENA, E., SACCOMANDI, P. \& FONG, Y. 2017. Laser ablation for cancer: past, present and future. Journal of functional biomaterials, 8, 19.

SCHUMANN, C., RIEDER, C., BIEBERSTEIN, J., WEIHUSEN, A., ZIDOWITZ, S., MOLTZ, J. H. \& PREUSSER, T. 2010. State of the art in computer-assisted planning, intervention, and assessment of liver-tumor ablation. Critical Reviews ${ }^{T M}$ in Biomedical Engineering, 38.

SCHUTT, D. J. \& HAEMMERICH, D. 2008. Effects of variation in perfusion rates and of perfusion models in computational models of radio frequency tumor ablation. Medical physics, 35, 3462-3470.

SCOTT, S. J., SALGAONKAR, V., PRAKASH, P., BURDETTE, E. C. \& DIEDERICH, C. J. 2014. Interstitial ultrasound ablation of vertebral and paraspinal tumours: Parametric and patient-specific simulations. International Journal of Hyperthermia, 30, 228-244.

SEBEK, J., ALBIN, N., BORTEL, R., NATARAJAN, B. \& PRAKASH, P. 2016. Sensitivity of microwave ablation models to tissue biophysical properties: A first step toward probabilistic modeling and treatment planning. Medical physics, 43, 2649-2661.

SEITEL, A., ENGEL, M., SOMMER, C. M., RADELEFF, B. A., ESSERT-VILLARD, C., BAEGERT, C., FANGERAU, M., FRITZSCHE, K. H., YUNG, K. \& MEINZER, H. P. 2011. Computer-assisted trajectory planning for percutaneous needle insertions. Medical physics, 38, 3246-3259.

SETH, B. \& DE GRAY, L. 2016. Genesis of chronic pain. Anaesthesia \& Intensive Care Medicine, 17, 431-435.

SHAO, Y., ARJUN, B., LEO, H. \& CHUA, K. 2017a. A computational theoretical model for radiofrequency ablation of tumor with complex vascularization. Computers in biology and medicine, 89, 282-292.

SHAO, Y., ARJUN, B., LEO, H. \& CHUA, K. 2017b. Nano-assisted radiofrequency ablation of clinically extracted irregularly-shaped liver tumors. Journal of thermal biology, 66, 101-113.

SHAO, Y., LEO, H. \& CHUA, K. 2017c. Studying the thermal performance of a bipolar radiofrequency ablation with an improved electrode matrix system: In vitro experiments and modelling. Applied Thermal Engineering, 116, 623-635.

SHENG, W., HE, S., SEARE, W. J. \& ALMUTAIRI, A. 2017. Review of the progress toward achieving heat confinement-the holy grail of photothermal therapy. Journal of biomedical optics, 22, 080901. 
SHIH, T.-C., LIU, H.-L. \& HORNG, A. T.-L. 2006. Cooling effect of thermally significant blood vessels in perfused tumor tissue during thermal therapy. International Communications in Heat and Mass Transfer, 33, 135-141.

SHUKLA, N. D., HO, A. L., PENDHARKAR, A. V., SUSSMAN, E. S. \& HALPERN, C. H. 2017. Laser interstitial thermal therapy for the treatment of epilepsy: evidence to date. Neuropsychiatric disease and treatment, 13, 2469.

SILVA, D., SHARMA, M. \& BARNETT, G. H. 2016. Laser ablation vs open resection for deep-seated tumors: evidence for laser ablation. Neurosurgery, 63, 15-26.

SILVA, D., SHARMA, M., JUTHANI, R., MEOLA, A. \& BARNETT, G. H. 2017. Magnetic resonance thermometry and laser interstitial thermal therapy for brain tumors. Neurosurgery Clinics, 28, 525-533.

SINGH, S. 2018. Thermal analysis of temperature-controlled radiofrequency ablation of cancerous tissue. Doctoral Dissertation, Indian Institute of Technology Ropar.

SINGH, S., BHOWMIK, A. \& REPAKA, R. Radiofrequency ablation of malignant breast tumor: A numerical study. Proc. 23rd National Heat and Mass Transfer Conference and 1st International ISHMT-ASTFE Heat and Mass Transfer Conference, 2015. 17-20.

SINGH, S., BHOWMIK, A. \& REPAKA, R. 2016. Thermal analysis of induced damage to the healthy cell during RFA of breast tumor. Journal of thermal biology, 58, 80-90.

SINGH, S. \& MELNIK, R. Computational Analysis of Pulsed Radiofrequency Ablation in Treating Chronic Pain. International Conference on Computational Science, 2019a. Springer, 436450.

SINGH, S. \& MELNIK, R. 2019b. Coupled thermo-electro-mechanical models for thermal ablation of biological tissues and heat relaxation time effects. Physics in Medicine \& Biology, 64, 245008.

SINGH, S. \& MELNIK, R. Effects of heterogeneous surrondings on the efficacy of continous radiofrequency for pain relief. International Conference on Bioinformatics and Neurosciences (ICoBN 2019), 26-28 August 2019c Vancouver, Canada.

SINGH, S. \& MELNIK, R. Radiofrequency Ablation for Treating Chronic Pain of Bones: Effects of Nerve Locations. International Work-Conference on Bioinformatics and Biomedical Engineering, 2019d. Springer, 418-429.

SINGH, S. \& REPAKA, R. Pre-clinical modelling and simulation of hepatic radiofrequency ablation. Proc. COMSOL Conference 2015, 29-30 October 2015 Pune, India.

SINGH, S. \& REPAKA, R. Effects of target temperature on ablation volume during temperaturecontrolled RFA of breast tumor. Proc. COMSOL Conference 2016, 20-21 October 2016 Bangalore, India.

SINGH, S. \& REPAKA, R. 2017a. Effect of different breast density compositions on thermal damage of breast tumor during radiofrequency ablation. Applied Thermal Engineering, 125, 443-451.

SINGH, S. \& REPAKA, R. EFFECT OF HETEROGENEOUS BLOOD PERFUSION DURING RFA OF BREAST TUMOR. ISHMT Digital Library, 2017b. Begel House Inc.

SINGH, S. \& REPAKA, R. 2017c. Temperature-controlled radiofrequency ablation of different tissues using two-compartment models. International Journal of Hyperthermia, 33, 122-134.

SINGH, S. \& REPAKA, R. 2018a. Numerical investigation of convective cooling in minimizing skin burns during radiofrequency ablation of breast tumor. Sādhanā, 43,90 .

SINGH, S. \& REPAKA, R. 2018b. Numerical study to establish relationship between coagulation volume and target tip temperature during temperature-controlled radiofrequency ablation. Electromagnetic biology and medicine, 37, 13-22.

SINGH, S. \& REPAKA, R. 2018c. Parametric sensitivity analysis of critical factors affecting the thermal damage during RFA of breast tumor. International Journal of Thermal Sciences, 124, 366374.

SINGH, S. \& REPAKA, R. 2018d. Quantification of thermal injury to the healthy tissue due to imperfect electrode placements during radiofrequency ablation of breast tumor. Journal of Engineering and Science in Medical Diagnostics and Therapy, 1, 011002.

SINGH, S. \& REPAKA, R. 2018e. Thermal characterization using fourier and non-fourier conduction during radiofrequency ablation of breast tumor. Multiphase Science and Technology, 30. 
SINGH, S., REPAKA, R. \& AL-JUMAILY, A. 2019. Sensitivity analysis of critical parameters affecting the efficacy of microwave ablation using Taguchi method. International Journal of RF and Microwave Computer-Aided Engineering, 29, e21581.

SOlER, L., NICOLAU, S., PESSAUX, P., MUTTER, D. \& MARESCAUX, J. 2014. Real-time 3D image reconstruction guidance in liver resection surgery. Hepatobiliary surgery and nutrition, 3, 73.

SOLOMAN, M., MEKHAIL, M. N. \& MEKHAIL, N. 2010. Radiofrequency treatment in chronic pain. Expert review of neurotherapeutics, 10, 469-474.

SOMMER, C. M., SOMMER, S. A., MOKRY, T., GOCKNER, T., GNUTZMANN, D., BELLEMANN, N., SCHMITZ, A., RADELEFF, B. A., KAUCZOR, H. U. \& STAMPFL, U. 2013. Quantification of tissue shrinkage and dehydration caused by microwave ablation: experimental study in kidneys for the estimation of effective coagulation volume. Journal of Vascular and Interventional Radiology, 24, 1241-1248.

SONI, S., TYAGI, H., TAYLOR, R. A. \& KUMAR, A. 2015a. Experimental and numerical investigation of heat confinement during nanoparticle-assisted thermal therapy. International Communications in Heat and Mass Transfer, 69, 11-17.

SONI, S., TYAGI, H., TAYLOR, R. A. \& KUMAR, A. 2015b. The influence of tumour blood perfusion variability on thermal damage during nanoparticle-assisted thermal therapy. International Journal of Hyperthermia, 31, 615-625.

SREBRO, D., VUCKOVIC, S., MILOVANOVIC, A., KOSUTIC, J., SAVIC VUJOVIC, K. \& PROSTRAN, M. 2017. Magnesium in pain research: state of the art. Current medicinal chemistry, 24, 424-434.

STAFFORD, R. J., FUENTES, D., ELLIOTT, A. A., WEINBERG, J. S. \& AHRAR, K. 2010. Laser-induced thermal therapy for tumor ablation. Critical Reviews ${ }^{\text {TM }}$ in Biomedical Engineering, 38.

STRUNIN, D., MELNIK, R. \& ROBERTS, A. 2001. Coupled thermomechanical waves in hyperbolic thermoelasticity. Journal of thermal stresses, 24, 121-140.

SURLERAUX, A., LEPERT, R., PERNOT, J.-P., KERFRIDEN, P. \& BIGOT, S. 2020. Machine Learning-Based Reverse Modeling Approach for Rapid Tool Shape Optimization in Die-Sinking Micro Electro Discharge Machining. Journal of Computing and Information Science in Engineering, 20.

TIEMANN, L., HOHN, V. D., DINH, S. T., MAY, E. S., NICKEL, M. M., GROSS, J. \& PLONER, M. 2018. Distinct patterns of brain activity mediate perceptual and motor and autonomic responses to noxious stimuli. Nature communications, 9, 4487.

TRUJILLO, M. \& BERJANO, E. 2013. Review of the mathematical functions used to model the temperature dependence of electrical and thermal conductivities of biological tissue in radiofrequency ablation. International Journal of Hyperthermia, 29, 590-597.

TRUJILLO, M., BON, J. \& BERJANO, E. 2017. Computational modelling of internally cooled wet (ICW) electrodes for radiofrequency ablation: impact of rehydration, thermal convection and electrical conductivity. International Journal of Hyperthermia, 33, 624-634.

TRUJILLO, M., BON, J., JOSÉ RIVERA, M., BURDÍO, F. \& BERJANO, E. 2016. Computer modelling of an impedance-controlled pulsing protocol for RF tumour ablation with a cooled electrode. International Journal of Hyperthermia, 32, 931-939.

TRUONG, V. G., JEONG, S. \& KANG, H. W. 2018. Computational analysis of linear energy modulation for laser thermal coagulation. Biomedical Optics Express, 9, 2575-2587.

TZOU, D. Y. 1995. The generalized lagging response in small-scale and high-rate heating. International Journal of Heat and Mass Transfer, 38, 3231-3240.

VAN RHOON, G. C. 2016. Is CEM43 still a relevant thermal dose parameter for hyperthermia treatment monitoring? International Journal of Hyperthermia, 32, 50-62.

VEDAVARZ, A., KUMAR, S. \& MOALLEMI, M. K. 1994. Significance of non-Fourier heat waves in conduction. Journal of Heat Transfer, 116, 221-226.

VERHAART, R. F., VERDUIJN, G. M., FORTUNATI, V., RIJNEN, Z., VAN WALSUM, T., VEENLAND, J. F. \& PAULIDES, M. M. 2015. Accurate 3D temperature dosimetry during hyperthermia therapy by combining invasive measurements and patient-specific simulations. International Journal of Hyperthermia, 31, 686-692.

VERNOTTE, P. 1958. Les paradoxes de la theorie continue de l'equation de la chaleur. Compt. Rendu, $246,3154-3155$. 
VOGEL, A. \& VENUGOPALAN, V. 2003. Mechanisms of pulsed laser ablation of biological tissues. Chemical reviews, 103, 577-644.

VOGLREITER, P., MARIAPPAN, P., POLLARI, M., FLANAGAN, R., SEQUEIROS, R. B., PORTUGALLER, R. H., FÜTTERER, J., SCHMALSTIEG, D., KOLESNIK, M. \& MOCHE, M. 2018. RFA guardian: comprehensive simulation of radiofrequency ablation treatment of liver tumors. Scientific reports, 8, 787.

WANG, H., DAI, W. \& MELNIK, R. 2006a. A finite difference method for studying thermal deformation in a double-layered thin film exposed to ultrashort pulsed lasers. International journal of thermal sciences, 45, 1179-1196.

WANG, H., DAI, W., NASSAR, R. \& MELNIK, R. 2006b. A finite difference method for studying thermal deformation in a thin film exposed to ultrashort-pulsed lasers. International Journal of Heat and Mass Transfer, 49, 2712-2723.

WANG, K., TAVAKKOLI, F., WANG, S. \& VAFAI, K. 2015. Analysis and analytical characterization of bioheat transfer during radiofrequency ablation. Journal of biomechanics, 48, 930-940.

WANG, S.-L., QI, H., REN, Y.-T., CHEN, Q. \& RUAN, L.-M. 2018a. Optimal temperature control of tissue embedded with gold nanoparticles for enhanced thermal therapy based on two-energy equation model. Journal of thermal biology, 74, 264-274.

WANG, Y. C., CHAN, T. C.-H. \& SAHAKIAN, A. V. 2018b. Real-time estimation of lesion depth and control of radiofrequency ablation within ex vivo animal tissues using a neural network. International Journal of Hyperthermia, 34, 1104-1113.

WANG, Z., LUO, H., COLEMAN, S. \& CUSCHIERI, A. 2016. Bicomponent Conformal Electrode for Radiofrequency Sequential Ablation and Circumferential Separation of Large Tumors in Solid Organs: Development and In Vitro Evaluation. IEEE Transactions on Biomedical Engineering, 64, 699-705.

WARD, R. C., HEALEY, T. T. \& DUPUY, D. E. 2013. Microwave ablation devices for interventional oncology. Expert review of medical devices, 10, 225-238.

WIDMER, L. A. \& STELLING, J. 2018. Bridging intracellular scales by mechanistic computational models. Current opinion in biotechnology, 52, 17-24.

WOEPPEL, K., YANG, Q. \& CUI, X. T. 2017. Recent advances in neural electrode-tissue interfaces. Current opinion in biomedical engineering, 4, 21-31.

WON, S. M., SONG, E., ZHAO, J., LI, J., RIVNAY, J. \& ROGERS, J. A. 2018. Recent advances in materials, devices, and systems for neural interfaces. Advanced Materials, 30, 1800534.

WONGCHADAKUL, P., RATTANADECHO, P. \& WESSAPAN, T. 2018. Implementation of a thermomechanical model to simulate laser heating in shrinkage tissue (effects of wavelength, laser irradiation intensity, and irradiation beam area). International Journal of Thermal Sciences, 134, 321-336.

WRIGHT, N. T. 2015. Quantitative models of thermal damage to cells and tissues. Heat Transfer and Fluid Flow in Biological Processes. Elsevier.

WU, W., WU, S., ZHOU, Z., ZHANG, R. \& ZHANG, Y. 2017. 3D liver tumor segmentation in CT images using improved fuzzy C-means and graph cuts. BioMed research international, 2017.

WU, W., ZHOU, Z., WU, S. \& ZHANG, Y. 2016. Automatic liver segmentation on volumetric CT images using supervoxel-based graph cuts. Computational and mathematical methods in medicine, 2016.

XU, F., LIN, M. \& LU, T. 2010. Modeling skin thermal pain sensation: Role of non-Fourier thermal behavior in transduction process of nociceptor. Computers in biology and medicine, 40, 478486.

XU, F., WEN, T., LU, T. \& SEFFEN, K. 2008. Modeling of nociceptor transduction in skin thermal pain sensation. Journal of biomechanical engineering, 130, 041013.

XU, Y., MOSER, M. A., ZHANG, E., ZHANG, W. \& ZHANG, B. 2019. Large and round ablation zones with microwave ablation: A preliminary study of an optimal aperiodic tri-slot coaxial antenna with the $\pi$-matching network section. International Journal of Thermal Sciences, 140, 539 548. 
YANG, D., CONVERSE, M. C., MAHVI, D. M. \& WEBSTER, J. G. 2006. Measurement and analysis of tissue temperature during microwave liver ablation. IEEE transactions on biomedical engineering, 54, 150-155.

YANG, D., CONVERSE, M. C., MAHVI, D. M. \& WEBSTER, J. G. 2007. Expanding the bioheat equation to include tissue internal water evaporation during heating. IEEE Transactions on Biomedical Engineering, 54, 1382-1388.

YILDIZ, F. \& ÖZDEMIR, A. T. 2019. Prediction of laser-induced thermal damage with artificial neural networks. Laser Physics, 29, 075205.

YOON, J., CHO, J., KIM, N., KIM, D. D., LEE, E., CHEON, C. \& KWON, Y. 2011. High-frequency microwave ablation method for enhanced cancer treatment with minimized collateral damage. International journal of cancer, 129, 1970-1978.

ZHANG, B., MOSER, M. A., ZHANG, E. M., LUO, Y., LIU, C. \& ZHANG, W. 2016. A review of radiofrequency ablation: Large target tissue necrosis and mathematical modelling. Physica Medica, 32, 961-971.

ZHANG, B., MOSER, M. A., ZHANG, E. M., LUO, Y. \& ZHANG, W. 2017. A new approach to feedback control of radiofrequency ablation systems for large coagulation zones. International Journal of Hyperthermia, 33, 367-377.

ZHANG, J. \& CHAUHAN, S. 2019. Neural network methodology for real-time modelling of bio-heat transfer during thermo-therapeutic applications. Artificial Intelligence in Medicine, 101, 101728.

ZHANG, J., ZHONG, Y. \& GU, C. 2019a. Neural network modelling of soft tissue deformation for surgical simulation. Artificial intelligence in medicine, 97, 61-70.

ZHANG, M., ZHOU, Z., WU, S., LIN, L., GAO, H. \& FENG, Y. 2015. Simulation of temperature field for temperature-controlled radio frequency ablation using a hyperbolic bioheat equation and temperature-varied voltage calibration: a liver-mimicking phantom study. Physics in Medicine \& Biology, 60, 9455.

ZHANG, R., WU, S., WU, W., GAO, H. \& ZHOU, Z. 2019b. Computer-assisted needle trajectory planning and mathematical modeling for liver tumor thermal ablation: A review. MATHEMATICAL BIOSCIENCES AND ENGINEERING, 16, 4846-4872.

ZHANG, R., ZHOU, Z., WU, W., LIN, C.-C., TSUI, P.-H. \& WU, S. 2018. An improved fuzzy connectedness method for automatic three-dimensional liver vessel segmentation in CT images. Journal of healthcare engineering, 2018.

ZHANG, S., DAI, W., WANG, H. \& MELNIK, R. V. 2008. A finite difference method for studying thermal deformation in a 3D thin film exposed to ultrashort pulsed lasers. International Journal of Heat and Mass Transfer, 51, 1979-1995.

ZHAO, J., LEE, P., J WALLACE, M. \& P MELANCON, M. 2015. Gold nanoparticles in cancer therapy: efficacy, biodistribution, and toxicity. Current pharmaceutical design, 21, 4240-4251.

ZHU, L. 2009. Heat Transfer Applications in Biological Systems. Biomedical Engineering \& Design Handbook, 1, 2.33-2.67.

ZHU, Y. \& LU, T. 2010. A multi-scale view of skin thermal pain: from nociception to pain sensation. Philosophical Transactions of the Royal Society A: Mathematical, Physical and Engineering Sciences, 368, 521-559.

ZIEMLEWICZ, T. J., WELLS, S. A., LUBNER, M. A., MUSAT, A. I., HINSHAW, J. L., COHN, A. R. \& LEE, F. T. 2014. Microwave ablation of giant hepatic cavernous hemangiomas. Cardiovascular and interventional radiology, 37, 1299-1305.

ZORBAS, G. \& SAMARAS, T. 2013. Parametric study of radiofrequency ablation in the clinical practice with the use of two-compartment numerical models. Electromagnetic biology and medicine, $32,236-243$.

ZORBAS, G. \& SAMARAS, T. 2014. Simulation of radiofrequency ablation in real human anatomy. International Journal of Hyperthermia, 30, 570-578.

ZORBAS, G. \& SAMARAS, T. 2015. A study of the sink effect by blood vessels in radiofrequency ablation. Computers in biology and medicine, 57, 182-186.

ZYGOMALAS, A. \& KEHAGIAS, I. 2019. Up-to-date intraoperative computer assisted solutions for liver surgery. World journal of gastrointestinal surgery, $11,1$. 
Table 1. Comparison of electrical properties of different tissues at $500 \mathrm{kHz}$ and $2.45 \mathrm{GHz}$.

\begin{tabular}{|c|c|c|c|}
\hline \multirow[b]{2}{*}{ Tissue Type } & \multirow{2}{*}{$\begin{array}{c}@ 500 \mathrm{kHz} \\
\text { Electrical } \\
\text { conductivity } \\
(\mathrm{S} / \mathrm{m})\end{array}$} & \multicolumn{2}{|c|}{ @ $2.45 \mathrm{GHz}$} \\
\hline & & \begin{tabular}{|c|} 
Electrical \\
conductivity \\
$(\mathrm{S} / \mathrm{m})$
\end{tabular} & $\begin{array}{c}\text { Relative } \\
\text { permittivity }\end{array}$ \\
\hline Adipose (fat) & 0.0438 & 0.268 & 10.8 \\
\hline Bone (cortical) & 0.0222 & 0.394 & 11.4 \\
\hline Blood & 0.748 & 2.54 & 58.3 \\
\hline Breast & 0.566 & 1.97 & 57.2 \\
\hline Kidney & 0.228 & 2.43 & 52.7 \\
\hline Liver & 0.148 & 1.69 & 43.0 \\
\hline Lung (inflated) & 0.123 & 0.804 & 20.5 \\
\hline Muscle & 0.446 & 1.74 & 52.7 \\
\hline Nerve & 0.111 & 1.09 & 30.1 \\
\hline
\end{tabular}


Table 2. Magnitudes of thermal relaxation time for biological tissues reported in previous experimental studies.

\begin{tabular}{|c|c|c|c|c|}
\hline Reference & Biological tissues & Source of heating & $\begin{array}{c}\tau_{\mathrm{q}} \\
{[\mathrm{s}]}\end{array}$ & $\begin{array}{c}\tau_{\mathrm{T}} \\
{[\mathrm{s}]}\end{array}$ \\
\hline $\begin{array}{c}\text { Mitraa et al. (Mitra } \\
\text { et al., 1995) }\end{array}$ & Processed meat & $\begin{array}{c}\text { Instantaneous contact of identical } \\
\text { meat samples maintained at } \\
\text { different initial temperatures }\end{array}$ & 16 & 0.043 \\
\hline $\begin{array}{c}\text { Roetzel et al. } \\
\text { (Roetzel et al., } \\
\text { 2003) }\end{array}$ & Processed meat & Planar Peltier heating and cooling & 1.77 & - \\
\hline $\begin{array}{c}\text { Jaunich et al. } \\
\text { (Jaunich et al., } \\
\text { 2008) }\end{array}$ & Tissue phantom & Laser ablation & $10-20$ & - \\
\hline $\begin{array}{c}\text { Liu and Chen (Liu } \\
\text { and Chen, 2010) }\end{array}$ & $\begin{array}{c}\text { Muscle tissue of a } \\
\text { cow }\end{array}$ & RFA & $7.4-8.9$ & $14.5-21.4$ \\
\hline $\begin{array}{c}\text { Sahoo et al. } \\
\text { (Sahoo et al., } \\
\text { 2014) }\end{array}$ & $\begin{array}{c}\text { Collagen gel } \\
\text { embedded with } \\
\text { gold nanoparticles }\end{array}$ & Laser ablation & $2-8$ & 0.045 \\
\hline
\end{tabular}




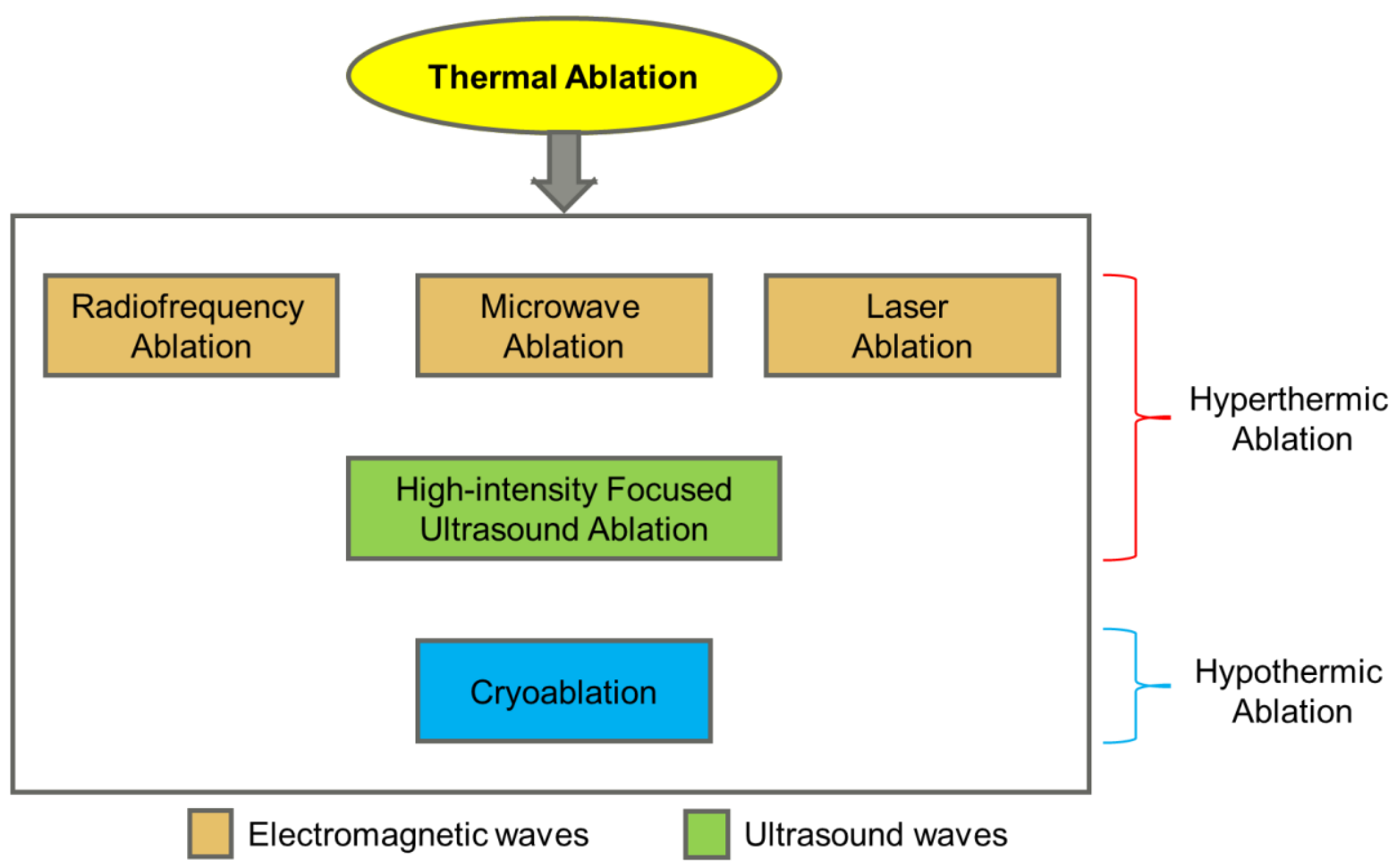

Figure 1. Different types of image-guided thermal ablative procedures. 


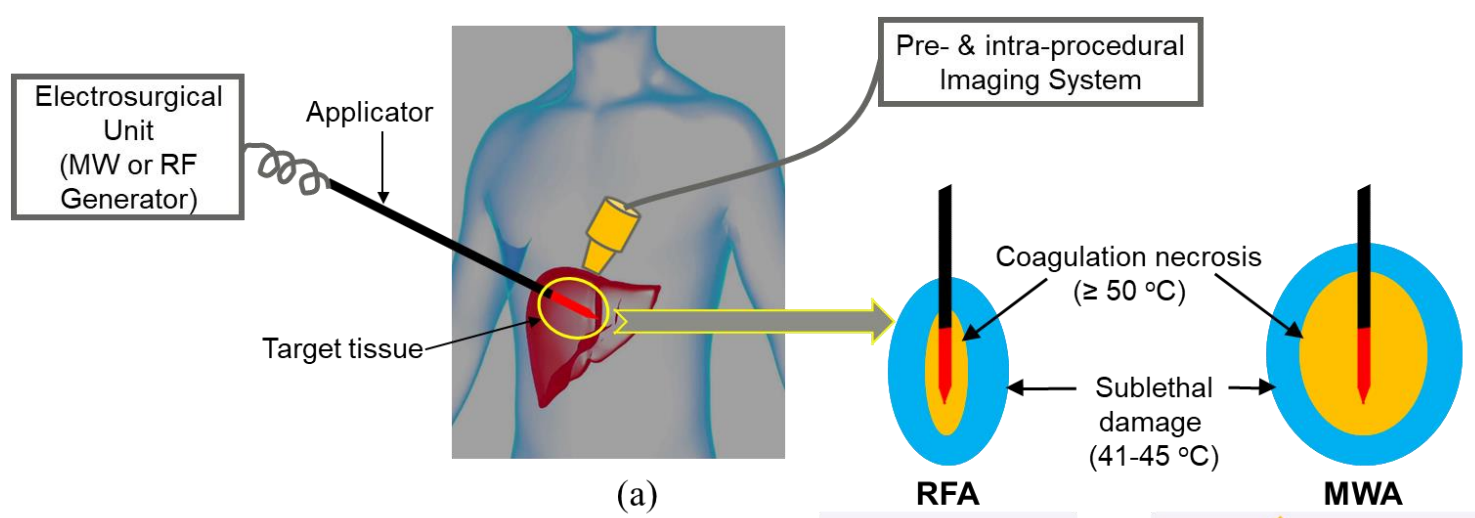

(a)
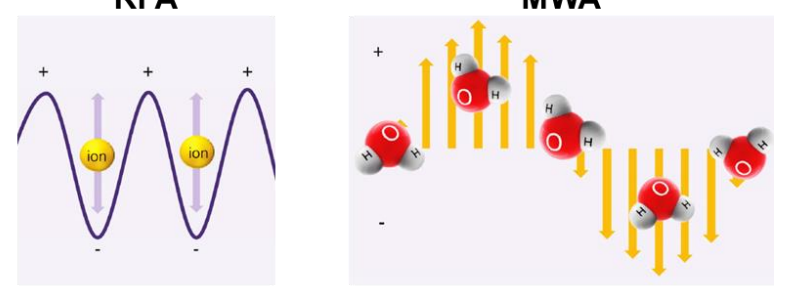

(b)

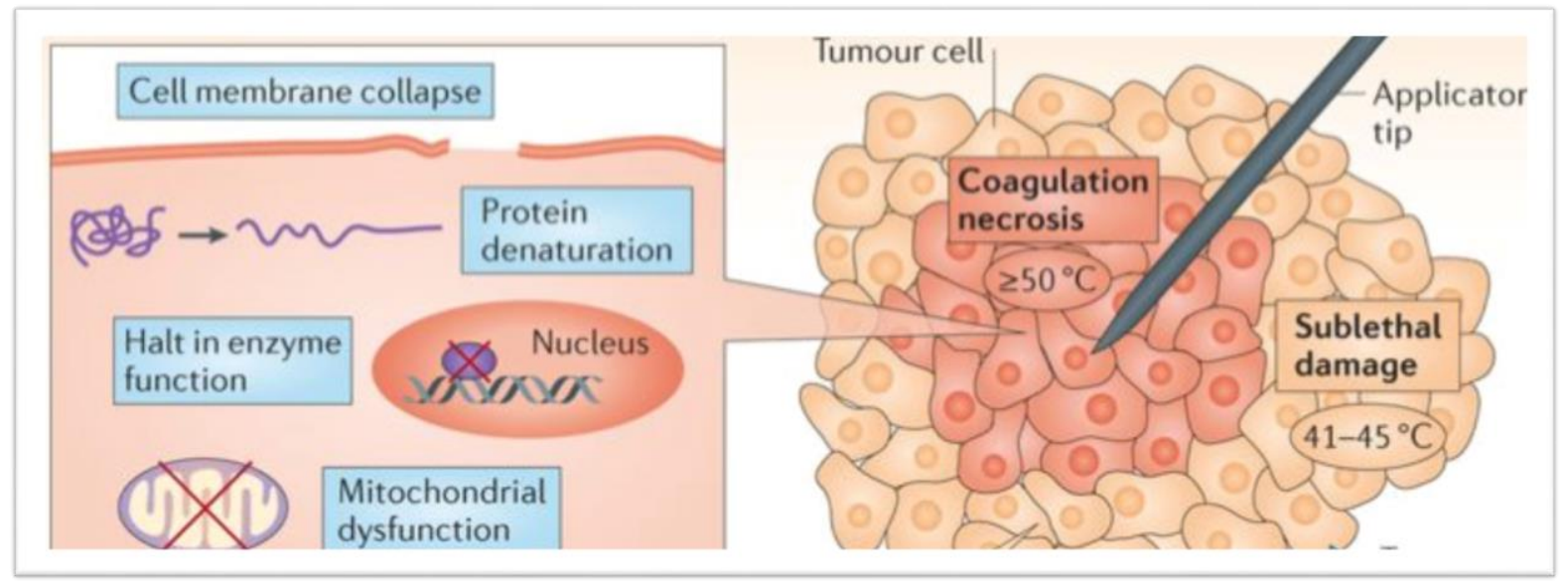

(c)

Figure 2. (a) Schematic of a generic thermal ablative system for treating tumors, (b) underlying mechanism of heat generation for the MWA and RFA procedures, and (c) the effects of coagulative necrosis on biological tissue during hyperthermic ablation (Figure 2(b) was reproduced from (Kim, 2018) with permission from Future Oncology as agreed by Future Medicine Ltd. and Figure 2(c) is reproduced with permission from (Chu and Dupuy, 2014)). 


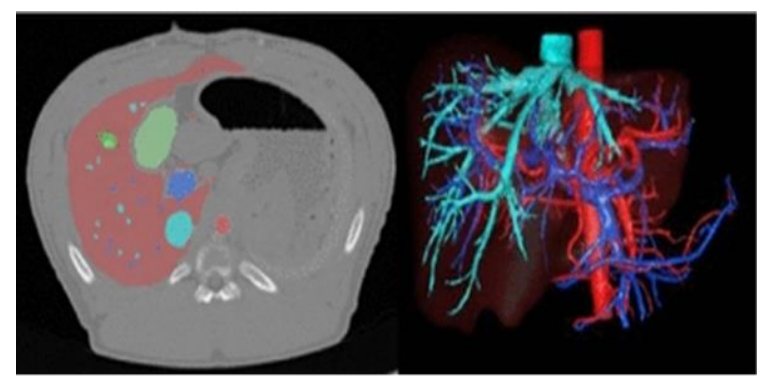

(a)

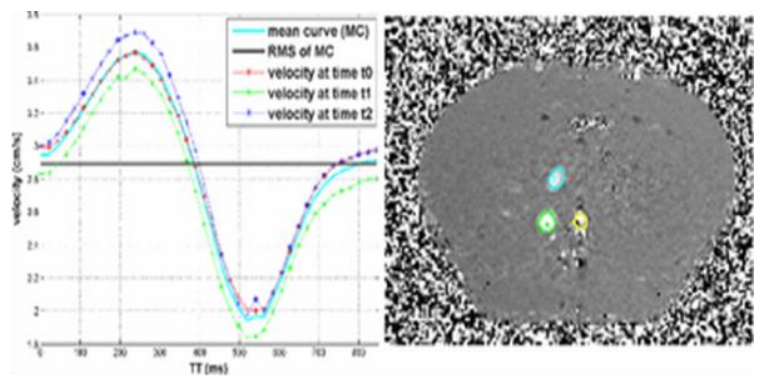

(b)

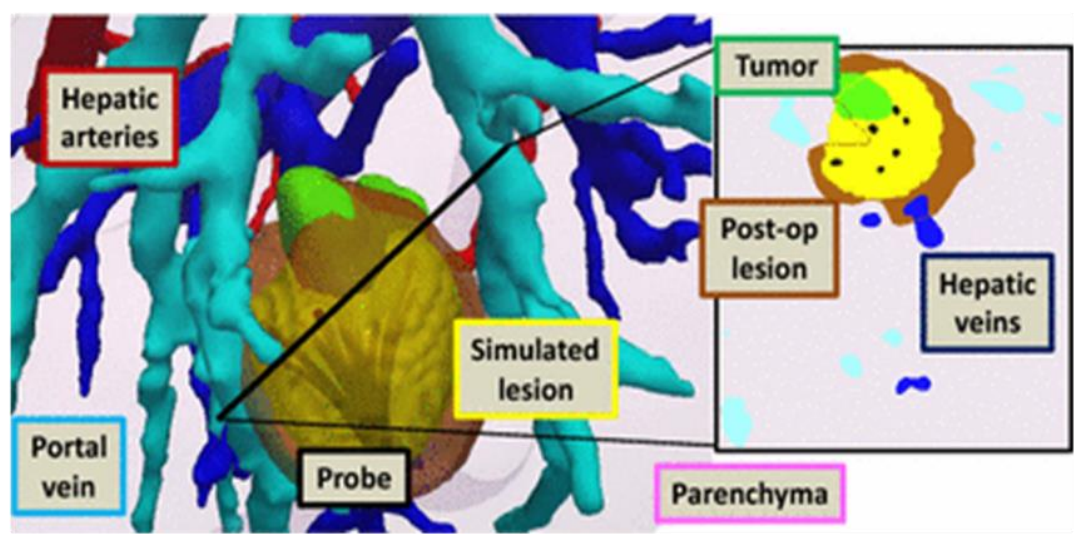

(c)

Figure 3. (a) Segmentation of liver (magenta), arterial vessels (red), portal networks (light blue), hepatic network (dark blue), surrogate tumor (dark green) and gall bladder (light green) from the preoperative CT image of pig, (b) Variation of blood velocity with respect to trigger time in the vena cava of pig on left and image of phase-contrast MRI of pig on right (vena cava in green; portal vein in blue and aorta in yellow), and (c) Simulated lesion (in yellow) during RFA procedure utilizing multitine probe on left and orthogonal slice depicting the comparison between the simulated and the actual postoperative lesion on right (color of boxes corresponds to the color of respective region) (reproduced with permission from (Audigier et al., 2017)). 


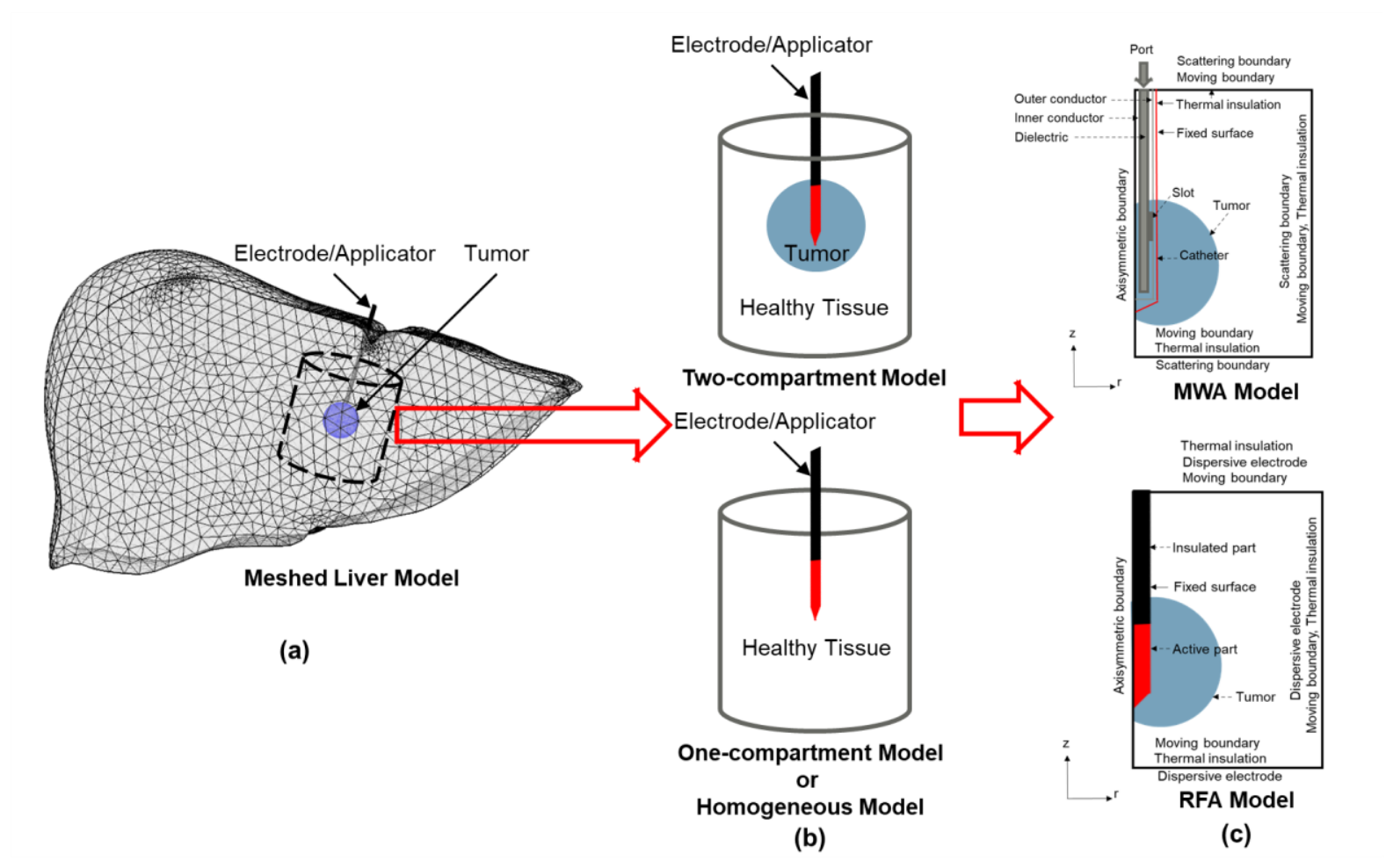

Figure 4. Reduction of computational domain from tissue level to axisymmetric model during thermal ablative procedure. (a) Whole tissue-level model, (b) Three-dimensional model derived from selected control volume, and (c) simplified axisymmetric model of MWA and RFA along with associated boundary conditions. 


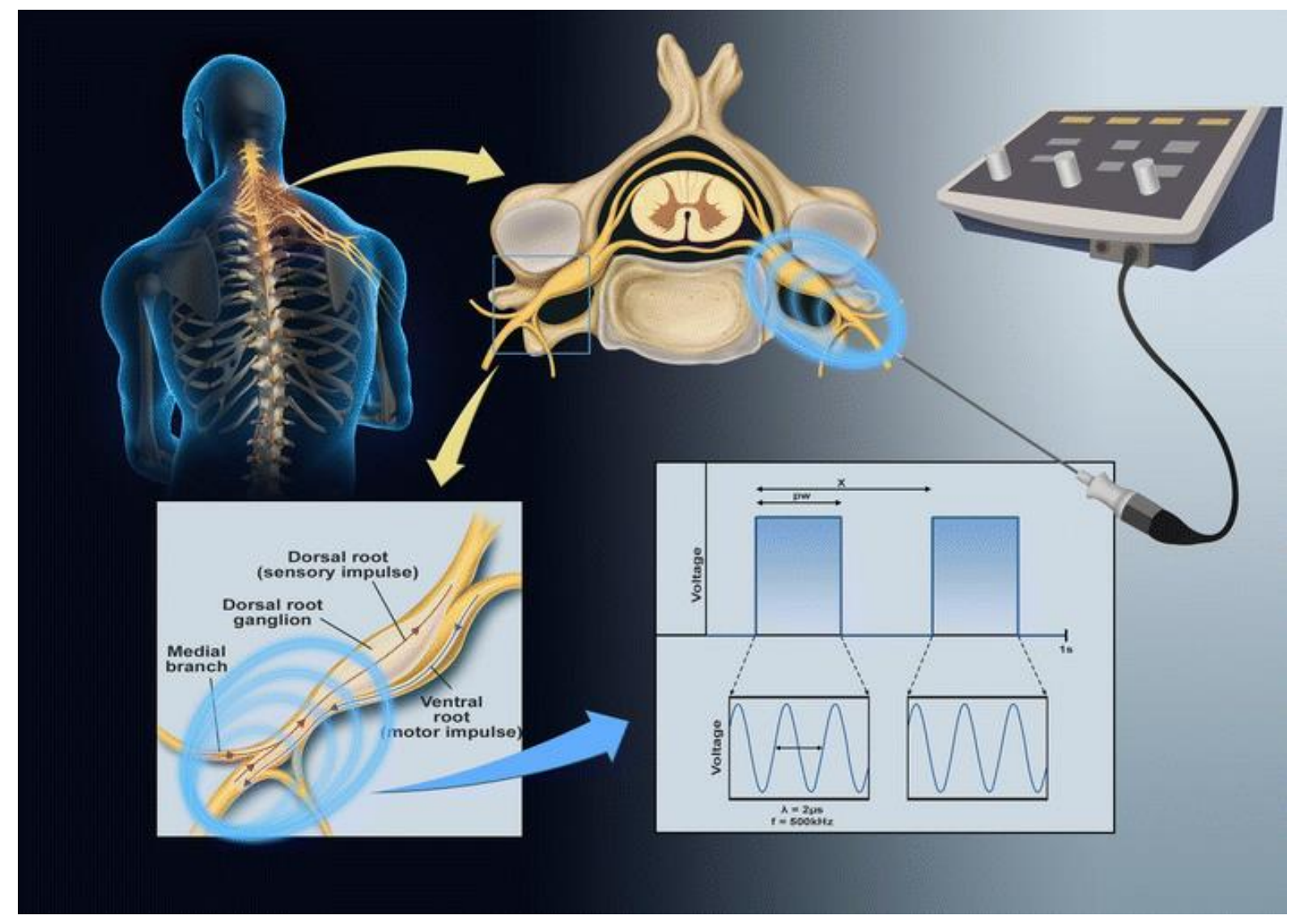

Figure 5. Components of pulsed radiofrequency procedure for chronic pain relief (Chua et al., 2011) (This image is reproduced under the terms of an open access license, Copyright (C) 2018, Springer Nature) 


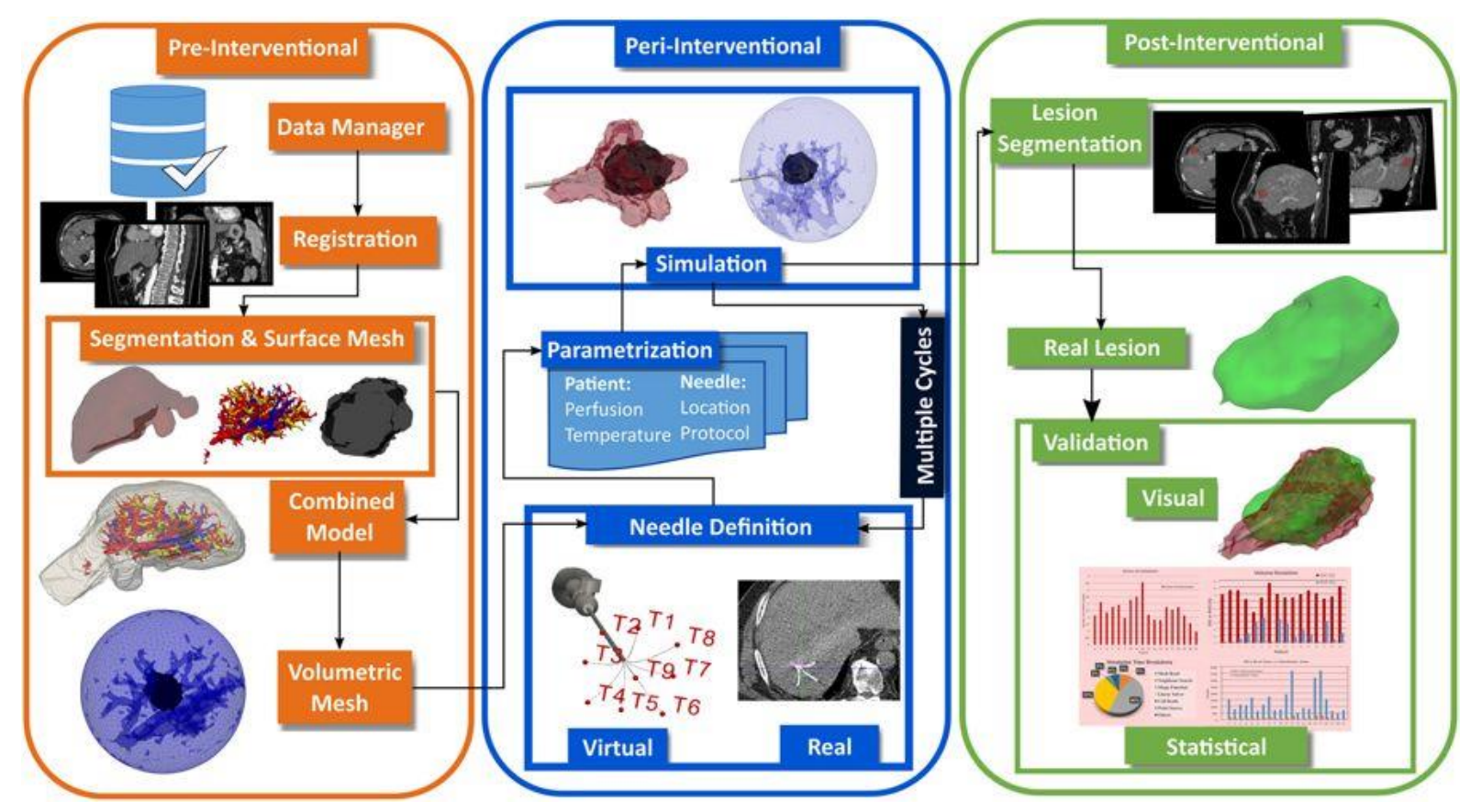

Figure 6. The technical workflow for computational modelling and simulation of thermal ablative procedure comprising of three different phases. The first phase is the preinterventional stage in which the image-guided patient-specific anatomical models are generated. The second phase is the peri-interventional stage where the high-performance simulations are conducted utilizing user-defined bio-physical properties and parameters of electrode/applicator. The last and final phase is the post-interventional stage where a priori estimates are predicted for optimizing the treatment outcomes, so as to perform safe and reliable thermal ablative procedure in patient's (Voglreiter et al., 2018) (This image is reproduced under the terms of the Creative Commons Attribution 4.0 International License (http://creativecommons.org/licenses/by/4.0/), Copyright (C) 2018, Springer Nature) 


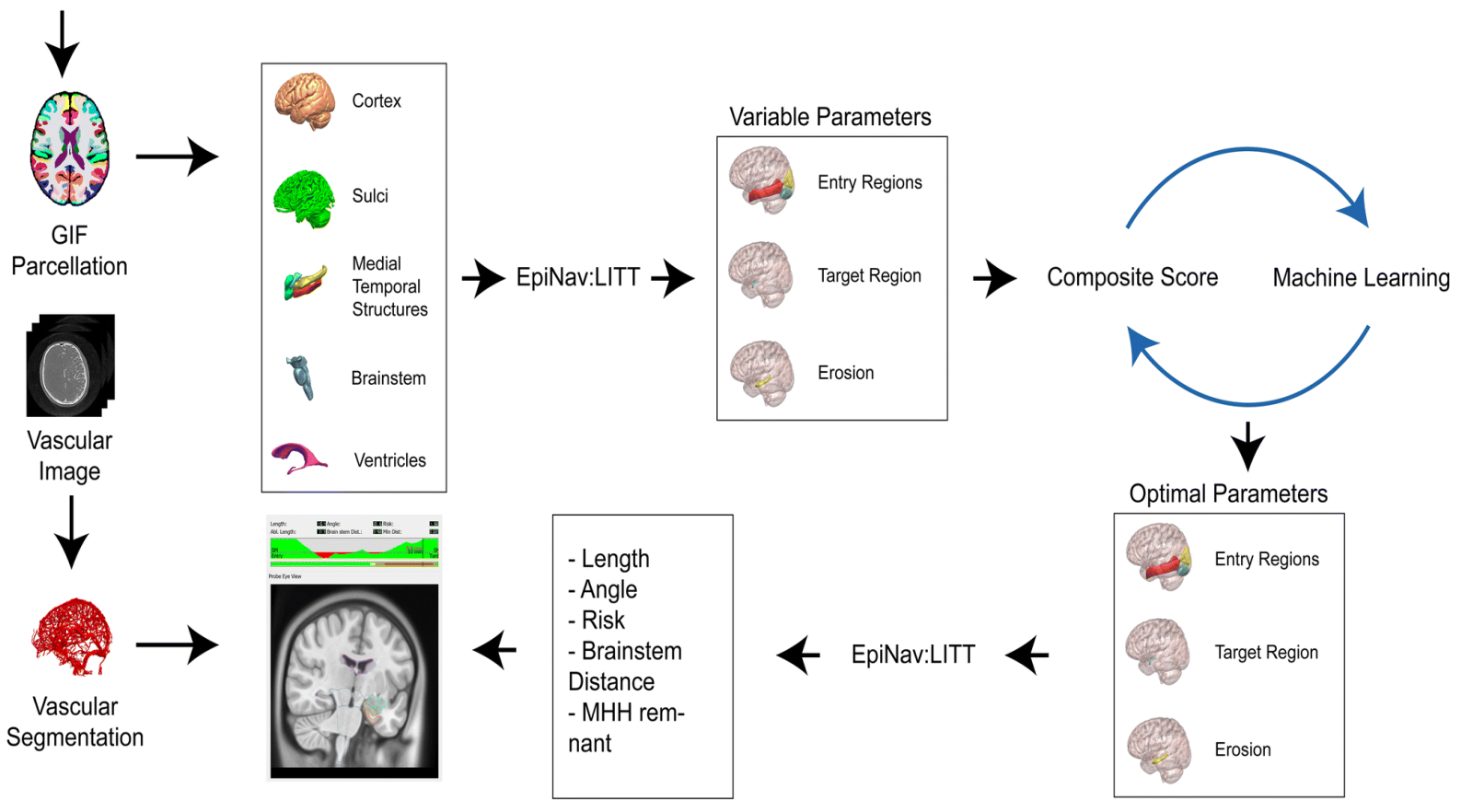

Figure 7. Flowchart for optimization of the catheter trajectory utilizing computational models and machine learning algorithms during laser interstitial thermal therapy (LITT) in brain. Initially, three-dimensional models are generated utilizing the segmentation of important structures using geodesic information flow (GIF) from the single T1 image. The automated trajectories are then calculated using EpiNav (epilepsy navigation), an image integration software, based on all the possible combinations of entry region, target region and amygdalohippocampal complex (AHC) erosion. The computed composited scores for each trajectory are then compared with that predicted from machine learning for 50\% training set and subsequently the machine learning parameters are used to optimize the safety metrics such as laser catheter intracerebral length, drilling angle to skull, risk score, and distance from the brainstem and mesial hippocampal head (MHH) remnant (Li et al., 2019) (This image is reproduced under the terms of the Creative Commons Attribution 4.0 International License (http://creativecommons.org/licenses/by/4.0/), Copyright (C 2018, Springer Nature) 


\section{Table Captions}

Table 1. Comparison of electrical properties of different tissues at $500 \mathrm{kHz}$ and $2.45 \mathrm{GHz}$.

Table 2. Magnitudes of thermal relaxation time for biological tissues reported in previous experimental studies. 


\section{Figure Captions}

Figure 1. Different types of image-guided minimally invasive thermal ablative procedures.

Figure 2. (a) Schematic of a generic thermal ablative system for treating tumors, (b) underlying mechanism of heat generation for the MWA and RFA procedures, and (c) the effects of coagulative necrosis on biological tissue during hyperthermic ablation (Figure 2(b) was reproduced from (Kim, 2018) with permission from Future Oncology as agreed by Future Medicine Ltd. and Figure 2(c) is reproduced with permission from (Chu and Dupuy, 2014)).

Figure 3. (a) Segmentation of liver (magenta), arterial vessels (red), portal networks (light blue), hepatic network (dark blue), surrogate tumor (dark green) and gall bladder (light green) from the preoperative CT image of pig, (b) Variation of blood velocity with respect to trigger time in the vena cava of pig on left and image of phase-contrast MRI of pig on right (vena cava in green; portal vein in blue and aorta in yellow), and (c) Simulated lesion (in yellow) during RFA procedure utilizing multitine probe on left and orthogonal slice depicting the comparison between the simulated and the actual postoperative lesion on right (color of boxes corresponds to the color of respective region) (reproduced with permission from (Audigier et al., 2017)).

Figure 4. Reduction of computational domain from tissue level to axisymmetric model during thermal ablative procedure. (a) Whole tissue-level model, (b) Three-dimensional model derived from selected control volume, and (c) simplified axisymmetric model of MWA and RFA along with associated boundary conditions.

Figure 5. Components of pulsed radiofrequency procedure for chronic pain relief (Chua et al., 2011) (This image is reproduced under the terms of an open access license, Copyright (C) 2018, Springer Nature)

Figure 6. The technical workflow for computational modelling and simulation of thermal ablative procedure comprising of three different phases. The first phase is the preinterventional stage in which the image-guided patient-specific anatomical models are generated. The second phase is the peri-interventional stage where the high-performance simulations are conducted utilizing user-defined bio-physical properties and parameters of electrode/applicator. The last and final phase is the post-interventional stage where a priori estimates are predicted for optimizing the treatment outcomes, so as to perform safe and reliable thermal ablative procedure in patient's (Voglreiter et al., 2018) (This image is reproduced under the terms of the Creative Commons Attribution 4.0 International License (http://creativecommons.org/licenses/by/4.0/), Copyright (C) 2018, Springer Nature)

Figure 7. Flowchart for optimization of the catheter trajectory utilizing computational models and machine learning algorithms during laser interstitial thermal therapy (LITT) in brain. Initially, three-dimensional models are generated utilizing the segmentation of important structures using geodesic information flow (GIF) from the single T1 image. The automated trajectories are then calculated using EpiNav (epilepsy navigation), an image integration software, based on all the possible combinations of entry region, target region and amygdalohippocampal complex (AHC) erosion. The computed composited scores for each trajectory are then compared with that predicted from machine learning for 50\% training set and subsequently the machine learning parameters are used to optimize the safety metrics such as laser catheter intracerebral length, drilling angle to skull, risk score, and distance 
from the brainstem and mesial hippocampal head (MHH) remnant (Li et al., 2019) (This image is reproduced under the terms of the Creative Commons Attribution 4.0 International License (http://creativecommons.org/licenses/by/4.0/), Copyright (C) 2018, Springer Nature) 